\title{
Computational environment for the development of an FAA compliant level 6 flight training device
}

Steven Mullins

West Virginia University

Follow this and additional works at: https://researchrepository.wvu.edu/etd

\section{Recommended Citation}

Mullins, Steven, "Computational environment for the development of an FAA compliant level 6 flight training device" (2009). Graduate Theses, Dissertations, and Problem Reports. 2077.

https://researchrepository.wvu.edu/etd/2077

This Thesis is protected by copyright and/or related rights. It has been brought to you by the The Research Repository @ WVU with permission from the rights-holder(s). You are free to use this Thesis in any way that is permitted by the copyright and related rights legislation that applies to your use. For other uses you must obtain permission from the rights-holder(s) directly, unless additional rights are indicated by a Creative Commons license in the record and/ or on the work itself. This Thesis has been accepted for inclusion in WVU Graduate Theses, Dissertations, and Problem Reports collection by an authorized administrator of The Research Repository @ WVU. For more information, please contact researchrepository@mail.wvu.edu. 


\title{
Computational Environment for the Development of an FAA Compliant Level 6 Flight Training Device
}

\author{
Steven Mullins
}

Thesis submitted to the

College of Engineering and Mineral Resources at West Virginia University

in partial fulfillment of the requirements

for the degree of

\author{
Master of Science \\ in Aerospace Engineering
}

Committee:

Dr. Larry Banta

Dr. Marcello Napolitano

Dr. Mario Perhinschi, Chair

Department of Mechanical and Aerospace Engineering

Morgantown, WV

2009 


\section{ABSTRACT \\ Computational Environment for the Development of an FAA Compliant Level 6 Flight Training Device}

\section{Steve Mullins}

A flight simulator can successfully achieve its purpose only if equipped with adequate mathematical models of the aircraft, its sub-systems, and the environment. The US Federal Aviation Administration (FAA) has instituted stringent regulations to ensure that flight simulators used for pilot training reach desirable levels of accuracy and fidelity. The purpose of this thesis is to present the development and application of a design strategy and the computational environment associated to it for building an aircraft simulation model that meets the FAA regulations for flight simulator performance. The proposed methodology is based on using flight test data in combination with analytical modeling tools and heuristics.

The Simulink simulation environment within Matlab was selected due to its recognized capabilities, flexibility, and portability. Several interactive computational tools have been developed to support the development. Flight test data of a business class jet was used for the purpose of this research effort. An important part of the proposed strategy consists of selecting the flight data and converting them into a usable format for Matlab/Simulink. Parameter identification techniques must then be applied at specific points in the flight envelope of the aircraft in order to create an accurate flight dynamics model. Two such modeling techniques, in time and frequency domain, were used within this project. Lookup tables for the stability and control derivatives were built based on dynamic pressure. Tuning of the aerodynamic model is required to meet all FAA criteria. Once the FAA objective tests were completed, another more organic set of tests were conducted by pilots. The outcomes of these subjective tests were analyzed and additional tuning of the aerodynamic and dynamic model were performed accordingly. Eventually, compliance with both FAA objective and subjective tests is ensured through several tuning iterations and demonstrated. 


\section{Acknowledgments}

I would like to thank Dr. Mario Perhinschi, Dr. Marcello Napolitano, and Phil Evans for their support on this project. 


\section{Table of Contents}

Title Page $\quad$ i

Abstract

Acknowledgements

Table of Contents $\quad$ iv

List of Figures vi vi

$\begin{array}{ll}\text { List of Tables } & \text { ix }\end{array}$

Nomenclature $\quad$ X

1. Introduction 1

2. History of Flight Simulators and Certification Requirements 5

3. General Structure of a Computational Environment for the Development 11 of an FAA Compliant Aircraft Simulation Model

4. Computational Tools for Flight Test Data Processing 15

5. Parameter Identification 26

5.1. Least Squares Estimator

5.2. Recursive Fourier Transform

5.3. Aircraft Parameter Identification

6. Development of a Simulation Environment for FAA Compliance 38 with Objective and Subjective Tests

6.1. General Architecture

6.2. Computation of Dynamic Characteristics of Slow Oscillatory Modes

6.3. Objective Tests

6.4. Subjective Testing

$\begin{array}{ll}\text { 7. Conclusions } & 74\end{array}$

$\begin{array}{ll}\text { References } & 75\end{array}$ 
Appendix B - Altered Flight Test Data Segments Example 81

Appendix C- State Variable Model of Aircraft Dynamics 85

Appendix D - User Manual for the Flight Simulation Environment 94 


\section{List of Figures}

Figure 1. Link Trainer.

Figure 2. Comet IV Simulator with Basic Pitch Motion System.

Figure 3. Six Degree of Freedom Stewart Platform.

Figure 2. Block Diagram of Flight Simulation Design Strategy.

Figure 3. Initializing the Plot Data Program.

Figure 4. Selection of Flight Test Data Variables.

Figure 5. Pitch Angle for Altered Short Period Flight Data.

Figure 6. Pitch Rate for Altered Short Period Flight Data.

Figure 7. Elevator Deflection of Altered Short Period Flight Data.

Figure 8. Reducing Flight Data to Desired Data Segments.

Figure 9. Pitch Angle Segment of Altered Short Period Flight.

Figure 10. Pitch Rate Segment of Altered Short Period Flight.

Figure 11. Elevator Deflection Segment of Altered Short Period Flight.

Figure 12. Final Choice Menu.

Figure 13. Normalized Least Squares and Computed Comparison of Pitching Moment Coefficient.

Figure 14. Recursive Fourier Transforms in Simulink.

Figure 15. Normalized Cm Stability and Control Derivatives Using Recursive Fourier Transforms.

Figure 16. Desktop Computer Implementation.

Figure 17. Desktop Computer Implementation - Interactive Visualization.

Figure 18. Motion-Based Flight Simulator Implementation.

Figure 19. Initial Simulation Menu.

Figure 20. Flight Conditon Menu. 
Figure 21. Input Menu.

Figure 22. Flight Test Selection Menu.

Figure 23. Parameters of the Peak-to-Valley Method to Determine the Characteristics of Slow Oscillatory Modes (Dutch Roll).

Figure 24. Normalized FAA Compliance Test 2.c.10. Short Period at Cruise Condition.

Figure 25. Normalized FAA Compliance Test 2.c.9. Phugoid at Cruise Condition.

Figure 26. Normalized FAA Compliance Test 2.d.7. Dutch Roll at Cruise Condition.

Figure 27. Normalized FAA Compliance Test 2.d.2. Roll Response Test at Cruise Condition.

Figure 28. Normalized FAA Compliance Test 2.d.4. Spiral Stability at Cruise Condition.

Figure 29. Normalized FAA Compliance Test 2.d.7. Dutch Roll at Approach Condition.

Figure 30. Normalized FAA Compliance Test 2.d.2 and 2.d.3. Roll Response at Approach Condition.

Figure 31. Normalized FAA Compliance Test 1.c.1. Normal Climb Requirements.

Figure 32. Normalized FAA Compliance Test 2.d.8. Steady State Sideslip at Approach Condition.

Figure 33. Normalized FAA Compliance Test 2.c.5. Longitudinal Trim at Cruise.

Figure 34. Normalized FAA Compliance Test 2.c.5. Longitudinal Trim at Approach.

Figure 35. Normalized FAA Compliance Test 2.c.5. Longitudinal Trim at Landing.

Figure 36. Normalized FAA Compliance Test 2.d.2 and 2.d.3. Roll Response at Cruise

Condition with Altered $\mathrm{C}_{\mathrm{lp}}$.

Figure 37. Piloted Input.

Figure A1. State Variables of Altered Flight Data for a Short Period Test.

Figure A2. State Variables of Altered Flight Data for a Short Period Test.

Figure A3. State and Control Variables of Altered Flight Data for a Short Period Test.

Figure A4. Control and Engine Variables of Altered Flight Data for a Short Period Test. 
Figure B1. State Variables of Altered Flight Data Segment for a Short Period Test.

Figure B2. State and Control Variables of Altered Flight Data Segment for a Short Period Test.

Figure B3. State, Control, and Engine Variables of Altered Flight Data Segment.

Figure B4. Engine Variables of Altered Flight Data Segment. 


\section{List of Tables}

Table 1. State Variables Save File Vectors.

Table 2. Control Variables Save File Vectors.

Table 3. Engine Parameters and Rate of Climb File Vectors.

Table 4. Normalized $\mathrm{C}_{\mathrm{m}}$ Stability and Control Derivatives Using Least Squares.

Table 5. Longitudinal Stability Derivatives Sensitivity.

Table 6. Lateral-Directional Stability Derivatives Sensitivity. 


\section{$\underline{\text { Nomenclature }}$}

\section{Acronyms}
FAA
Federal Aviation Administration
PID
Parameter Identification

\section{Stability and Control Derivatives}

\begin{tabular}{|c|c|}
\hline \multirow{3}{*}{$\begin{array}{l}\mathrm{C}_{1} \\
\mathrm{C}_{10}\end{array}$} & Rolling Moment Coefficient \\
\hline & Initial Rolling Moment Coefficient \\
\hline & Variation of Airplane Rolling Moment Coefficient with Angle of \\
\hline \multirow[t]{2}{*}{$\mathrm{C}_{1 \beta}$} & Sideslip \\
\hline & Variation of Airplane Rolling Moment Coefficient with Aileron \\
\hline \multirow[t]{2}{*}{$\mathrm{C}_{1 \delta \mathrm{a}}$} & Deflection Angle \\
\hline & Variation of Airplane Rolling Moment Coefficient with Rudder \\
\hline \multirow[t]{2}{*}{$\mathrm{C}_{1 \delta \mathrm{r}}$} & Deflection Angle \\
\hline & Variation of Airplane Rolling Moment Coefficient with Change of \\
\hline \multirow[t]{2}{*}{$\mathrm{C}_{\mathrm{lp}}$} & Roll Rate \\
\hline & Variation of Airplane Rolling Moment Coefficient with Change of \\
\hline $\mathrm{C}_{\mathrm{lr}}$ & Yaw Rate \\
\hline $\mathrm{C}_{\mathrm{m}}$ & Pitching Moment Coefficient \\
\hline \multirow[t]{2}{*}{$\mathrm{C}_{\mathrm{m} 0}$} & Initial Pitching Moment Coefficient \\
\hline & Variation of Airplane Pitching Moment Coefficient with Change \\
\hline \multirow[t]{2}{*}{$\mathrm{C}_{\mathrm{m} \alpha}$} & of Angle of Attack \\
\hline & Variation of Airplane Pitching Moment Coefficient with Change \\
\hline $\mathrm{C}_{\mathrm{mq}}$ & of Rate of Pitch \\
\hline $\mathrm{C}_{\mathrm{n}}$ & Yawing Moment Coefficient \\
\hline \multirow[t]{2}{*}{$\mathrm{C}_{\mathrm{n} 0}$} & Initial Yawing Moment Coefficient \\
\hline & Variation of Airplane Yawing Moment Coefficient with Change of \\
\hline \multirow[t]{2}{*}{$\mathrm{C}_{\mathrm{n} \beta}$} & Sideslip Angle \\
\hline & Variation of Airplane Yawing Moment Coefficient with Change of \\
\hline \multirow[t]{2}{*}{$\mathrm{C}_{\mathrm{n} \delta \mathrm{a}}$} & Aileron Deflection \\
\hline & Variation of Airplane Yawing Moment Coefficient with Change of \\
\hline \multirow[t]{2}{*}{$\mathrm{C}_{\mathrm{n} \delta \mathrm{r}}$} & Rudder Deflection \\
\hline & Variation of Airplane Yawing Moment Coefficient with Change of \\
\hline \multirow[t]{2}{*}{$\mathrm{C}_{\mathrm{np}}$} & Roll Rate \\
\hline & Variation of Airplane Yawing Moment Coefficient with Change of \\
\hline $\mathrm{C}_{\mathrm{nr}}$ & Yaw Rate \\
\hline $\mathrm{C}_{\mathrm{x}}$ & Force Coefficient along the $\mathrm{X}$-axis \\
\hline \multirow[t]{2}{*}{$\mathrm{C}_{\mathrm{x} 0}$} & Initial Force Coefficient in the $\mathrm{X}$-axis \\
\hline & Variation of airplane X-axis Force Coefficient with Angle of \\
\hline \multirow[t]{2}{*}{$\mathrm{C}_{\mathrm{x} \alpha}$} & Attack \\
\hline & Variation of airplane X-axis Force Coefficient with Change of \\
\hline $\mathrm{C}_{\mathrm{x} \delta \mathrm{e}}$ & Elevator Deflection \\
\hline
\end{tabular}


Variation of airplane X-axis Force Coefficient with Change of

$\mathrm{C}_{\mathrm{xq}} \quad$ Pitch Rate

$\mathrm{C}_{\mathrm{y}} \quad$ Force Coefficient along the $\mathrm{Y}$-axis

Variation of airplane Y-axis Force Coefficient with Change of

$\mathrm{C}_{\mathrm{y} \delta \mathrm{r}}$

Rudder Deflection

$\mathrm{C}_{\mathrm{y} 0}$

Initial Force Coefficient in the $\mathrm{Y}$-axis

$\mathrm{C}_{\mathrm{y} \beta}$

Variation of airplane Y-axis Force Coefficient with Change of Sideslip Angle

Variation of airplane Y-axis Force Coefficient with Change of

$\mathrm{C}_{\mathrm{y} \delta \mathrm{a}}$

$\mathrm{C}_{\mathrm{yp}}$

$\mathrm{C}_{\mathrm{yr}}$

$\mathrm{C}_{\mathrm{z}}$

$\mathrm{C}_{\mathrm{z} 0}$

$\mathrm{C}_{\mathrm{za}}$

$\mathrm{C}_{\mathrm{z} \delta \mathrm{e}}$

$\mathrm{C}_{\mathrm{zq}}$

\section{Variables}

Variation of airplane Y-axis Force Coefficient with Change of Roll

Rate

Variation of airplane Y-axis Force Coefficient with Change of

Yaw Rate

Force Coefficient along the Z-axis

Initial Force Coefficient in the Z-axis

Variation of airplane Z-axis Force Coefficient with Change of Angle of Attack

Variation of airplane Z-axis Force Coefficient with Change of Elevator Deflection

Variation of airplane Z-axis Force Coefficient with Change of Pitch Rate

$\alpha$

b

$\beta$

c_bar

C1

$\mathrm{C} 2$

$\delta \mathrm{a}$

$\Delta$

$\delta \mathrm{e}$

$\delta \mathrm{r}$

$\mathrm{H}$

I

$\mathrm{J}(\theta)$

$\omega$

$\mathrm{p}$

$\mathrm{q}$

$\overline{\boldsymbol{q}}$

$\mathrm{r}$

$\mathrm{R}^{-1}$
Angle of Attack

Wing Span

Sideslip Angle

Mean Aerodynamic Chord

Left Bound

Right Bound

Aileron Deflection

Change in

Elevator Deflection

Rudder Deflection

Known Matrix

Moments of Inertia

Cost Function

Frequency

Roll Rate

Pitch Rate

Dynamic Pressure

Yaw Rate

Positive Definite Weighting Matrix 


$\begin{array}{ll}\text { R1 } & \text { Upper Bound } \\ \text { R2 } & \text { Lower Bound } \\ \mathrm{t} & \text { Time } \\ \theta & \text { Unknown Matrix } \\ \theta \_ \text {hat } & \text { Parameter Vector } \\ \mathrm{V} & \text { Noise Measurement } \\ \mathrm{V} & \text { Velocity } \\ \mathrm{X} & \text { Matrix of Vectors and Regressors } \\ \mathrm{X} \_ \text {hat } & \text { Fourier Transform for Frequency Domain } \\ \mathrm{z} & \text { Measurement } \\ \dagger & \text { Conjugate Transpose }\end{array}$




\section{Introduction}

Flight simulation is the inexpensive and effective way for pilots to gain proficiency in specific aircraft. With this type of training, the pilot can be more focused on the specific task at hand without exposure to inherent risks of actual flight. Flight simulation has always been an important part of flight training in the brief history of aviation, which shows that the flight simulation process has been in the minds of many flight instructors since near the beginning of mechanical flight. Instructors needed a tool that was safe, yet effective at teaching beginner pilots the intricacies of flying. The beginning of flight simulation can be identified with the Penguin System in the paper by Page [1]. This was then followed by the Sanders Teacher, Link Trainer, analog computers, and then the first digital simulator, the Link Mark 1. After this point, the digital flight simulation process was expanded on in many ways with advances in technology. Today, sophisticated flight simulators are used on a large scale for pilot training, but not only. Flight simulators have become an indispensable tool for the design of new aircraft contributing substantially to reducing duration and cost of development.

A flight simulator can successfully achieve its purpose only if equipped with adequate mathematical models of the aircraft, its sub-systems, and the environment. Although the necessary mathematics, physics knowledge and tools had been available for more than a century, how exactly to apply them to the problem of flight is a relatively recent discovery. Flight dynamics and aerodynamics, as a framework for flight modeling and simulation have achieved fast progress shortly before and during World War II. As a result, the first classic textbooks were published by Perkins (1949) [2], followed by Etkin (1959) [3], and Miele (1962) [4]. Other

early contributions that are still very useful, include the books by Seckel (1964) [5], McCormick (1979) [6], and Babister (1980) [7]. Currently, numerous textbooks are available offering new 
perspectives and methodologies for flight simulation and development of aircraft sub-system models [8 - 13]. Modeling of aircraft has benefited tremendously from the development of advanced methodologies and algorithms that allow the determination of the mathematical model of a dynamic system from series of experimental tests that explicitly relate known inputs to measured resulting outputs. These parameter identification (PID) techniques rely on a predefined structure of the model, which depends on a set of constant parameters that are unknown and must be determined. The experimental data points allow a system of equations to be built whose solution is the set of unknown parameters. Two large classes of methods have been developed, usually referred to as "time domain methods" [14-15] and "frequency domain methods" [14-16].

Worldwide, the engineering communities and governmental authorities have acknowledged the need for systematic and scientifically formulated requirements and criteria that could ensure the objective assessment of flight simulators performance level and accuracy. The US Federal Aviation Administration (FAA) has instituted, as early as 1973, regulations to this respect from the United States Advisory Circular 120-40B [17]. In the United States FAR regulations Part 60, a section was devoted to giving each type of flight training device a classification. In order for a simulator to be in a classification it must meet certain requirements. There a total of 7 different levels of flight training devices. Level 1 is the lowest flight training devices recognized by the FAA. Level 2 and 3 flight training devices are used for simulating a range of aircraft and have a generic cockpit setup. Level 4 through 7 flight training devices are made for a specific aircraft and have a replica of the cockpit for the aircraft. As the level of the flight training device increases the requirements set by the FAA become more stringent due to the complex nature of the flight training devices at the higher levels [18]. 
Compliance with such regulations requires that the development of the mathematical model and, in general, the design of the flight simulator be conducted following an ad-hoc strategy. The purpose of this thesis is to present the development and application of a design process and the computational environment associated to it for building an aircraft simulation model that meets the FAA regulations for flight simulator performance. The proposed methodology is based on using flight test data in combination with analytical modeling tools and heuristics to create a model that is accurate enough to pass the very stringent FAA requirements.

The Simulink simulation environment in Matlab was selected due to its recognized capabilities, flexibility, and portability. Matlab is a widely used software for simulation and the outcomes of this project may be easily accessible to wide categories of users throughout the aircraft modeling and simulation community.

Flight test data of a business class jet was used for the purpose of this research effort. An important part of the strategy of designing this aircraft model was to convert the flight test data into a usable format for Matlab/Simulink. Two Parameter Identification techniques were applied at specific points in the flight envelope of the jet aircraft in order to create an accurate flight dynamics model. Lookup tables for the stability derivatives at these flight conditions were built dependent on dynamic pressure. The first PID technique is the least squares estimator approach in the time domain found in [14]. The other technique is the recursive Fourier transform approach in the frequency domain found in [14].

Once a preliminary model of the aircraft was determined and put into the simulation, tests were then run using the inputs of the flight data. The flight test data was then compared to the output of the aircraft model as part of the objective FAA requirements for a Level 6 training 
device. Tuning of the aerodynamic model was performed to meet all FAA criteria. Once the FAA objective tests were completed, another more organic set of tests were conducted by pilots. These subjective tests were not checked with flight test data; instead, pilot subjective evaluation was used. All issues that came up from the subjective tests were analyzed and solved by changing the aerodynamic and dynamic model accordingly. Finally, another iteration was performed to ensure that the FAA objective tests are satisfied.

This thesis is organized as follows. After this brief introduction, in Chapter 2, some of the most important milestones in the development of flight simulators and performance evaluation criteria are outlined. The general structure of the computational environment for the development of an FAA compliant aircraft simulation model is presented in Chapter 3. The next three chapters are dedicated to each of the main components of the proposed design strategy. Chapter 4 presents the computational tools developed for processing of the flight test data. The aircraft parameter identification techniques used are discussed in Chapter 5. The simulation environment developed for FAA requirements compliance and its use for performing objective and subjective tests are presented in Chapter 6. Finally, some conclusions are drawn in Chapter 7 followed by a list of references. Several appendices are included with relevant additional information. 


\section{History of Flight Simulation and Certification Requirements}

The start of flight simulation was not a true flight simulator per se. Most of the first pilots learned to fly by starting off with a machine that was not airworthy but acted like an aircraft while on the ground. After the pilot was comfortable with the handling on the ground they then graduated to an aircraft that would be able to do small "hops" that would teach the pilot how to take off and land safely. After the pilot was skilled with small hops, the pilot would then move on to large hops and then to an actual flight. A similar style of training was adopted just before World War I known as the Penguin system [1]. With the Penguin system, instead of providing the trainees with an aircraft incapable of flight, an aircraft would be taken and its wingspan reduced so it would remain ground borne. This technique was effective and was used through the First World War. Although this was not true ground borne simulation, these beginning ideas transformed flight simulation into what it is today.

After the initial "hopping", or Penguin system was used, a new approach was attempted for flight simulation. The technique essentially created an aircraft that was attached to the ground and used the wind to create actual aerodynamic forces and moments similar to aircraft. One of the first known devices using this technique was the Sander's Teacher [1]. The problem with this technique was that in order for it to be successful there had to be a constant wind to make the simulator work. This type of simulation was abandoned due to the unreliable nature of wind.

The next stage in simulation was developed in the mid-1920's and it involved using mechanical or electrical actuators to orient the trainer in the orientation that was given from the 
pilot inputs. The most famous of these trainers was known as the Link Trainer (see Figure 1) that was developed in 1929.

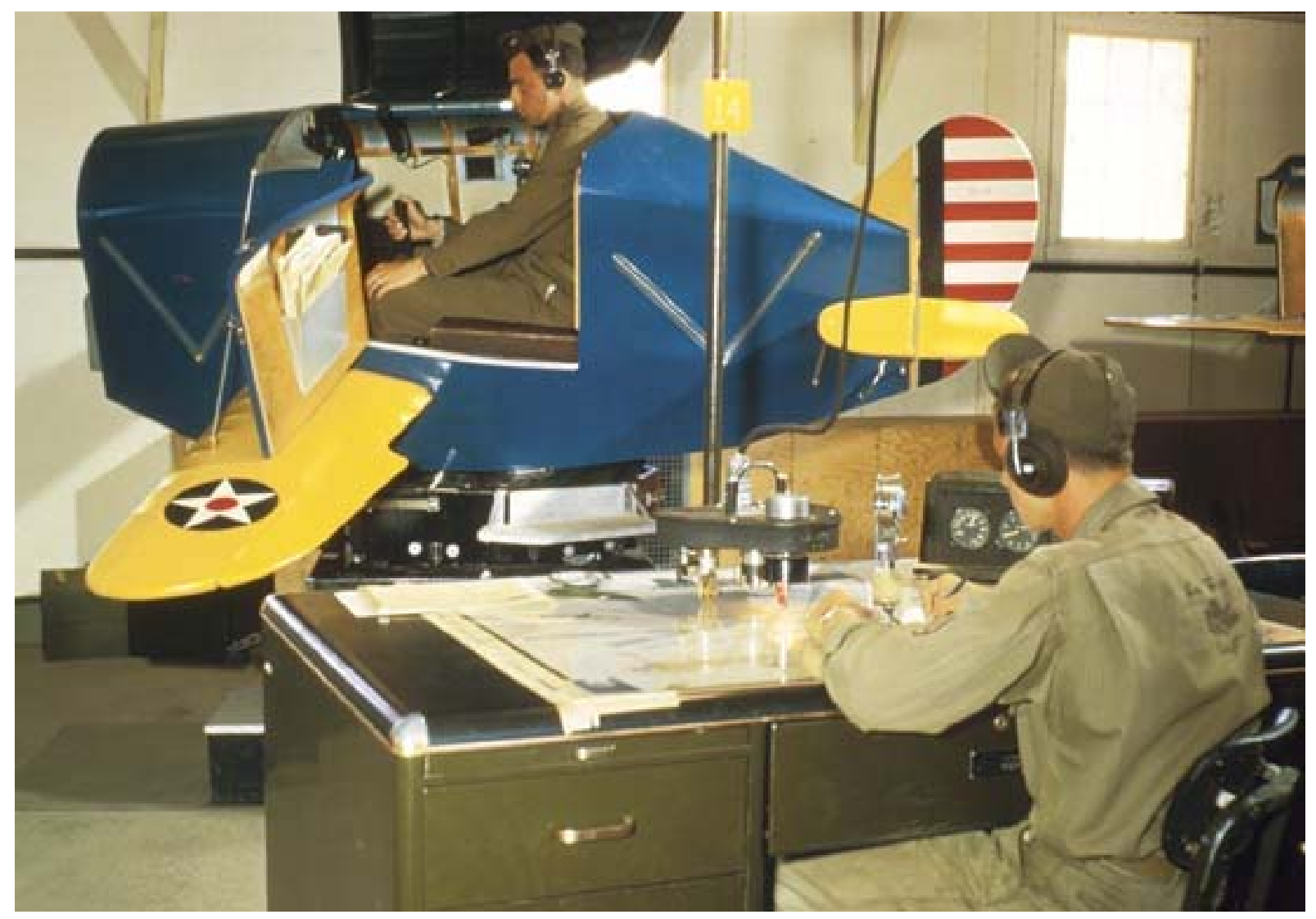

Figure 1. Link Trainer (http://www.britannica.com)

The main issue with these first simulators is that it was not actually simulating aircraft dynamics. To get the response similar to the aircraft, pilots would use the simulator and tune the simulator to what the aircraft felt like. This was not the best scenario because although pilots would get the simulator close to the aircraft's abilities, the important modes of motion (the short period, phugoid, and dutch roll) could not be reproduced accurately. The Link trainers were used widely in World War II due to the high volume of pilots that were needed at the time to be trained. 
During World War II, analog computers were developed along with electronics were able to lead flight simulation in the right direction. With analog computers, the aircraft equations of motion could be solved and therefore could then be simulated. This would replace the pilots "intuition" of response of the aircraft to a more realistic model of what the aircraft should do. After World War II the first full flight simulator was developed for Pan American Airways through Curtiss-Wright for the Boeing 377 Stratocruiser [1] and was the first full simulator to be owned by an airline. There was a major issue with analog flight training simulators, the simulators had a lot of down time due to maintenance associated with analog computers.

With the reliability of analog flight simulators very low and the invention of digital computers, it was only logical that flight simulators would be created using digital instead of analog computers. The evolution from analog to digital flight simulation was initiated by the United States Navy in 1950 with a research into creating a reliable flight simulator using a digital computer. At that time though, digital computers were not powerful enough and could not be used for real time simulation of aircraft dynamics. In the early 1960's digital computers were becoming more powerful and thus real time simulation became more feasible. The first well received real time digital flight simulator was the Link Mark 1[1]. It was a very good simulator for its day and was purchased by both the U.S. military and airlines and is still the same basic concept used today in modern flight simulators.

In the 1950s motion systems were nonexistent for and flight training devices were known as fixed base systems. The reasoning behind this was that the general consensus at the time was that motion was not needed because pilot did not fly "by the seat of their pants," or by feeling the forces exerted when doing maneuvers, anymore and thus it was not needed. This notion was 
overturned at the end of the 1950s and in 1958 a basic pitch motion system was created for the Comet IV simulator as seen in Figure 2.

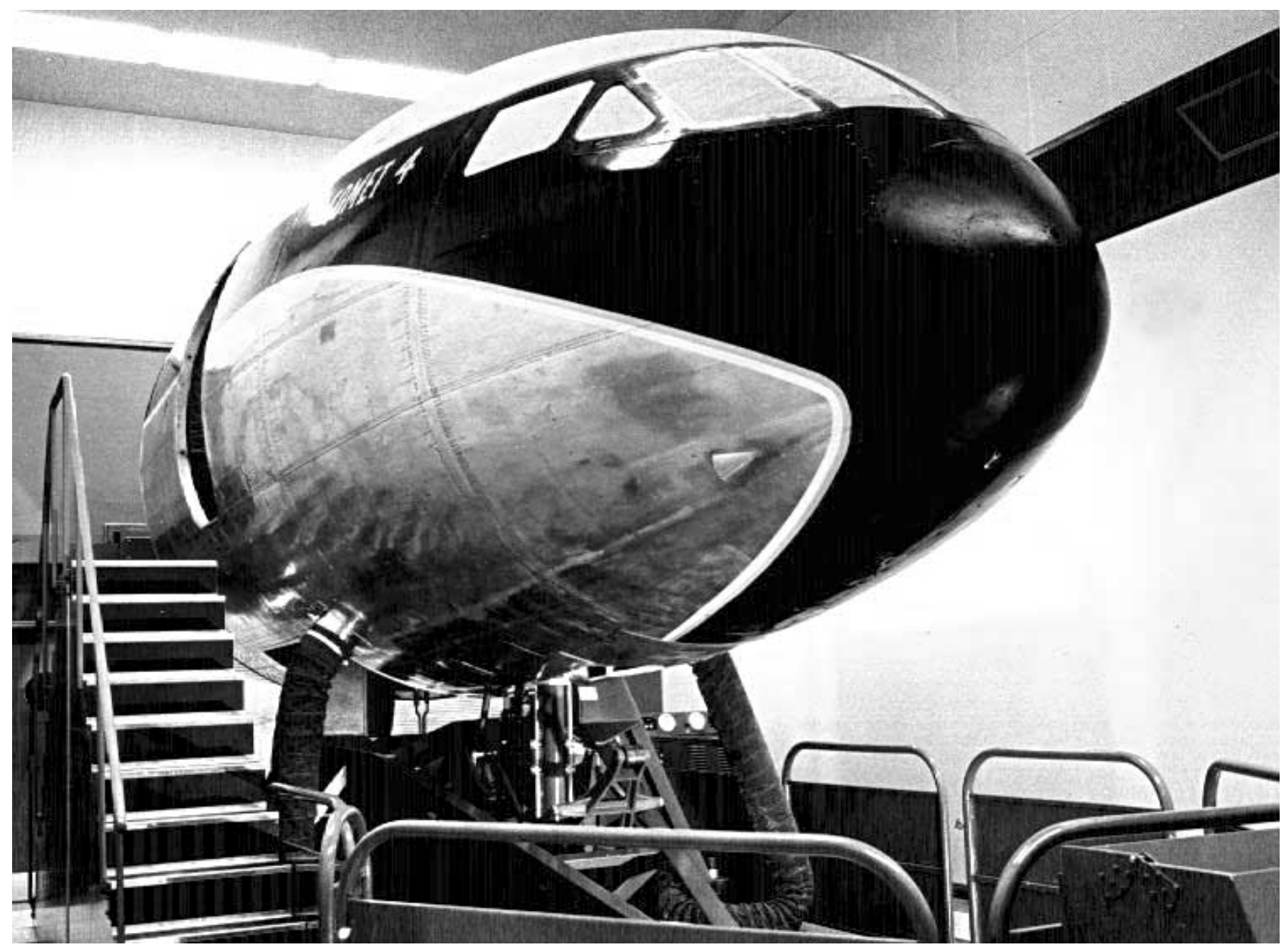

Figure 2. Comet IV Simulator with Basic Pitch Motion System.

(http://homepage.ntlworld.com/bleep/SimHist8.html)

With the pitch motion system of the Comet IV simulator, the industry saw the need for motion systems and two and three degree of freedom motion systems were then created. As the need for more complex motion systems arose, the six degree of freedom motion system was created. With the six degree of freedom motion system, translation and rotation can be achieved in three dimensions. An example of type of six degree motion system is seen in Figure 3 and is known as the Stewart platform and is a common platform used in the industry. For the motion 
systems, hydraulics or electric motors are used to orient the simulator depending on the size or requirements of the flight training device.

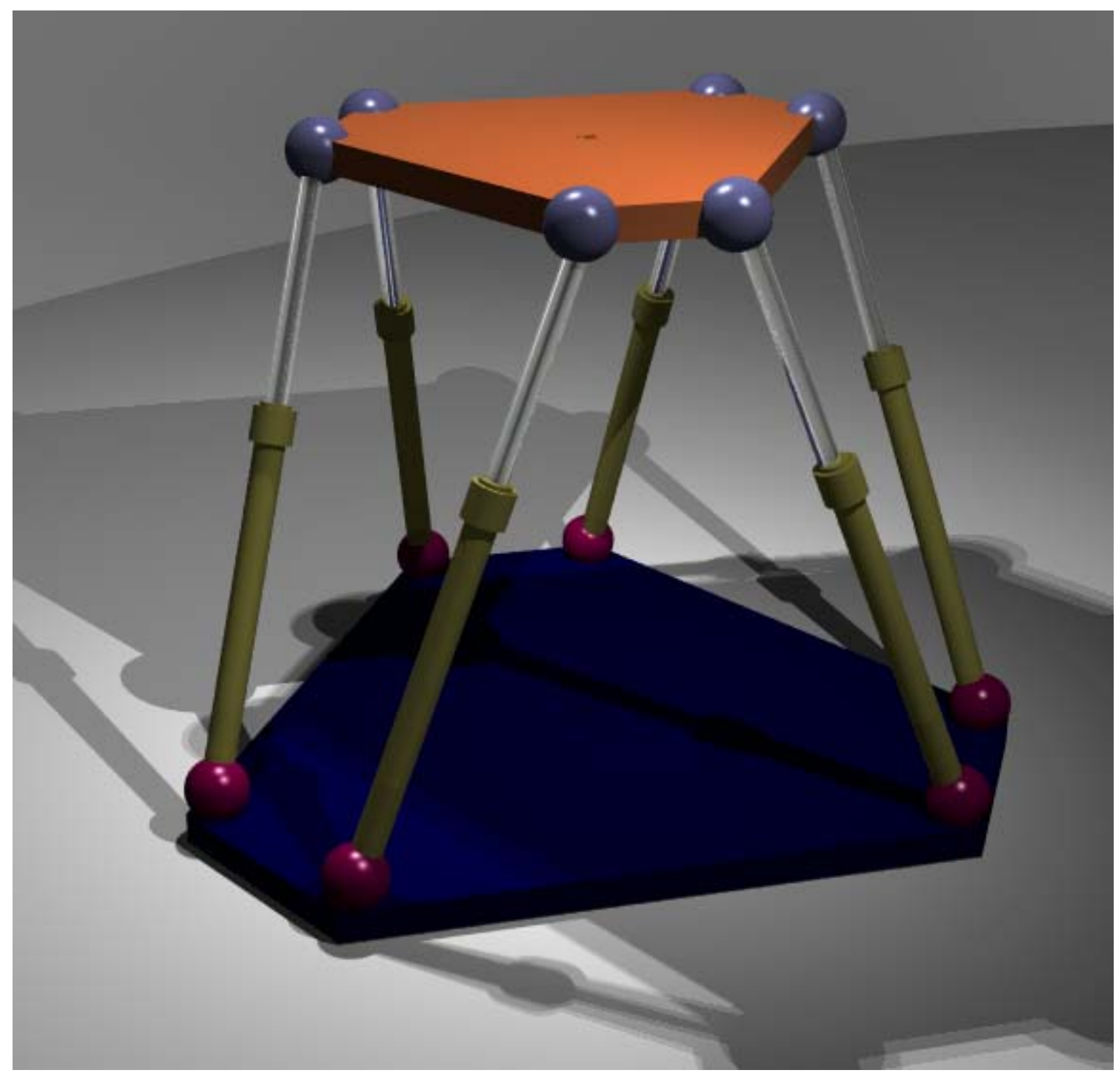

Figure 3. Six Degree of Freedom Stewart Platform.

Most early flight simulators did not use any sort of visual system as they were mainly used for instrument training. The first major visual system was point light source projection and was developed in the 1950s. The first modern visual system, i.e. computer video graphics was created by General Electric specifically for the space program. Modern visual aide systems 
consist of computer video graphics which are run by the aircraft dynamics to simulate visually what the aircraft is doing. Thus, digital simulation along with modern motion and visual systems are still an effective method for implementing a flight training device.

Along with better modeling of aircraft, the Federal Aviation Administration started looking at flight simulators as a serious training method for pilots. One of the first regulations set by the FAA that was imposed on flight simulators occurred in 1973. This requirement was that the simulator had to handle like the aircraft it was simulating well enough that landing could be done in the simulator for pilots that needed to update their qualification of experience. Thus a very integral part of flight training, the landing, was finally able to be taught in a less stressful environment and therefore increased the knowledge retained by the pilot using the simulator.

The FAA decided that there should be more regulations on how a simulator was designed and implemented and in June of 1980 the Federal Aviation Regulations Part 121 (FAR) were amended and the FAA flight simulation plan was created [17]. With this amendment, flight simulators then had to pass more stringent requirements because a set of qualifications had to be met in order to be considered for use as flight training devices. As flight simulators become more advanced, more requirements have been added. Part of these requirements is to simulate the aircraft very accurately to get optimal training for the specified aircraft. Therefore the FAA saw a need to create objective requirements. The requirements of the simulator tend to be limits/thresholds on errors of the modal parameters for slow oscillations and/or limits on time histories of relevant parameters in specific maneuvers in comparison to flight test data of the given aircraft. Subjective requirements call for handling qualities assessment for specific maneuvers that are done by pilots and are analyzed by the pilots to get the right "feel" of the aircraft. 


\section{General Structure of a Computational Environment for the Development of an FAA Compliant Aircraft Simulation Model}

A strategy had to be devised to take the flight data given by the manufacturer of the aircraft and create an aircraft dynamics model that would be able to pass FAA regulations. To begin the process, the flight data that was available had to be processed and converted from the file format that resulted from the data acquisition process to a format that was acceptable and convenient to be used within Matlab.

To process the data, the state variable and control variables of the flight test data were plotted. By analyzing the state and the control variables in these plots and considering the purpose of each flight test, (for example short period or dutch roll), a segment of the data would be selected for the FAA tests. Once the data segment was selected, Matlab would then convert the segment into .mat files with all of the desired state and control variables.

After the data has been processed, the next stage was to take the selected data for the FAA tests and then use parameter identification software to find the aircraft dynamics model. To do this, two approaches to parameter identification were used. These approaches were the least squares estimator in the time domain and the recursive Fourier transform in the frequency domain [14]. Using a combination of the results from both approaches and a background in aircraft dynamics (both analytical tools and heuristics), the model was created using the state space representation.

Once the basic aircraft dynamics were created, several subsystems had to be modeled and added to the flight simulation in order for the simulation to be used as a flight training device. The main subsystems in the model were the landing gear model and the engine dynamics model 
that were developed separately from the aircraft dynamics model. After the subsystems were added, the simulation had to be run with the control inputs of the selected flight test data. The simulation was then initiated with the flight test data control inputs and the simulation data was compared with the flight test data and was checked for compliance with the FAA regulations. The only requirement by the FAA in regards to comparing the flight test data with the flight simulation data is that it has to be a snapshot of the response of the aircraft, meaning that the coefficients found using the parameter identification had to be compared with the original flight test data only.

If the aircraft model did not comply with FAA regulations one of two choices had to be made. The first was to use knowledge of aircraft dynamics to tweak the model parameters to meet the requirements. There were several possible causes of the model of the aircraft not matching the flight test data. Noise and sensor bias in the flight test data are large contributors to the problems with the model. The second choice was to alter the control inputs slightly. The second choice is most feasible for small changes to the response of the aircraft model. Changing the control inputs for the simulation is tolerable due to a possible bias in the control input sensors and is acknowledged by the FAA regulations. Tweaking the model is a more effective way of meeting the FAA regulations due to the stringent requirements set.

Once the model has been tweaked and complies with the FAA regulations, pilots that are qualified experts on the aircraft, then test the model subjectively by using the simulation with hardware control inputs. The pilots attempt to fly the aircraft as it should be flown and if it does not "feel" like the aircraft, the aircraft model is then altered to meet the subjective testing of the pilots and the model is retested to meet the objective FAA requirements. 
Finally, after both the subjective tests of the pilots and the FAA test requirements have been achieved - possibly after several iterations - the model is completed and the final phase begins. In the final phase the FAA requires the data from the simulation to be in a certain format for ease of certification of the flight simulator. Figure 2 shows the general block diagram for the strategy of creating a flight simulation model from flight test data that can be evaluated for compliance with FAA flight simulator performance requirements. 


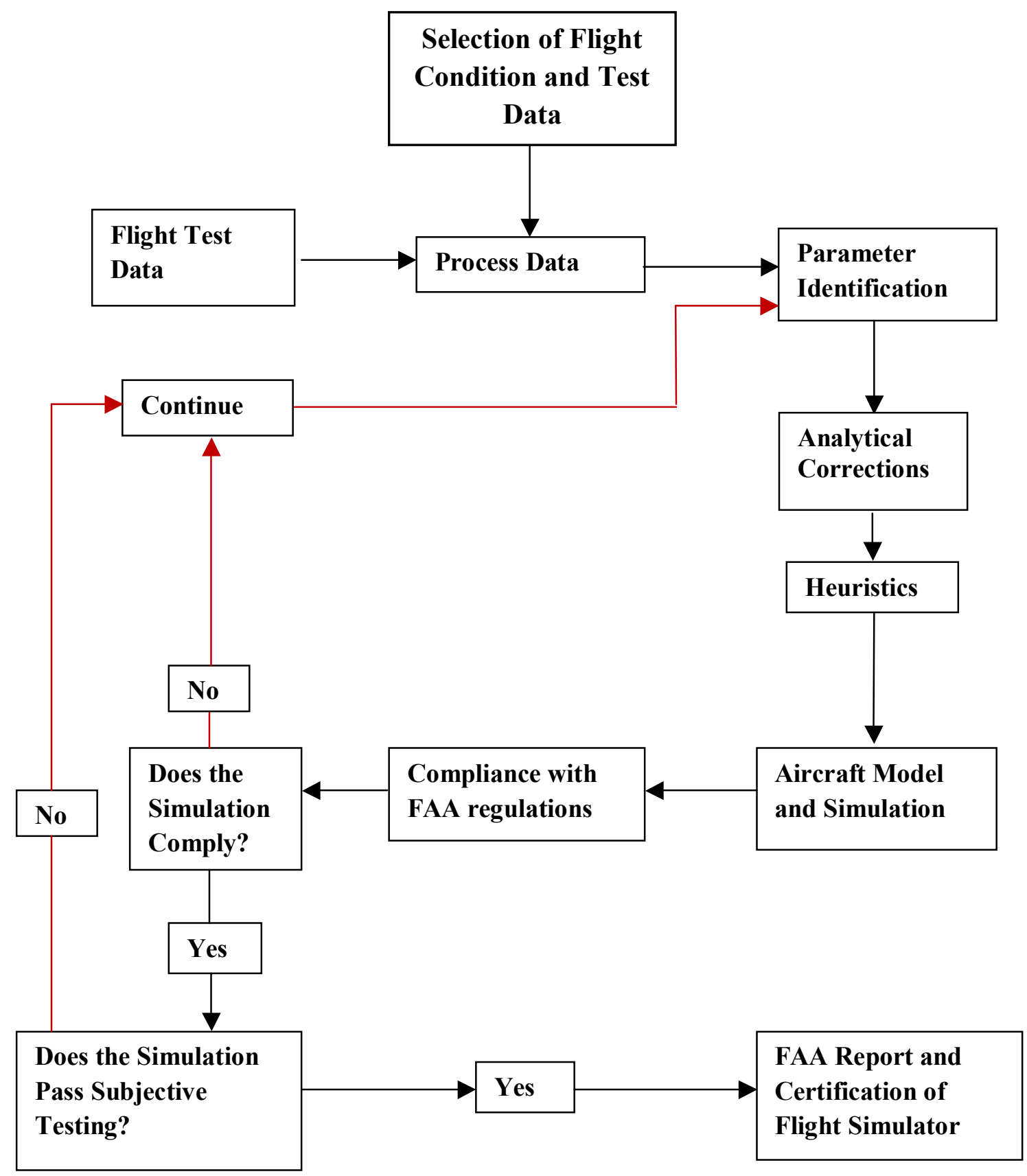

Figure 2. Block Diagram of Flight Simulation Design Strategy. 


\section{Computational Tools for Flight Data Processing}

Flight data was given on a number of flights and for each flight, the data were compiled into one file that contained all of the parameters that were measured for that flight. The content and the general format of the flight test data file is typical for what is currently used in the industry. It should be noted that, throughout this thesis, all flight test data have been normalized and/or altered such that the proprietary rights of the manufacturer are protected.

The flight data were recorded in a comma separated variable file (.csv) and Matlab does not directly support the .csv file. Matlab has a function called csvread that takes .csv files and converts them to Matlab data files (.mat files). The main issue that came up was that the files were not just data. The data was accompanied with a heading that displayed the flight number and what each column of data represented, i.e. angle of attack, control deflections, engine parameters, etc. Matlab's csvread command would only read data and therefore the data could not be read just using the plain csvread command. Matlab's csvread did have an option that would read a certain range of data in the file. The range was set up in a [R1 C1 R2 C2] format where R1 and C1 were the upper-left bounds of the data and R2 and C2 were the lower-right bounds of the data. Once the range was set up, the data was then able to be read and reduced by Matlab.

Since there were many flight test data files and so many measured outputs in the .csv file, finding desired data would be difficult without the help of a program to reduce the time searching for desired data points. Another issue was that there are large amounts of data in each flight test that part of the program had to be designed to take desired data points, such as a noncross controlled short period maneuver, and convert them into a matrix in a Matlab .mat file for 
use in the parameter identification process. A program was created to do that and it will be referred to as the Plot Data program.

To start the Plot Data program, a menu was created to initialize all of the ranges of data for each of the flight test data files as seen in Figure 3. After the program has been initialized and the continue button is clicked, the program brings up another menu, which is shown in Figure 4. In this menu, each of the parameters required for FAA tests can be selected along with the flight data file. Figure 4 shows all of the parameters that are required for FAA compliance tests. Once the desired file and data are selected the continue button becomes active and when clicked loads the desired data and plots the data. The data is plotted on separate plots in Matlab for ease in finding data that can be used for parameter identification and FAA compliance.

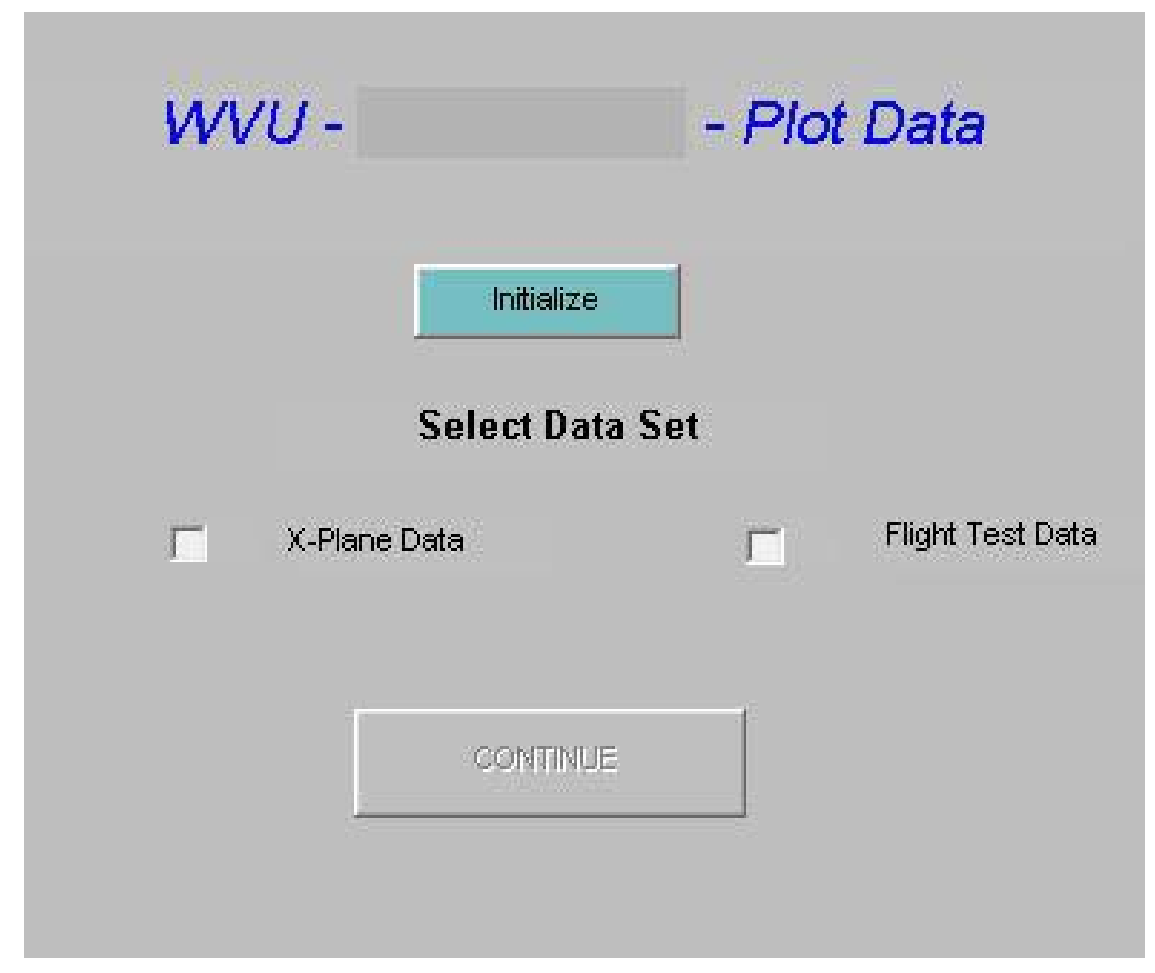

Figure 3. Initializing the Plot Data Program. 
Select Flight Test

flt0020gr00_20.cs-

$5 \quad$ N1 (Left and Right)

$\Gamma \quad$ N2 (Left and Right)

$5 \quad$ Rate of Climb

5 Longitudinal Acceleration (g)

5 Lateral Acceleration (g)

$\Gamma$ Vertical Acceleration [g]

$\Gamma \quad$ Altitude
Select State Variables

I All

$\Gamma \quad$ Velocity

I Angle of Attack

ᄃ Sideslip Angle

$\Gamma \quad$ Roll Rate

$\ulcorner\quad$ Pitch Rate

Г Yaw Rate

Г Roll Angle

Г Pitch Angle

I Heading
Select Control Variables

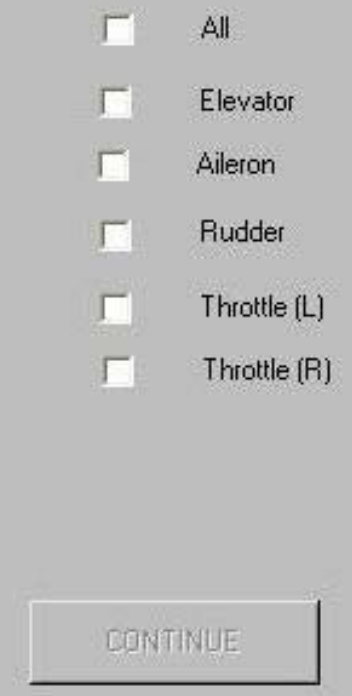

Figure 4. Selection of Flight Test Data Variables.

For example, Flight Test \#1, which is altered flight test data by using a multiplier, was the flight test data for the short period response of the aircraft. Plotting the state and control variables shows the response of the aircraft very clearly. For this example, Figures 5 through 7 show the pitch angle, pitch rate, and elevator deflection respectively. The rest of the state and control variables for Flight Test \#1 can be seen in Appendix A. 


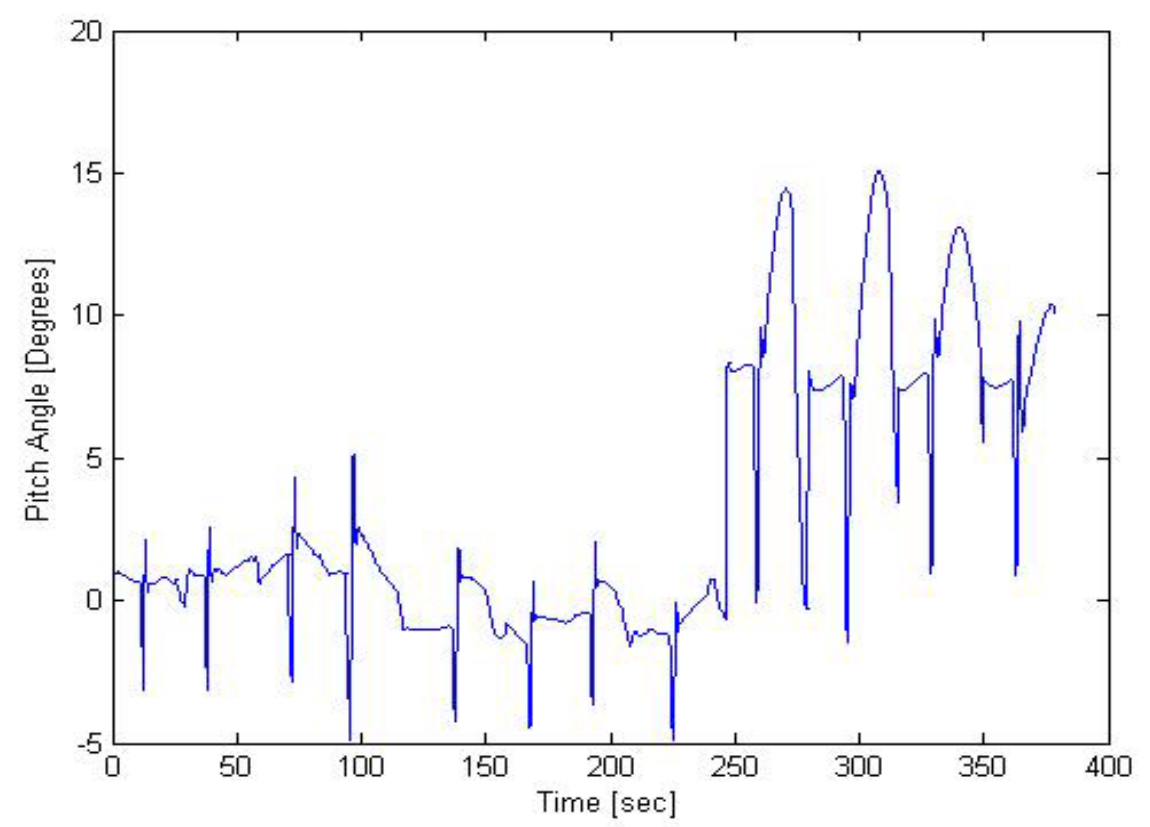

Figure 5. Pitch Angle for Altered Short Period Flight Data.

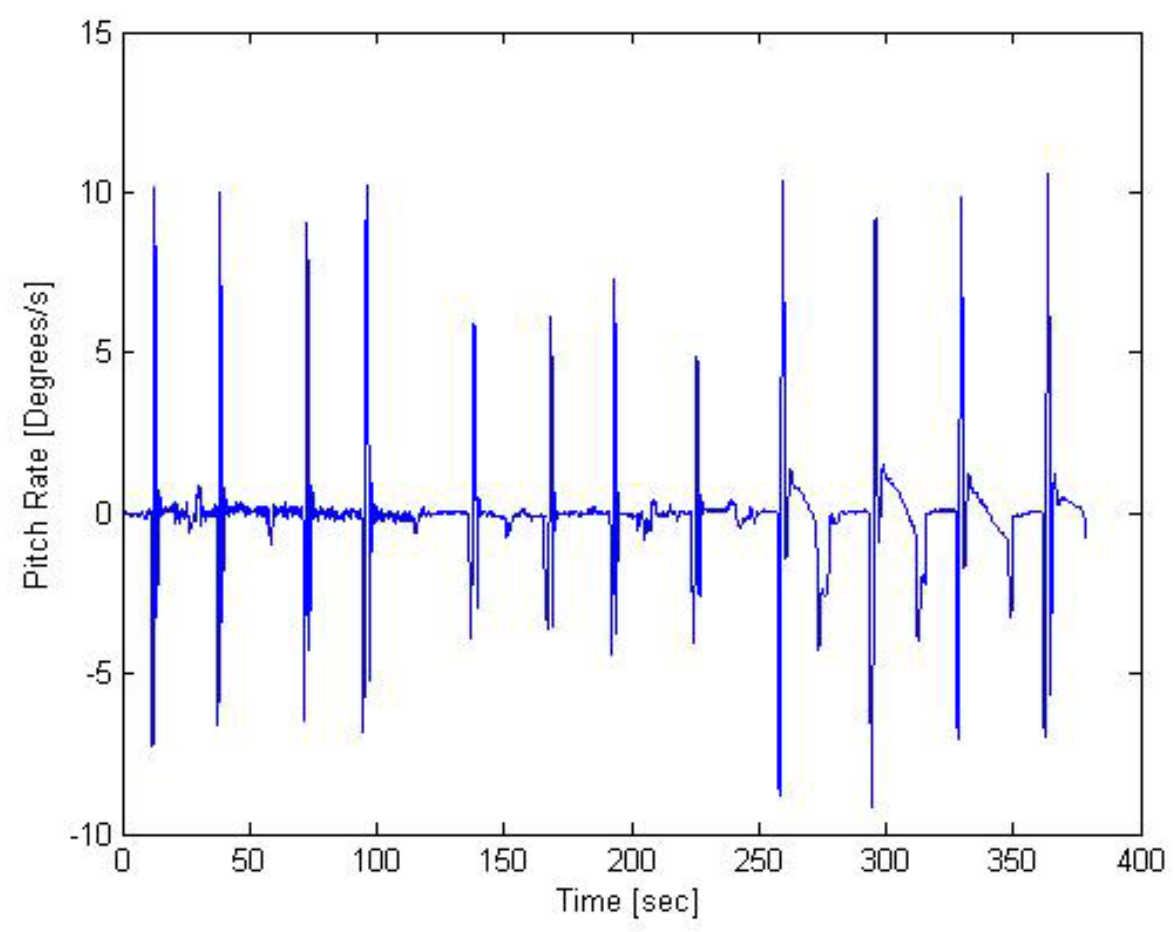

Figure 6. Pitch Rate for Altered Short Period Flight Data. 


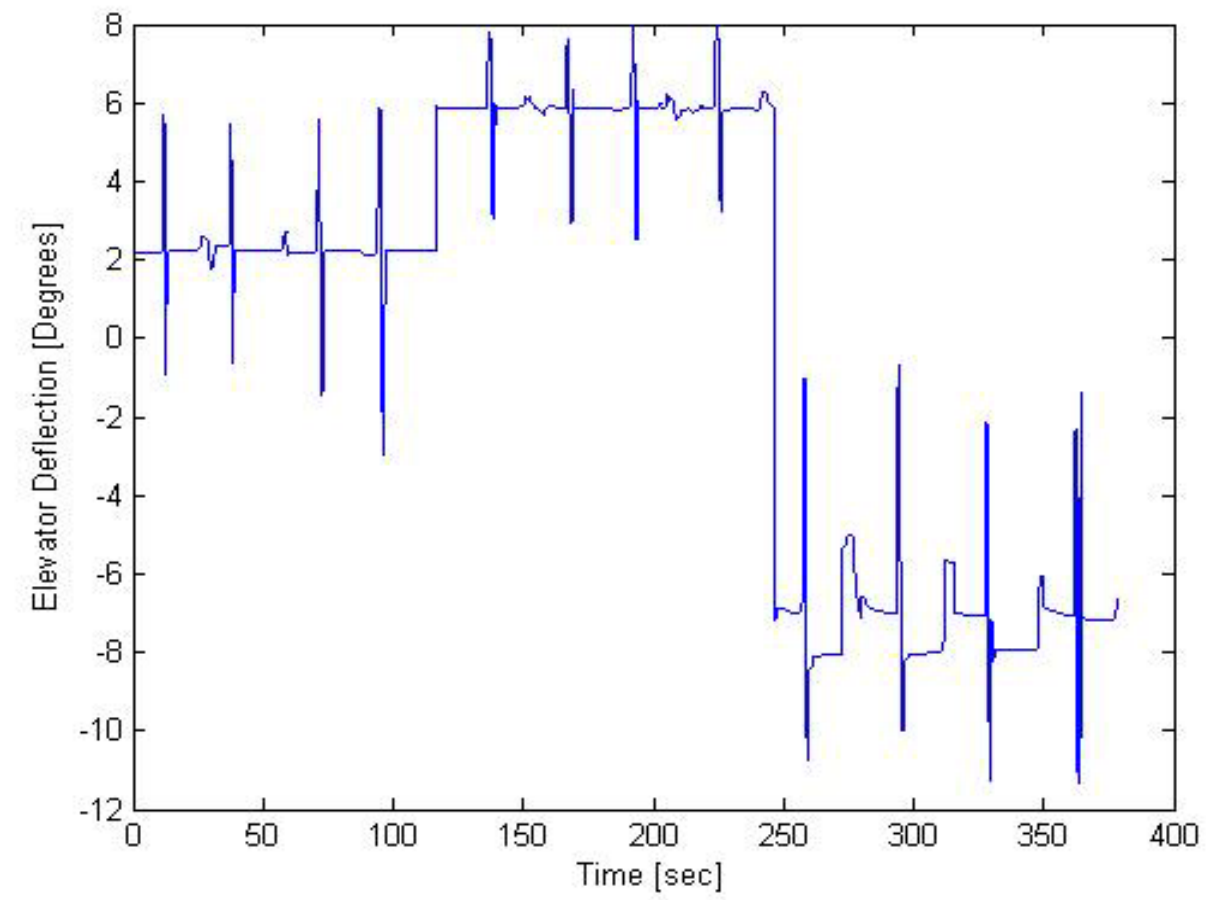

Figure 7. Elevator Deflection of Altered Short Period Flight Data.

After analyzing the flight test data, there are 12 short period maneuvers in the data set. For parameter identification it is best to select data that closest meet the flight condition. The flight conditions are cruise, approach, landing, and steady state sideslip. Constraints on the general conditions of the test have been considered for each particular FAA objective test. In this example pertinent to the short period evaluation, these constraints are:

- General consistency of the data with the baseline steady state horizontal, symmetric, rectilinear, uniform flight

- The existence of an initial and final (before and after the maneuver) steady state segment of adequate duration

- Absence of crossed inputs (Avoid data with multiple inputs, for example not having both aileron and rudder deflection in the desired data)

- Non-violation of linear domain boundaries 
- $\quad$ Limited input sensor bias

After analyzing the whole flight data file, a maneuver within the flight data can be selected by specifying the start and end time of the maneuver, within the interactive menu shown in Figure 8. The desired variables that need to be saved can be selected by clicking on the checkboxes. Figure 8 has the same basic format as Figure 4 except for some slight variations. The first variation is the "Save as" column. The "Save as" column shows what the name of the vector will be in the .mat file. The next difference is the "Save in" column that creates the name of the .mat file. The following tables show what vectors are saved in each save data file.

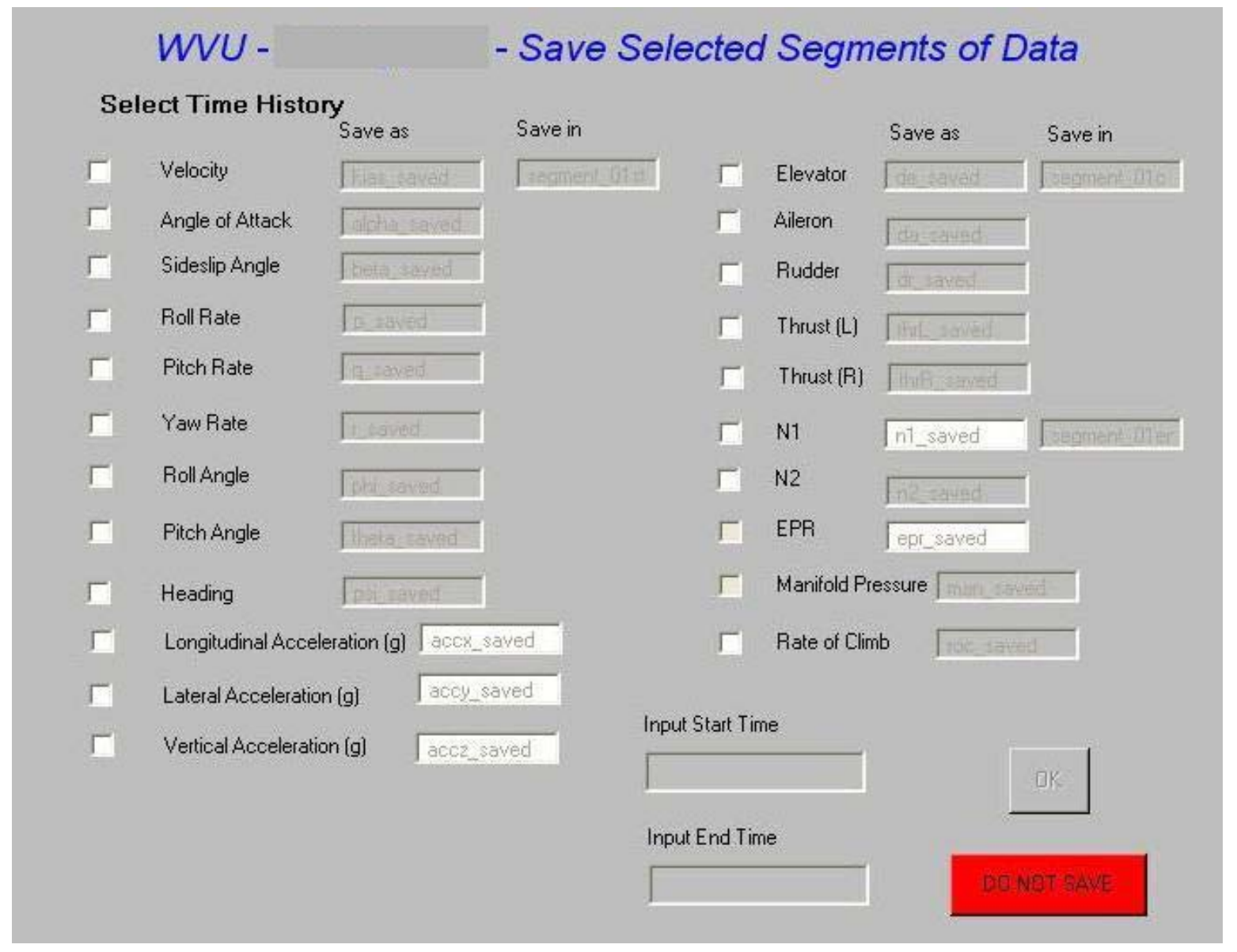

Figure 8. Reducing Flight Data to Desired Data Segments. 
Table 1. State Variables Save File Vectors.

\begin{tabular}{|c|c|}
\hline Segment $01^{\text {st }}$ file & \\
\hline Variable & Save as \\
\hline Velocity & kias_saved \\
\hline Angle of Attack & alpha_saved \\
\hline Sideslip Angle & beta_saved \\
\hline Roll Rate & p_saved \\
\hline Pitch Rate & q_saved \\
\hline Yaw Rate & r_saved \\
\hline Roll Angle & phi_saved \\
\hline Pitch Angle & theta saved \\
\hline Heading & psi_saved \\
\hline $\begin{array}{l}\text { Longitudinal } \\
\text { Acceleration }\end{array}$ & accx_saved \\
\hline Lateral Acceleration & accy_saved \\
\hline Vertical Acceleration & accz-saved \\
\hline
\end{tabular}

Table 2. Control Variables Save File Vectors.

\begin{tabular}{|l|l|}
\hline segment_01c file & \\
\hline Variable & Save as \\
\hline Elevator & de_saved \\
\hline Aileron & da_saved \\
\hline Rudder & dr_saved \\
\hline $\begin{array}{l}\text { Thrust(Throttle) } \\
\text { Left }\end{array}$ & thrL_saved \\
\hline $\begin{array}{l}\text { Thrust(Throttle) } \\
\text { Right }\end{array}$ & thrR_saved \\
\hline
\end{tabular}


Table 3. Engine Parameters and Rate of Climb File Vectors.

\begin{tabular}{|l|l|}
\hline Segment_01eng file & \\
\hline Variable & Save as \\
\hline & N1_L_saved and \\
N1 & N1_R_saved \\
\hline & N1_L_saved and \\
N2 & N1_R_saved \\
\hline EPR & epr_saved \\
\hline Manifold Pressure & man_saved \\
\hline Rate of Climb & roc_saved \\
\hline
\end{tabular}

In Table 3, the rate of climb was added to the engine parameters because it was added to the program at the same time the engine parameters were added. As an example, from the altered flight data of Flight Test \#1 shown in Figures 5 through 7, the time of $130 \mathrm{sec}$ was selected as the start time and the end time was selected as 150 because it encapsulates one of the short periods in the flight test. This segment was selected because it contains a very clear short period maneuver complying with all the requirements formulated earlier. Figures 9 through 11 show the segment of data that were selected for pitch, pitch rate, and elevator deflection respectively of the selected short period segment and the rest of the altered flight tests data of the same segment can be seen in Appendix B. Several such segments were used in the PID process, however, the FAA regulations only require that compliance be demonstrated for one case. 


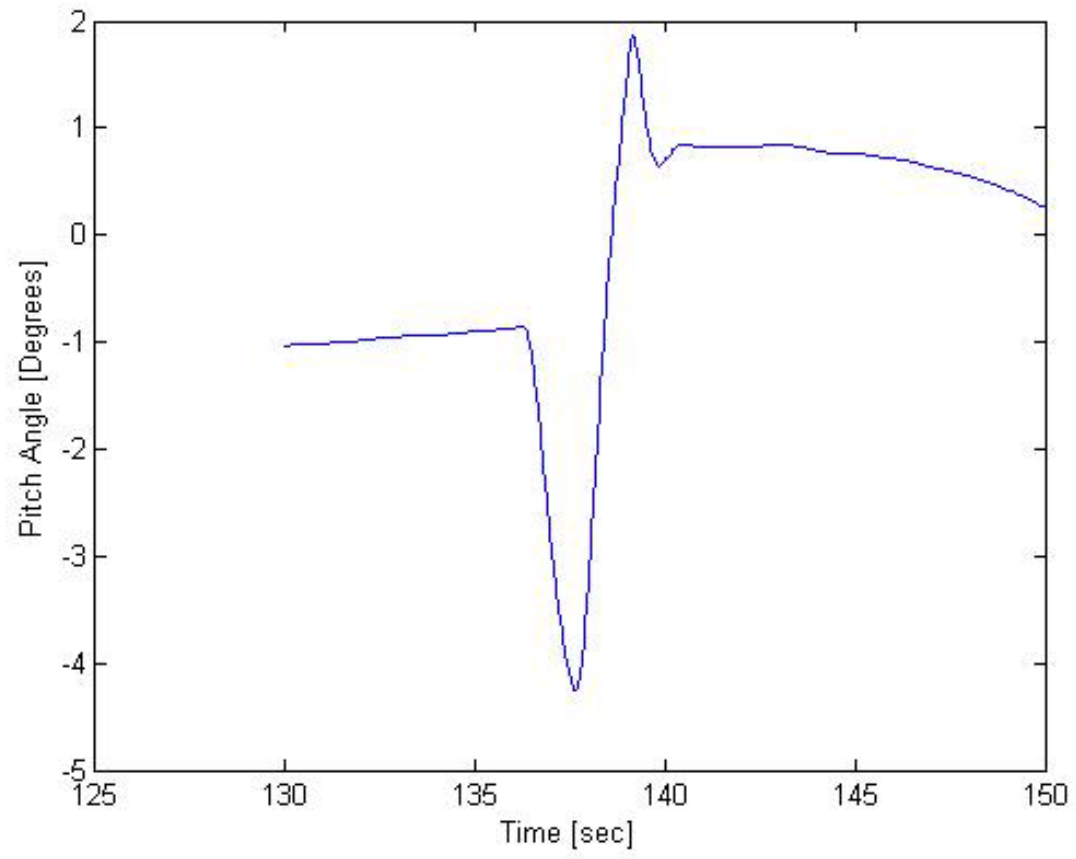

Figure 9. Pitch Angle Segment of Altered Short Period Flight.

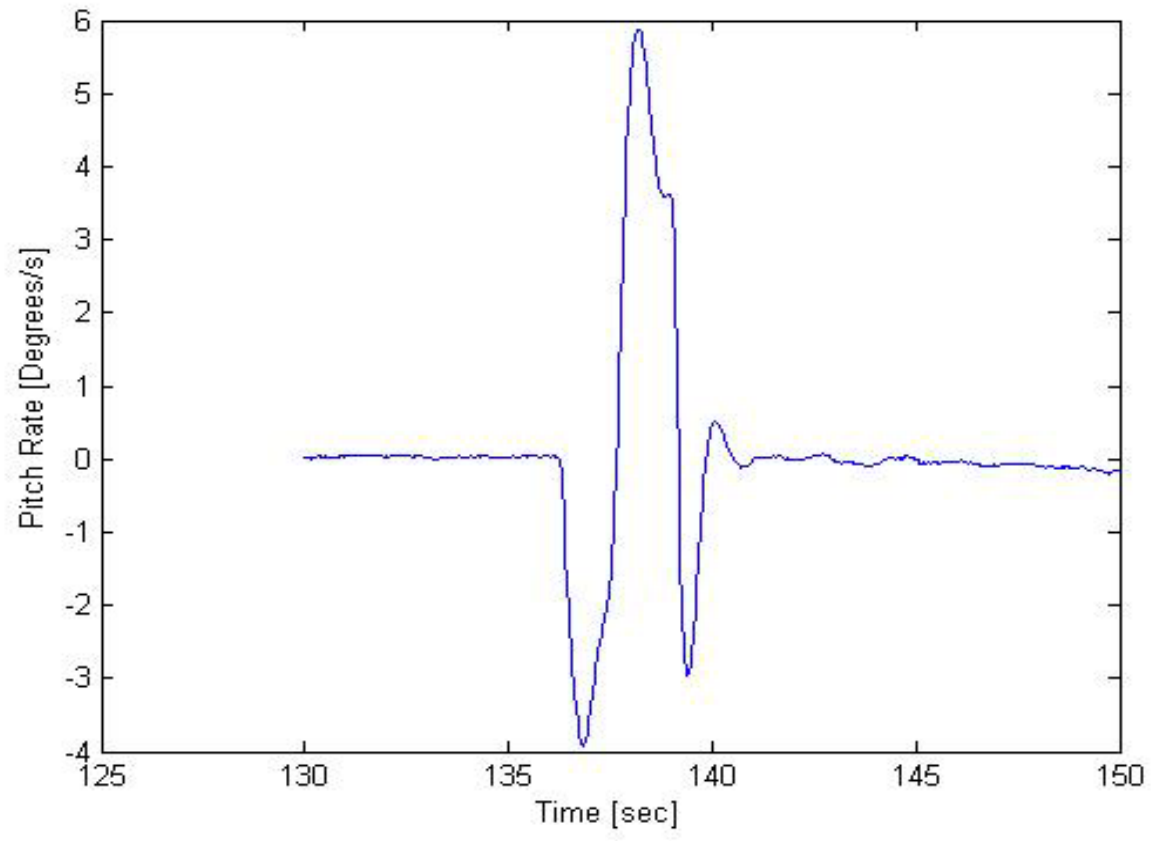

Figure 10. Pitch Rate Segment of Altered Short Period Flight. 


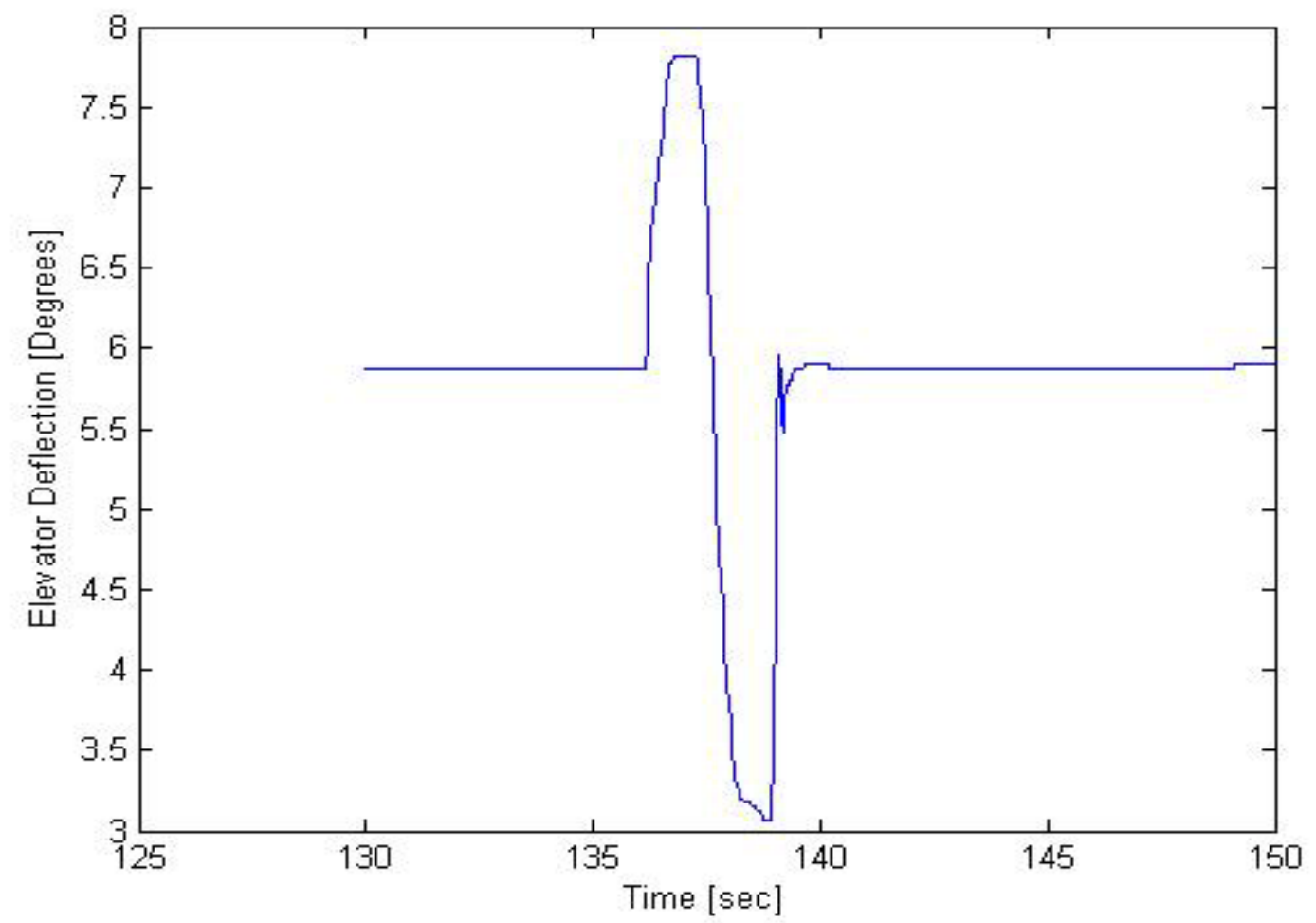

Figure 11. Elevator Deflection Segment of Altered Short Period Flight.

Figure 12 shows the final menu in the Plot Data program. When the first option is selected the program reloads all of the same flight test data and brings up the menu to select certain data from the flight test data. The second option brings up the menu to select a new flight test data at the menu from Figure 4. The third option closes all of the figures open including the menu and stops the program. 


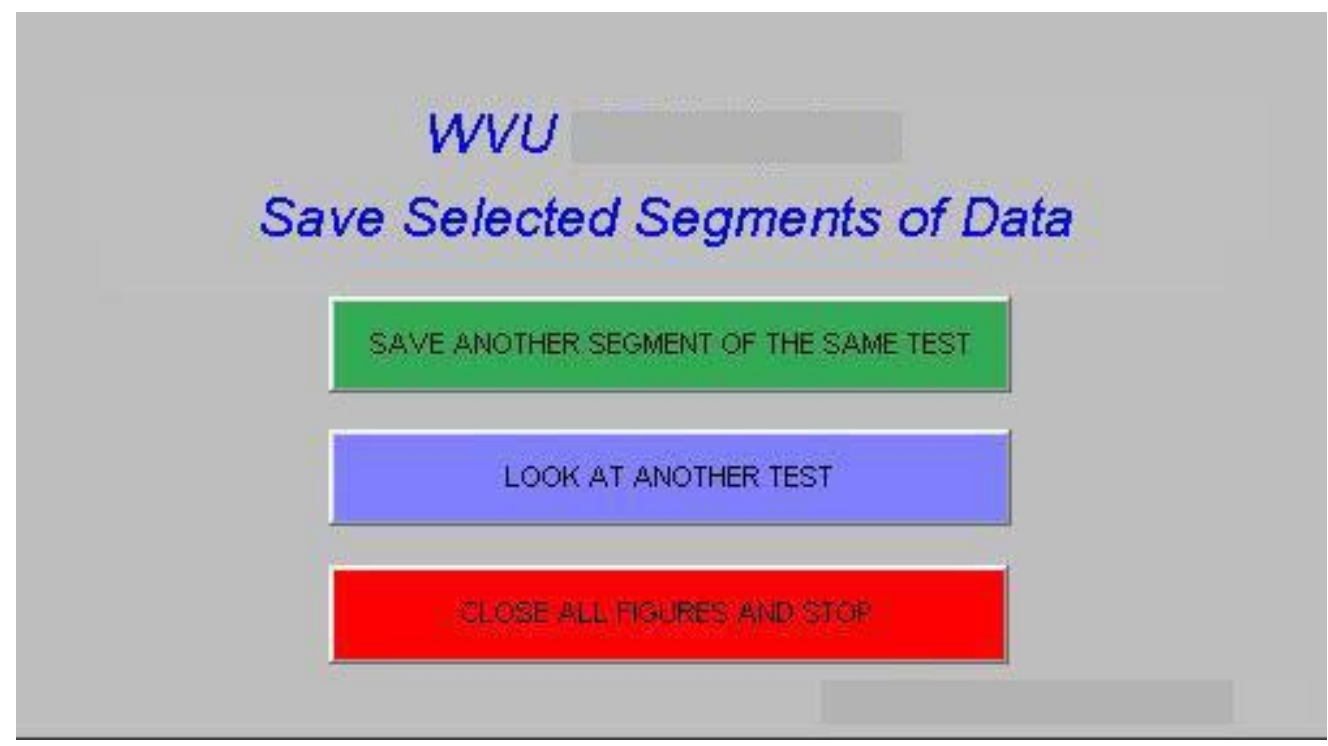

Figure 12. Final Choice Menu.

Once the program is finished, the selected flight test data for each test is processed and is now compatible with Matlab. The processed data can now be put through parameter identification software to regress the flight data into a mathematical model of the aircraft. 


\section{Parameter Identification}

PID is a group of linear regression techniques that take a known output data, in this case flight test data of a business jet aircraft. Knowing how the system should respond mathematically, a set of unknown parameters, the stability and control derivatives, can be regressed to create a linear equation approximation of the data. A simple state variable model of aircraft dynamics can be seen in Appendix C. Given the flight test data of the aircraft and geometry, parameter identification was well suited to what was required. Two methods of parameter identification were used to determine the preliminary aircraft aerodynamic model. Both methods were used due to the reliability of both approaches and it gave the ability to check the results and give them The first is the least squares estimator. This approach takes the data and tries to do a best-fit linear regression for all data points with the assumption of a linear representation of the forces and moments as functions of state and control variables.

The other approach is called the recursive Fourier transform. The recursive Fourier transform takes the same approach as the least square estimator but applies it to the frequency domain. These approaches to parameter identification were selected because of the similar performance between the two techniques in accuracy and convergence [18]. Both the recursive Fourier transform and the least squares estimator both use the same basic equation to solve for the unknown parameters which is:

$$
z=H \theta+v
$$




\subsection{Least Squares Estimator}

Parameter estimation using the least squares estimator assumes that $\theta$ is a vector of unknown constant parameters, $\mathrm{H}$ is a known matrix, $\mathrm{v}$ is the measurement noise, and $\mathrm{z}$ is the measurement. An assumption made in the parameter identification is that $\mathrm{v}=0$. The best way to estimate $\theta$ is to minimize the weighted sum of squared differences between the measured outputs and the model outputs. This is accomplished by using the equation known as the cost function $\mathrm{J}(\theta)$ :

$$
J(\theta)=\frac{1}{2}(z-H \theta)^{T} R^{-1}(z-H \theta)
$$

where $\mathrm{R}^{-1}$ is a positive definite weighting matrix (4). An assumption was made for this project where the difference will be equally weighted therefore $\mathrm{R}^{-1}=1$ and the equation simplifies to:

$$
J(\theta)=\frac{1}{2}(z-H \theta)^{T}(z-H \theta)
$$

This is known as ordinary least squares. For ordinary least squares the $\mathrm{H}$ matrix is changed to the $\mathrm{X}$ matrix that is a matrix of vectors and regressors. To minimize the sum of square differences between the measurements and the model must satisfy.

$$
\frac{\partial J}{\partial \theta}=-X^{T} z+X^{T} X \vec{\theta}=0
$$

Solving for $\vec{\theta}$, the parameter vector, the equation reduces to:

$$
\bar{\theta}=\left(X^{T} X\right)^{-1} X^{T} z
$$


Using Matlab to find the parameters of the least square estimator the $C_{m}$ values normalized values Table 4 and the normalized $C_{m}$ are compared against the computed value of $\mathrm{C}_{\mathrm{m}}$ from measured states and controls (flight data) in Figure 13.

Table 4. Normalized Pitching Moment Stability Coefficient and Control Derivatives Using Least Squares.

\begin{tabular}{|c|r|}
\hline $\mathrm{Cm}$ & \\
\hline 0 & 0 \\
\hline $\mathrm{V}$ & -0.001 \\
\hline$\alpha$ & -0.01214 \\
\hline $\mathrm{q}$ & -1 \\
\hline$\alpha$ dot & 0.146866 \\
\hline$\delta \mathrm{e}$ & -0.00049 \\
\hline
\end{tabular}




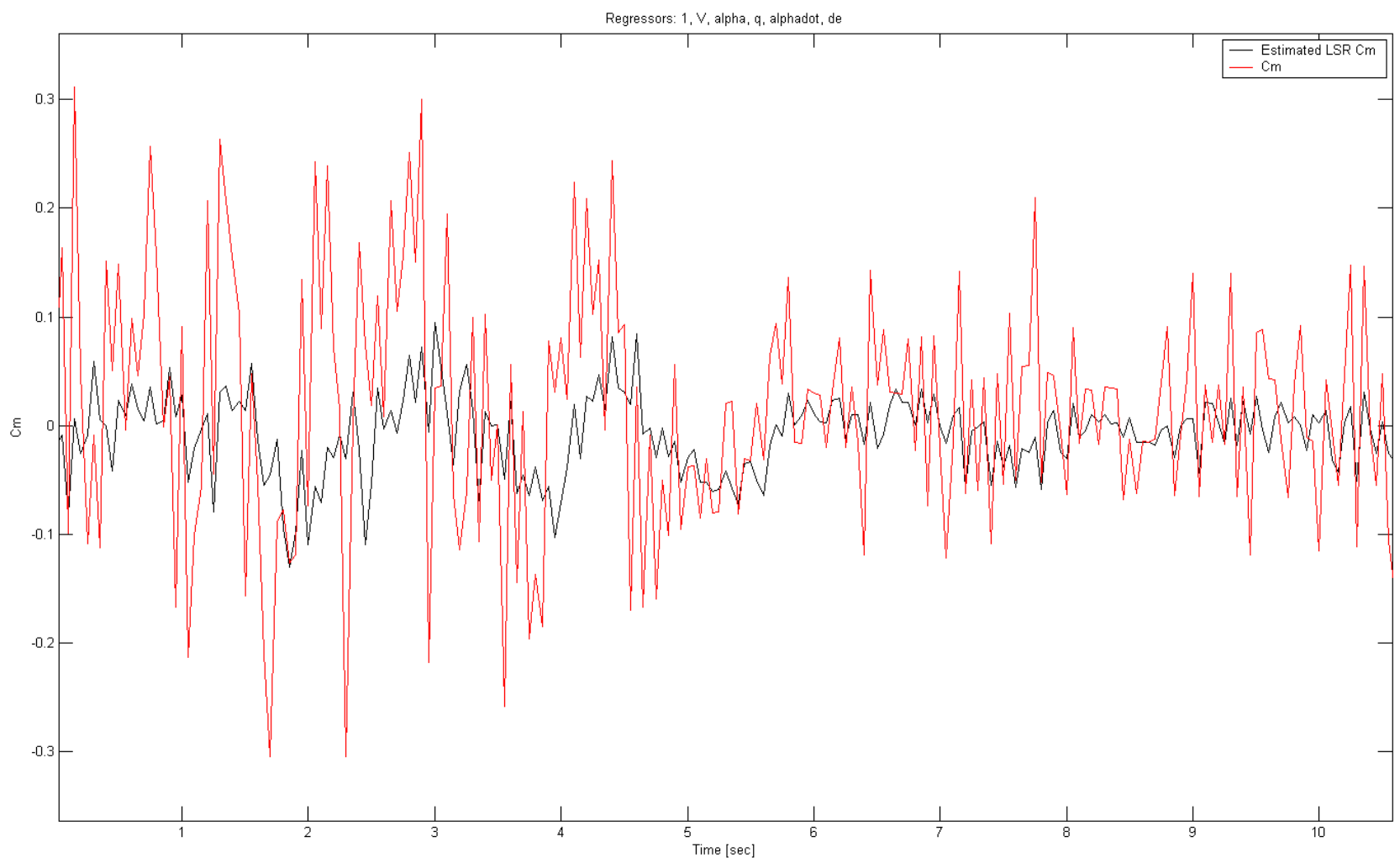

Figure 13. Comparison of Normalized Least Squares Estimated and Measured Pitching Moment Coefficient

\subsection{Recursive Fourier Transform}

The Fourier transform of a signal is defined by:

$$
\bar{x}(\omega)=\int_{0}^{T} x(t) e^{-j \omega t} d t
$$

Transforming the Fourier transform to a discrete form that is required for data that has sampled yields the equation, 


$$
\bar{x}(\omega) \equiv \Delta t \sum_{i=0}^{N-1} x\left(b e^{-j \omega i \Delta t}\right.
$$

and defining,

$$
X(\omega) \equiv \sum_{i=0}^{N-1} x(i) e^{-j \omega i s t}
$$

Therefore the finite Fourier transform approximation is,

$$
\bar{x}=\Delta t X(\omega)
$$

For regression in the frequency domain, the least squares estimation equation must be changed due to complex numbers in the system, which the equation now becomes,

$$
z=\bar{x} \theta
$$

Where $\bar{z}$ is the measurement data in the frequency domain and $\bar{X}$ is the matrix of finite Fourier transforms of the unknown parameter matrix. The cost function, $J(\theta)$, for an ordinary least squares becomes,

$$
J(\theta)=\frac{1}{2}(\tilde{z}-\tilde{X} \theta)^{\dagger}(z-\tilde{X} \theta)
$$

Where $t$ is the conjugate transpose of the matrix. Minimizing the sums of the cost function by taking the derivative of the cost function matrix and solving for the parameter vector, $\vec{\theta}$ yields, 


\section{$\hat{\theta}=\operatorname{Re}\left[\tilde{X}^{\dagger} \tilde{X}\right]^{-1} \operatorname{Re}\left[\tilde{X}^{\dagger} \tilde{z}\right]$}

Parameter Identification has one major issue in finding the stability derivatives. In order for parameter identification to work the stability derivatives much benefit from a direct cause and effect relationship between the aircraft dynamics and the control surface deflections. The issue is for certain coefficients, such as the drag coefficient, since the drag cannot be directly affected from control surface deflections. This is an issue that was resolved by using empirical methods to derive the drag coefficients of the aircraft.

Using PID software designed for aircraft parameter identification in Matlab and Simulink the stability derivatives can be found. To start the PID program, the initial conditions of all of the state variables must be set into an initial conditions file. Once the initial conditions file is completed and the data processed from the flight test data is loaded, the least squares estimator is run in Matlab. Once the least squares estimator has been run in Matlab, the recursive Fourier transform approach is then run in Simulink as seen in Figure 14. The recursive Fourier transform is run in real time, therefore as the data is analyzed it can be plotted and the normalized values at which the stability and control derivatives converge can be seen in Figure 15. 


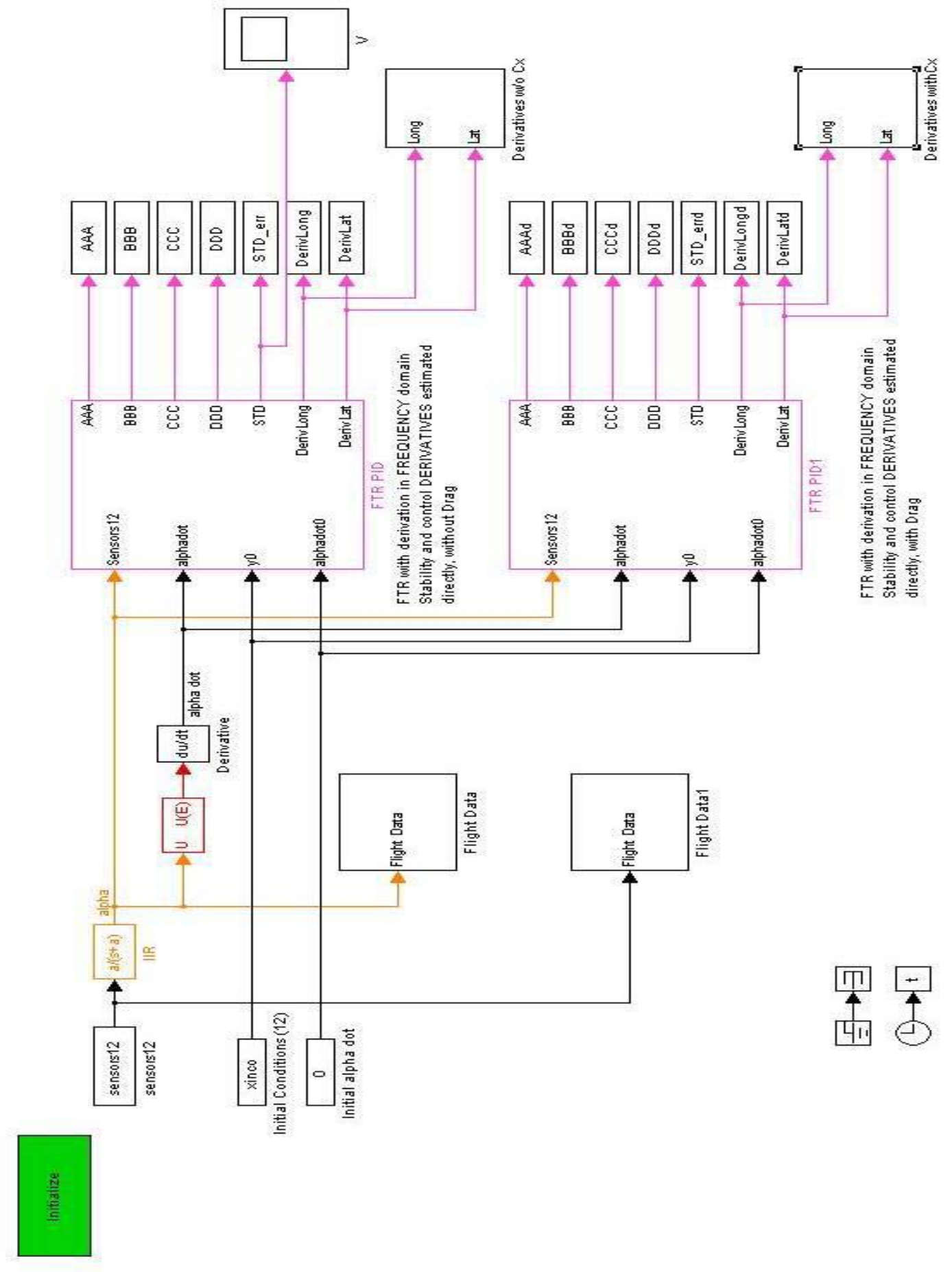


Figure 14. Recursive Fourier Transforms in Simulink
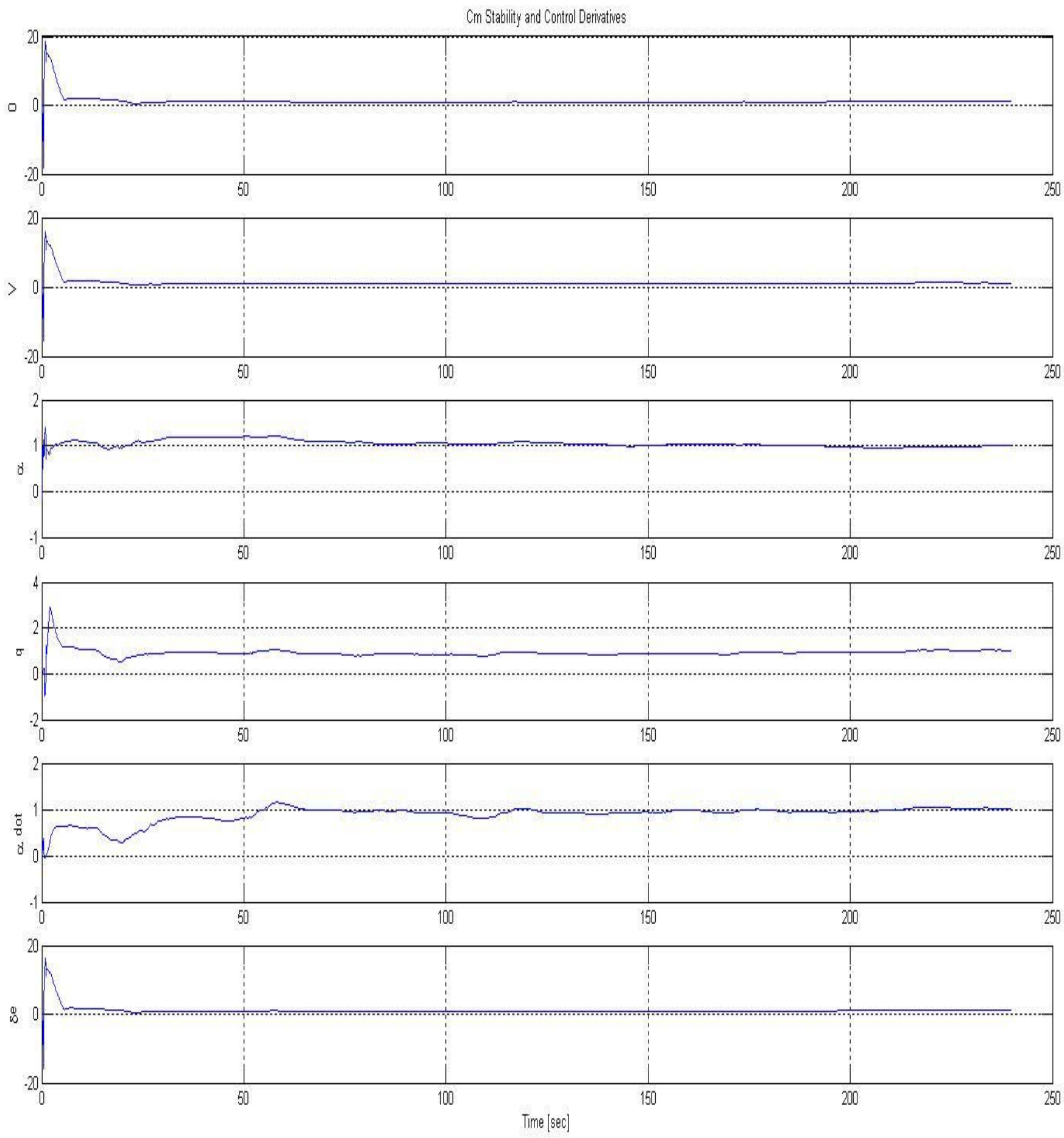
Figure 15. Normalized Pitching Moment Stability Coefficient and Control Derivatives Using Recursive Fourier Transforms.

\subsection{Aircraft Parameter Identification}

For aircraft parameter identification there are six main equations of motion that use parameter identification to find the stability and control derivatives. The six equations of motion are:

$$
\begin{aligned}
& C_{\mathrm{X}}=C_{\mathrm{X}_{a}} \Delta \alpha+C_{\mathrm{X}_{\dot{\alpha}}} \Delta \dot{\alpha}+C_{\mathrm{X}_{q}} \frac{\Delta q \bar{c}}{2 V}+C_{\mathrm{X}_{s}} \Delta \delta_{e}+C_{\mathrm{XV}} \frac{\Delta V}{V}+C_{\mathrm{X}_{0}} \\
& C_{Z}=C_{Z_{\alpha}} \Delta \alpha+C_{Z_{\dot{\alpha}}} \Delta \dot{\alpha}+C_{Z_{q}} \frac{\Delta q \bar{c}}{2 V}+C_{Z_{\delta}} \Delta \delta_{e}+C_{Z_{0}} \\
& C_{m}=C_{m_{\alpha}} \Delta \alpha+C_{m_{\dot{\alpha}}} \Delta \dot{\alpha}+C_{m_{q}} \frac{\Delta q \bar{c}}{2 V}+C_{m_{\tilde{\sigma}}} \Delta \delta_{e}+C_{m_{0}} \\
& C_{Y}=C_{Y_{\beta}} \Delta \beta+C_{Y_{p}} \frac{\Delta p b}{2 V}+C_{Y_{r}} \frac{\Delta r b}{2 \underline{-}}+C_{Y_{\delta_{\alpha}}} \Delta \delta_{a}+C_{Y_{\delta_{r}}} \Delta \delta_{r}+C_{Y_{0}} \\
& C_{l}=C_{l_{\beta}} \Delta \beta+C_{l_{p}} \frac{\Delta p b}{2 V}+C_{l_{r}} \frac{\Delta r b}{2 V}+C_{l_{\delta_{a}}} \Delta \delta_{a}+C_{l_{\delta_{r}}} \Delta \delta_{r}+C_{l_{0}} \\
& C_{n}=C_{n_{\beta}} \Delta \beta+C_{n_{p}} \frac{\Delta p b}{2 V}+C_{n_{r}} \frac{\Delta r b}{2 V}+C_{n_{\sigma_{\alpha}}} \Delta \delta_{a}+C_{n_{\sigma_{r}}} \Delta \delta_{r}+C_{n_{0}}
\end{aligned}
$$

Assumptions were made in the parameter identification process that helped simplify the process of parameter identification. A very common assumption is to decouple the longitudinal and lateral-directional dynamics. Another was that the stability derivatives that affect short 
period and phugoid are not the same derivatives and therefore the assumption of decoupling the short period and phugoid can be made. Although PID is very accurate for some of the equations of motion, some of the equations derivatives cannot be accurately found. An example is represented by the derivatives of the longitudinal force component coefficient, $\mathrm{C}_{\mathrm{x}}$, which is typically not accurate because the drag of the aircraft cannot be accurately represented in the parameter identification process. Therefore, from experience, the drag of the aircraft was calculated and was applied as known in the parameter identification process and then the rest of the derivatives values could be found using PID. To get the parameters to converge in many of the tests; the selected flight test data for the test was concatenated several times to get the stability and control derivatives to converge to the correct values. After the stability and control derivatives were found, there were some values of the derivatives which appeared to be identified incorrectly, an assumption was made that these values were wrong and they were removed from the PID. The PID process was repeated with reduced number of parameters and it was noticed that the initially incorrectly determined parameters had little effect on the identification of the others.

After the values had been identified, a weighted average was taken of all of the values and a preliminary set of stability and control derivatives were created for the model. These preliminary values were then put into the model of the aircraft and the response was compared to the flight test data. If the model did not meet the FAA requirements, experience was used to alter the stability derivatives to improve the model's modes by using sensitivity analysis. The main derivatives that affect the longitudinal modes are $\mathrm{C}_{\mathrm{mq}}, \mathrm{C}_{\mathrm{m} \alpha}$, and $\mathrm{C}_{\mathrm{mV}}$. Derivatives that affect the longitudinal modes not as strongly as the main derivative are known as the secondary longitudinal derivatives which are: $\mathrm{C}_{\mathrm{Zadot}}, \mathrm{C}_{\mathrm{ZV}}$, and $\mathrm{C}_{\mathrm{Xv}}$. Table 5 shows how the derivatives 
affect each of the modal parameters of the short period and phugoid. For the lateral-directional stability derivatives, the most important are $\mathrm{C}_{\mathrm{lp}}, \mathrm{C}_{\mathrm{n} \beta}$, and $\mathrm{C}_{1 \beta}$. A secondary derivative for the lateral-directional derivative is $\mathrm{C}_{\mathrm{nr}}$. Table 6 shows how the derivatives affect the lateraldirectional derivatives affect on the modal parameters.

Table 5. Longitudinal Stability Derivatives Sensitivity.

\begin{tabular}{|c|c|c|c|c|c|}
\hline Stability Derivative & & $\omega_{\mathrm{nSP}}$ & $\zeta_{\mathrm{SP}}$ & $\omega_{\mathrm{nP}}$ & $\zeta_{P}$ \\
\hline$\left|\mathrm{C}_{\mathrm{mq}}\right|$ & $\uparrow$ & - & $\uparrow$ & - & - \\
\hline$\left|\mathrm{C}_{\mathrm{m} \alpha}\right|$ & $\uparrow$ & $\uparrow$ & - & - & - \\
\hline $\mathrm{C}_{\mathrm{m} \alpha \text { dot }}$ & $\uparrow$ & - & $\downarrow$ & $\uparrow$ & $\uparrow$ \\
\hline$\left|\mathrm{C}_{\mathrm{mV}}\right|$ & $\uparrow$ & - & - & $\uparrow$ & $\downarrow$ \\
\hline $\mathrm{C}_{\mathrm{za} \_ \text {dot }}$ & $\uparrow$ & $\uparrow$ & $\downarrow$ & - & - \\
\hline $\mathrm{C}_{\mathrm{ZV}}$ & $\uparrow$ & - & - & $\uparrow$ & - \\
\hline $\mathrm{C}_{\mathrm{XV}}$ & $\uparrow$ & - & - & - & $\uparrow$ \\
\hline
\end{tabular}


Table 6. Lateral-Directional Derivative Sensitivity.

\begin{tabular}{c|ccc} 
Stability Derivative (Increase) & T $_{\mathbf{r}}$ & $\omega_{\mathrm{nDR}}$ & $\zeta_{\mathrm{DR}}$ \\
\hline $\mathrm{C}_{\mathrm{lp}}$ & $\downarrow$ & - & - \\
& & & \\
$\mathrm{C}_{\mathrm{n} \beta}$ & - & $\uparrow$ & $\downarrow$ \\
$\left|\mathrm{C}_{1 \beta}\right|$ & & & \\
& - & - & $\downarrow$ \\
$\mathrm{C}_{\mathrm{nr}}$ & - & $\uparrow$ & -
\end{tabular}




\section{Development of a Simulation Environment for FAA Compliance with Objective and Subjective Tests}

\subsection{General Architecture}

The results of the FAA compliance tests have been normalized due to the proprietary nature of the data given by the manufacturer. Also, any of the FAA compliance tests that require numerical evaluation of the data, for example damping or period, can only be expressed as percent difference or differences from the flight data values. The results are only for the aerodynamics of the FAA requirements.

All of the stability derivative coefficients that were found using the parameter identification software at different points in the flight envelope were put into look up tables with respect to dynamic pressure. The model was then generated in Simulink that could take recorded inputs from the flight test data, pilot commands from a joystick, or a mixture of the two. Two different implementations were developed including the same dynamic model. One was meant to be used on a regular desktop computer and was interfaced with the Aviator Visual Design Simulator (AVDS) [19] a commercial visualization software compatible with Matlab/Simulink. Figure 16 shows the general architecture of this aircraft model implementation including the engine model and landing gear model subsystem. Figure 17 shows the visual interface including AVDS. The second implementation was meant to be used with the WVU 6 degrees of freedom motion-based flight simulator. The Simulink model was customized to interact with X-Plane [20], the software that produces the visual cues within the motion-based flight simulator. This model is shown in Figure 18 [21]. 


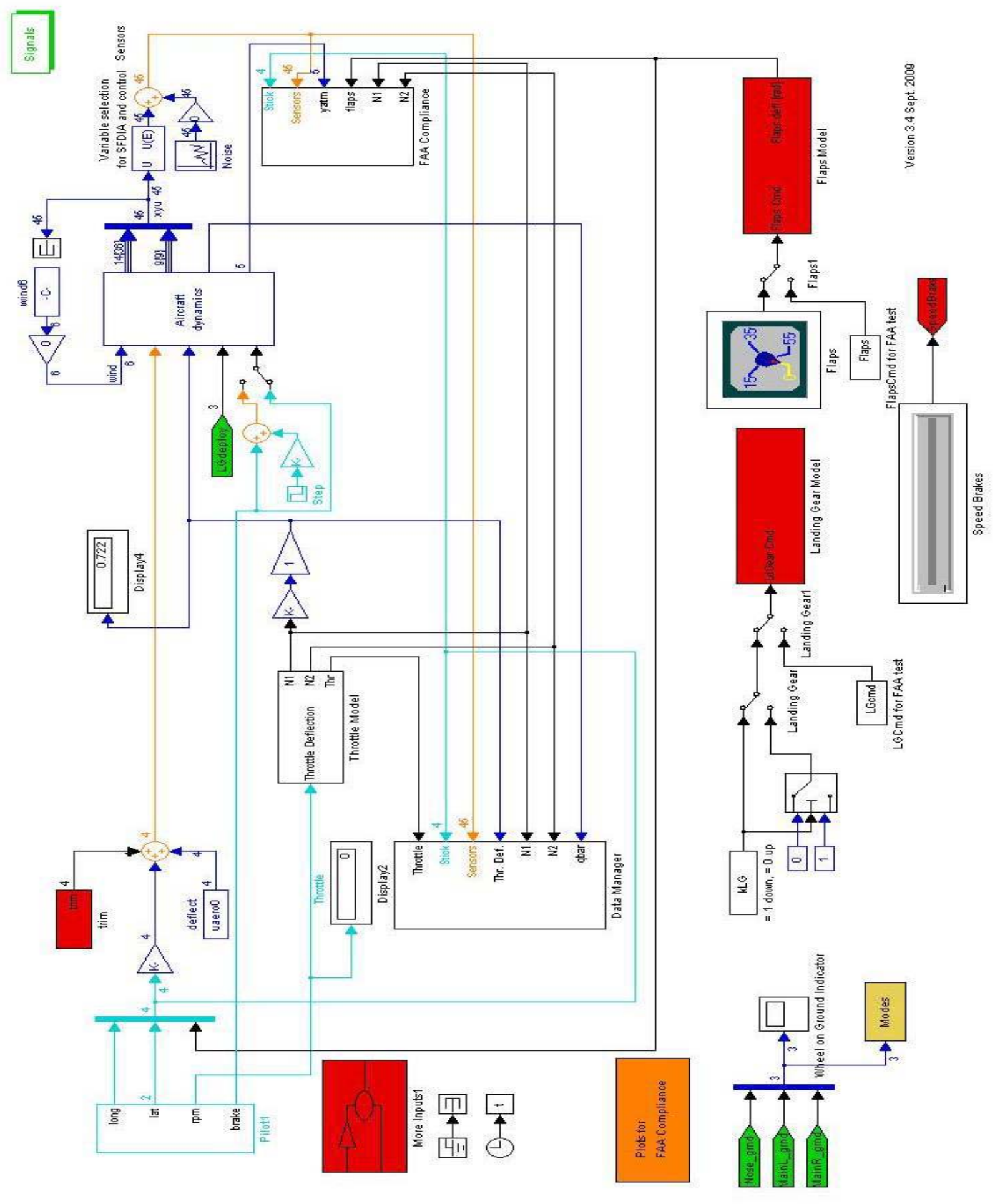


Figure 16. Desktop Computer Implementation.

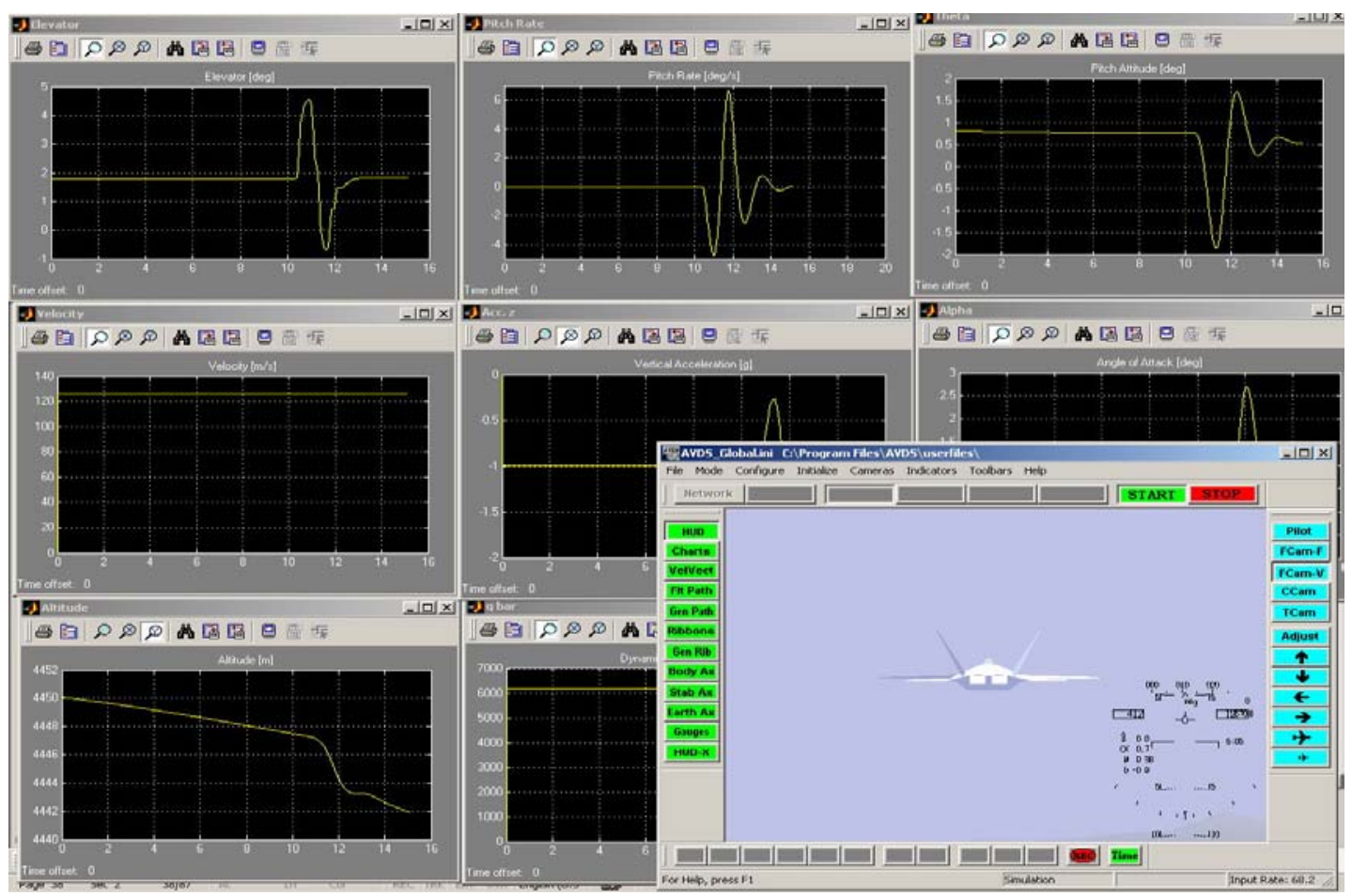

Figure 17. Desktop Computer Implementation - Interactive Visualization. 


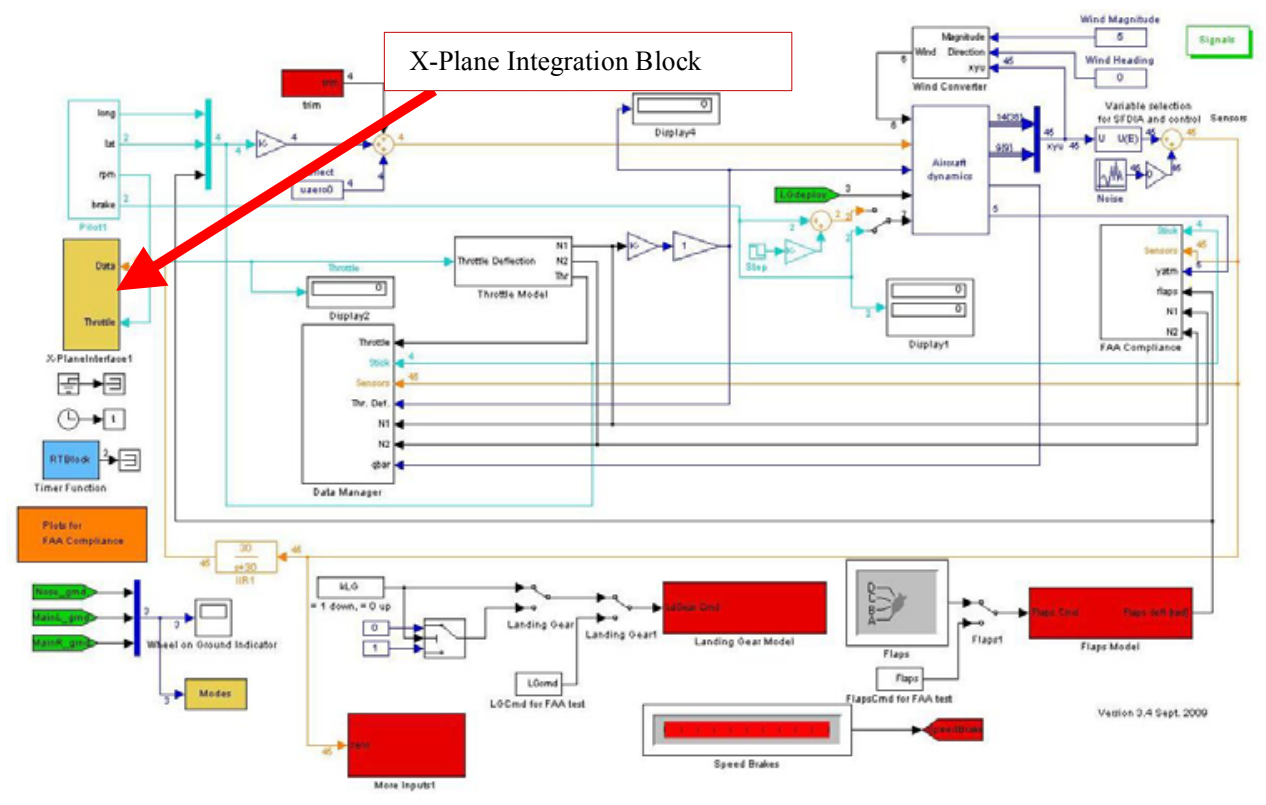

Figure 18. Motion-Based Flight Simulator Implementation [21].

To run the simulation, interactive menus were created to help load the initial conditions and the piloted input or FAA compliance inputs and flight test data. The menus and a brief explanation of how they are used are presented in this section and the user manual of the flight simulation can be seen in Appendix D. Figure 19 shows the initial menu for the flight simulator. In this menu, a choice of the FAA Compliance or piloted input is selected. The FAA compliance loads all of the flight data and the inputs from the flight data and the flight model. The piloted input choice loads all the pertinent information to the flight model only. 


\section{WVU Jet Simulation}

SELECT MODEL

\section{FAA Compliance}

\section{Piloted Flight}

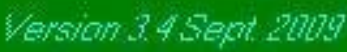

Figure 19. Initial Simulation Menu.

If the FAA Compliance is selected, the next menu(see Figure 20) selects the desired flight condition, i.e. cruise, approach, climb, steady state sideslip, or longitudinal trim.

\section{WVU Jet Simulation}

SELECT FLIGHT CONDITION

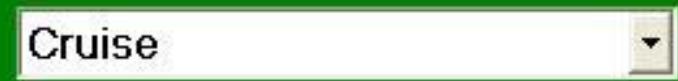

\section{Continue}

Figure 20. Flight Conditon Menu. 
Once the flight condition has been selected or the piloted input from Figure 19 is selected the next menu (see Figure 21) selects the desired inputs.

\section{WVU - Simulation Pilot Input}

\section{PILOT INPUT \\ 8 ALL JOY-STICK GENERATED \\ - MIXED \\ - ALLFROM FLIGHT}

SELECT PRE-RECORDEDDATA FILES CHANNELS FOR MIXED NAMES

INPUT

口 Longitudinal

$\square$ Lateral

I Directional

प Throtle

NOTE:

If the pre-recorded input option is selected the user must provide two-rows files for each control channel.

First row is time and second is recorded command.

Figure 21. Input menu.

If the FAA compliance was chose this menu will require the all from flight option, while the piloted input will require the joy-stick generated choice. This menu can also have a mixture of pre-recorded inputs with joystick inputs. After the continue button is selected, another menu is opened. For the FAA compliance, the menu shown in see Figure 22 is opened. In this menu, the desired flight test requirement is selected for the flight conditon. The piloted input menu is the same except for the desired flight condtion is selected instead of the flight test requirement. 


\section{WVU - Jet Simulation}

\section{SELECT TEST FOR COMPLIANCE}

\section{Cruise - Flight 20 \#01 - FAA 2.c.5}

\section{Continue}

Figure 22. Flight Test Selection Menu.

\subsection{Computation of Dynamic Characteristics of Slow Oscillatory Modes}

FAA regulations require that the difference between the modal characteristics of the actual aircraft and the simulation model be within strict limits. In particular, there are criteria on the damping and natural frequency of both the phugoid and the dutch roll modes. These parameters must be computed for both the flight data and the simulation data. The so-called Peak-to-Valley method [22] was implemented for this purpose. Next, the Peak-to-Valley is 
presented for the dutch roll mode; however, the algorithm is applied identically for the Phugoid, except that the variable to be considered is the pitch attitude angle instead of the sideslip angle.

The dutch roll mode can be approximated by a second order transfer function. The contribution of the dutch roll mode to the time history of the sideslip angle $\beta$ can be expressed as:

$$
\beta(t)=A e^{-\zeta_{D R} \omega_{n D R} t} \sin \left(\omega_{d D R} t+\mu\right)
$$

where $\omega_{n D R}$ is the "undamped" or "natural" Dutch Roll frequency, $\omega_{d D R}$ is the "damped" dutch roll frequency, $\zeta_{D R}$ is the dutch roll damping coefficient, $A$ is the amplitude, and $\mu$ is the phase angle. The values of both $A$ and $\mu$ depend on the initial conditions. The well known relationship between the "damped" and "undamped" frequencies is given by:

$$
\omega_{d}=\omega_{n} \sqrt{1-\zeta^{2}}
$$

Assume that a 'peak' and 'valley' of the sideslip angle time history succeed each other at times $t_{1}$ and $t_{2}$. They are one half cycle apart as shown in Figure 23. Using equation (19) to express $D A_{1}$ and $D A_{2}$, one can determine the transient peak ratio (TPR) to be equal to:

$$
T P R=\frac{D A_{2}}{D A_{1}}=e^{-\zeta_{D_{R}} \omega_{D D R} T_{D} / 2}
$$

To mitigate measurements error and improve accuracy, the value for $T P R$ is actually computed by evaluating the average over several consecutive peak/valley pairs. From the expression for $T P R$, the associated logarithmic decrement can be evaluated using:

$$
\delta=\ln (T P R)=-\zeta_{D R} \omega_{n D R}\left(\frac{\pi}{\omega_{d D R}}\right)
$$

Finally, the damping of the dutch roll mode can be obtained using: 


$$
\zeta_{D R}=\frac{|\ln (T P R)|}{\sqrt{\pi^{2}+\ln ^{2}(T P R)}}
$$

and the natural frequency of the dutch roll mode can be obtained using:

$$
\omega_{n D R}=\frac{2 \pi}{T_{p} \sqrt{1-\zeta_{D R}^{2}}}
$$

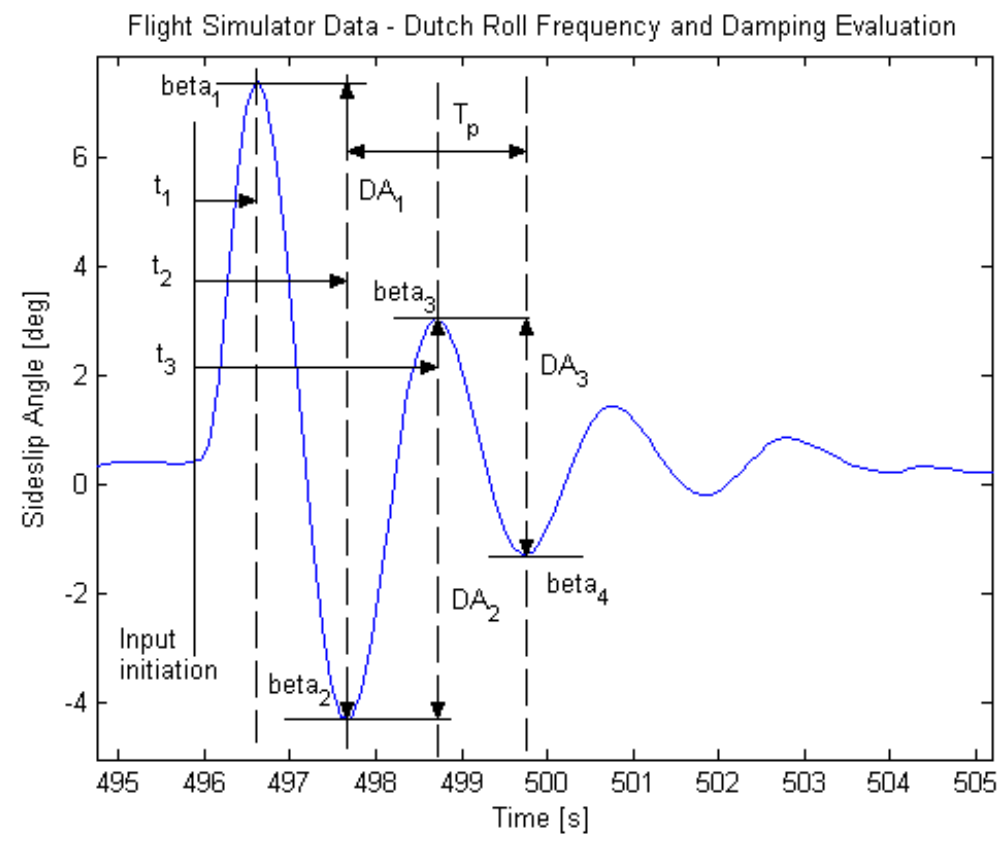

Figure 23. Parameters of the Peak-to-Valley Method to Determine the Characteristics of Slow Oscillatory Modes (Dutch Roll) [22]

\subsection{Objective Tests}

For the aerodynamic modeling, four flight conditions were necessary to pass the tests. These conditions were cruise, approach, climb, and steady state sideslip on approach. For the cruise condition the configuration of the aircraft was clean, i.e. landing gear up and flaps retracted to zero. For the approach condition the configuration of the aircraft was given as approach flaps at low altitudes. The climb condition had the same clean configuration of the 
aircraft as the cruise condition. The steady state sideslip on approach is its own condition due to the fact that the aircraft has cross controlled inputs as the initial conditions. For all of the compliance tests done in this paper, the results were normalized due to the proprietary nature of the flight test data.

For the cruise condition there were five separate tests that the simulator had to comply with. The first test was the short period test. The requirements of the short period test require that the pitch angle must be within $+/-1.5$ degrees of the flight data. The pitch rate must be within $+/-2$ degrees per second of the flight data. The vertical acceleration must be within $+/-.1$ $\mathrm{g}$ of the flight data. As seen in Figure 24, the flight simulator conforms to the Federal Aviation Regulations Part 121. 

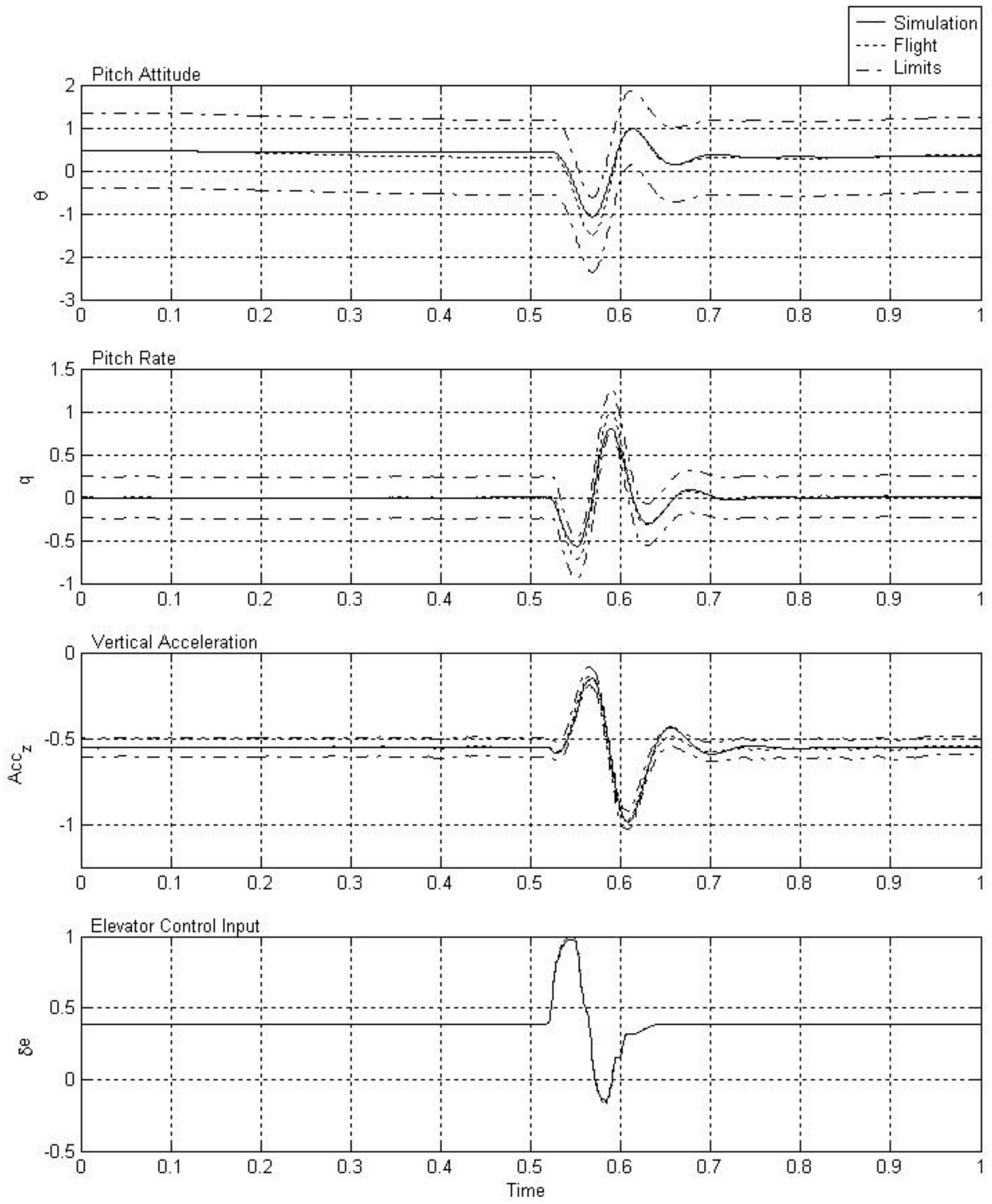

Figure 24. Normalized FAA Compliance Test 2.c.10. Short Period at Cruise Condition. 
Figure 25 is the phugoid test at the cruise condition. The first requirement for the test is that the period be within $+/-10 \%$ of the flight data. The Peak-to-Valley method presented in section 6.2 was used to determine the phugoid modal parameters and the dutch roll modal parameters in later test requirements. The period cannot be directly seen in the figured do the normalization of the data, but does comply with the requirement. The next requirement was the damping be within plus/minus .02 of the flight data and does comply with the requirement. 

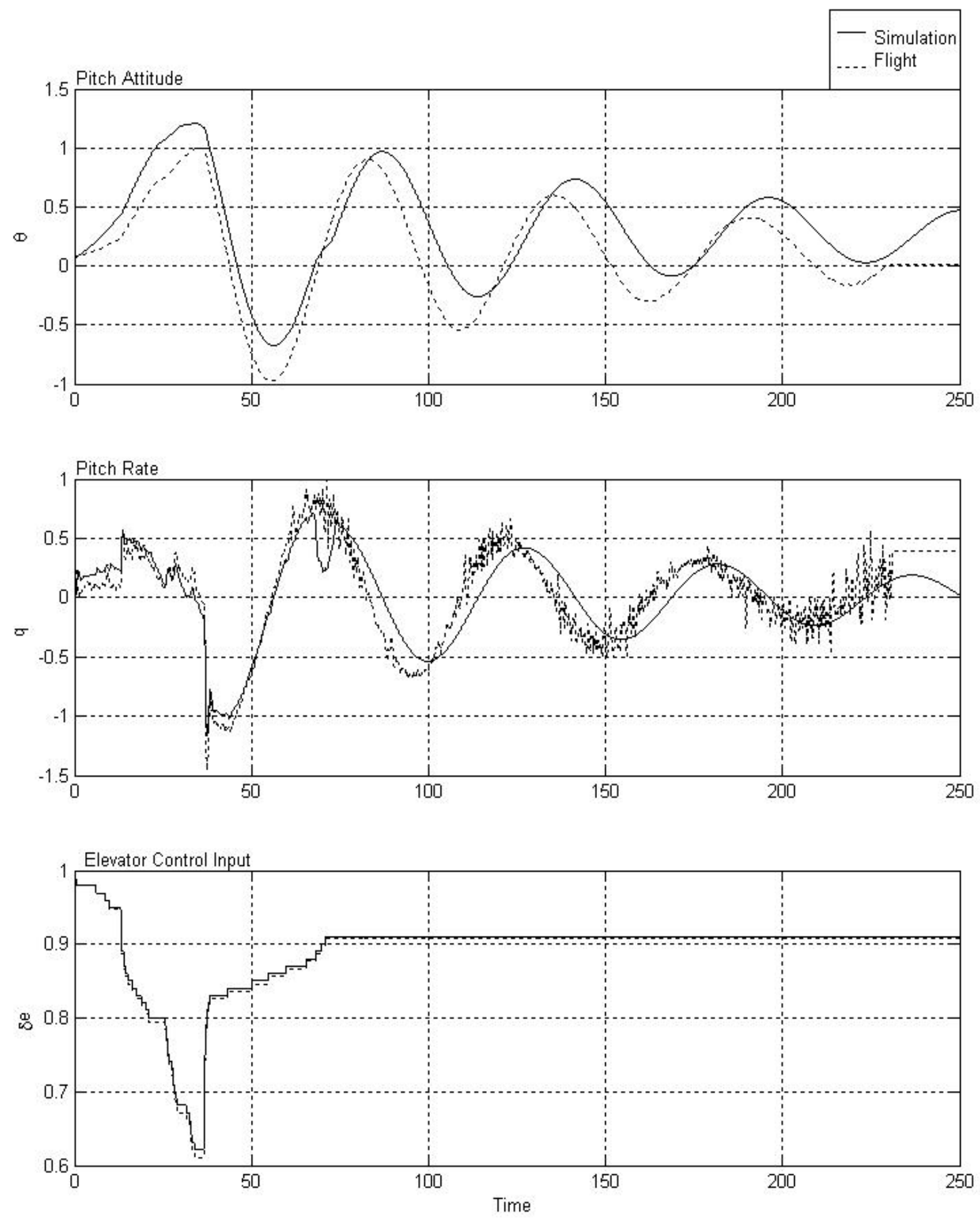

Figure 25. Normalized FAA Compliance Test 2.c.9. Phugoid at Cruise Condition. 
Figure 26 shows the dutch roll test at the cruise condition. This test required a period of $+/-10 \%$ and a damping ratio of .02 . The flight simulator does comply with both of the requirements for this test. The Peak-to-Valley method presented in section 6.2 was used to determine the dutch roll modal parameters. 

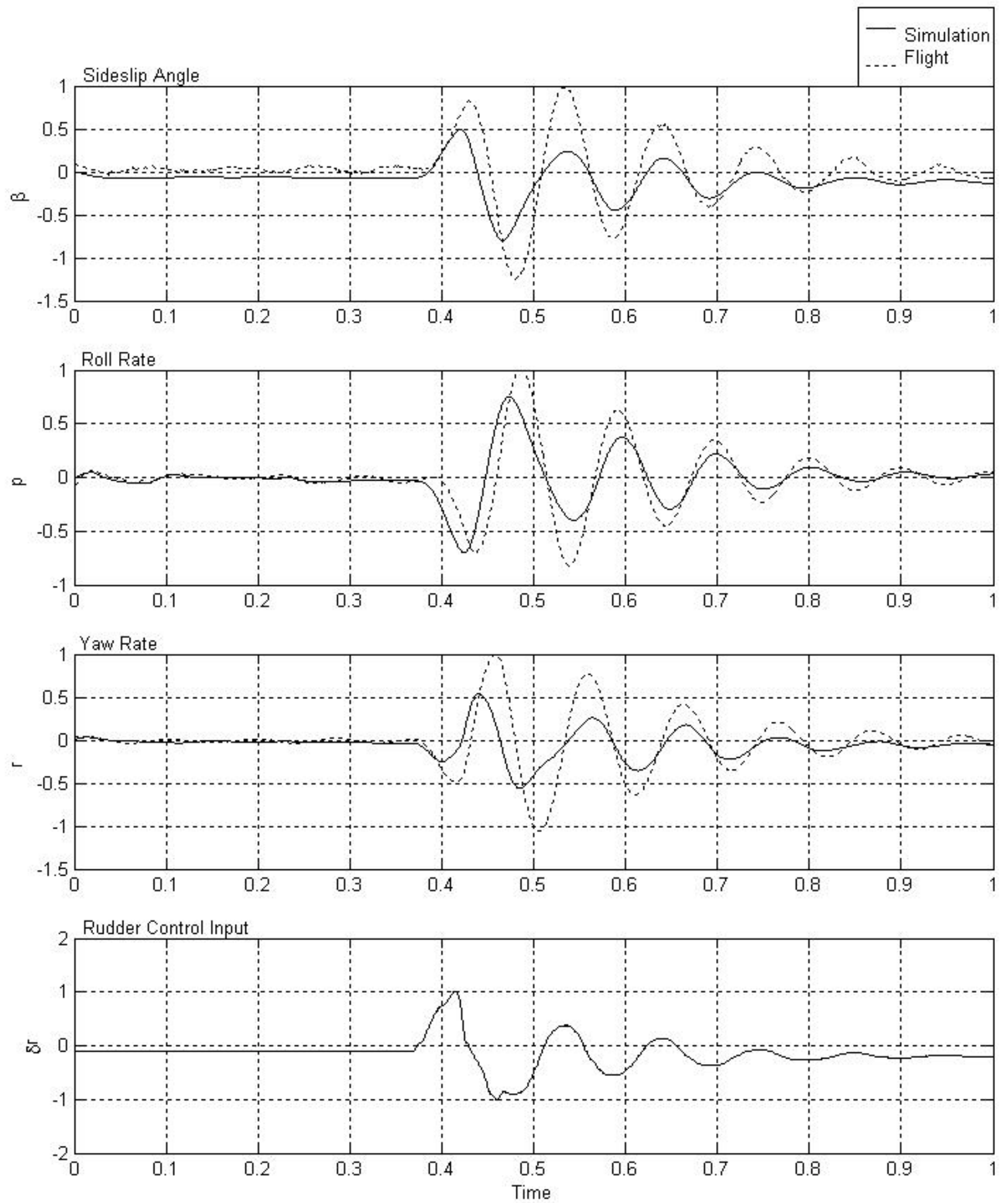

Figure 26. Normalized FAA Compliance Test 2.d.7. Dutch Roll At Cruise Condition. 
Figure 27 is the roll response test at cruise condition. For this requirement, the simulator must be within $+/-10 \%$ of the flight data in the roll rate. Figure 27 shows the compliance with this test. 

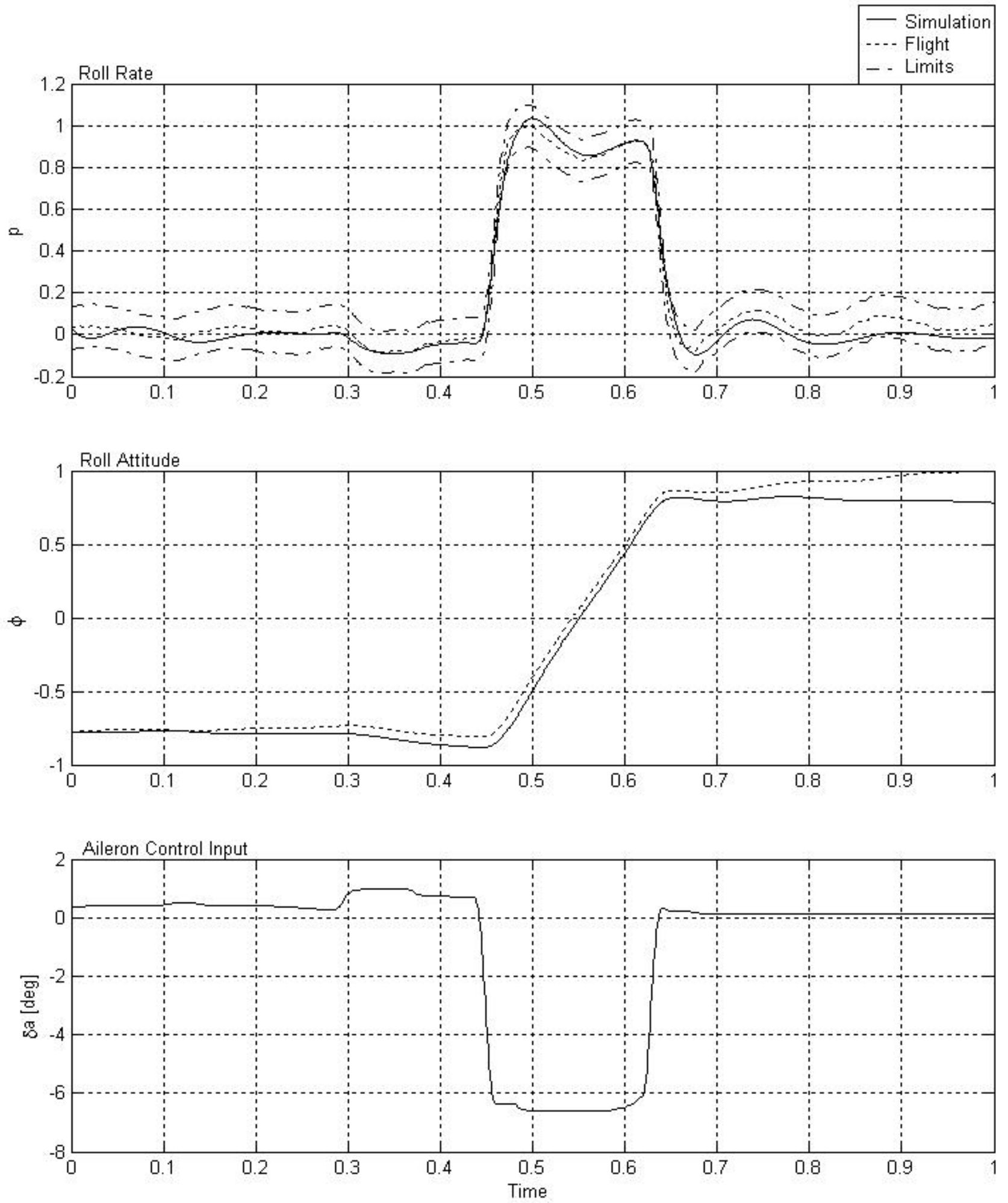

Figure 27. Normalized FAA Compliance Test 2.d.2. Roll Response Test at Cruise Condition. 
Figure 28 is the FAA compliance test for spiral stability at cruise. For this test aircraft must show the correct trend in the bank angle, and the bank angle must be within $+/-10 \%$ in 30 seconds. As seen in the figure, the trend is the same as the flight data and complies with the $+/$ $10 \%$ requirement for the roll angle. 

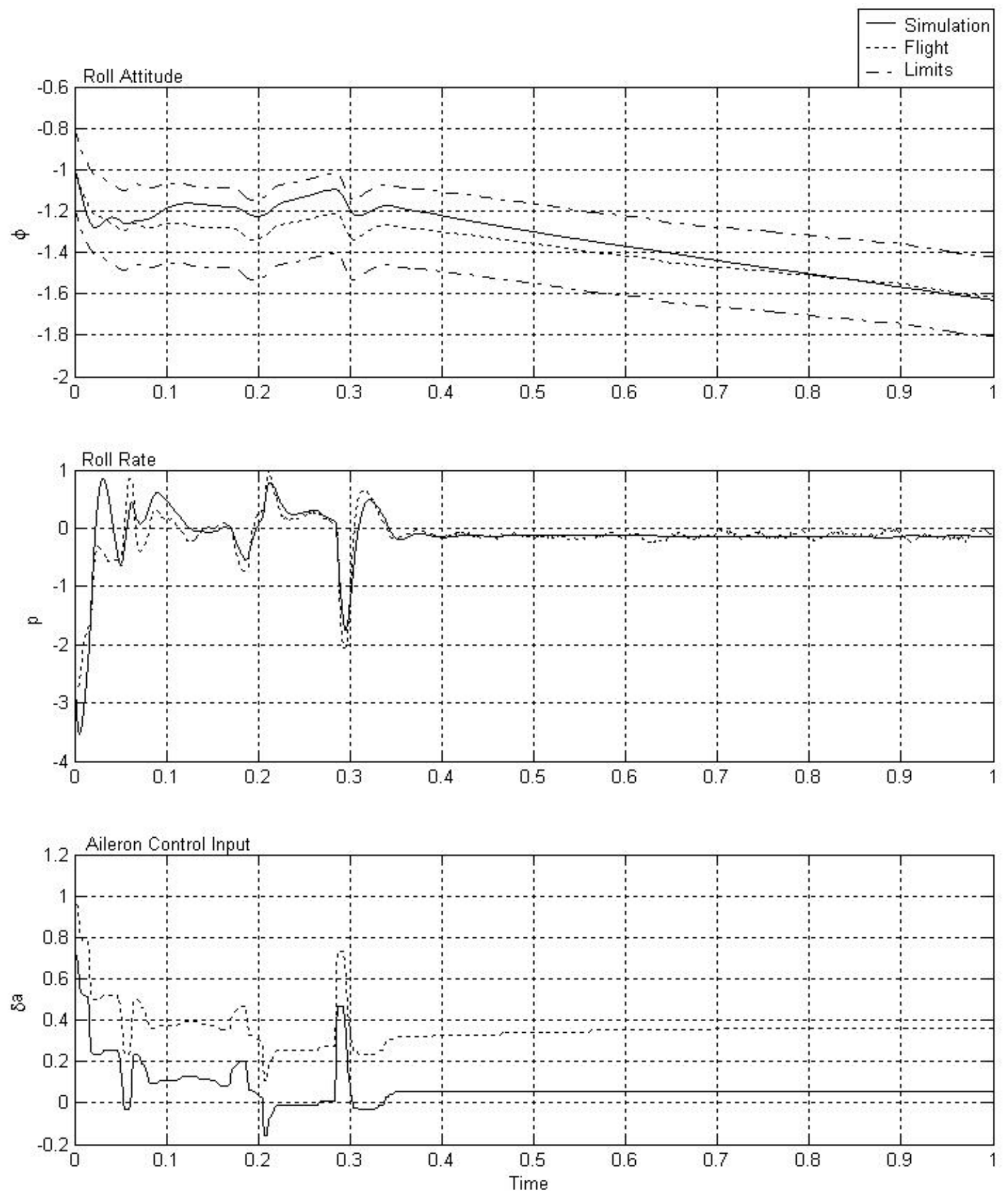

Figure 28. Normalized FAA Compliance Test 2.d.4. Spiral Stability at Cruise Condition. 
The next flight condition was the approach condition. At this condition there are two tests. The first test is for the dutch roll on approach, in Figure 29. This test required a period of $+/-10 \%$ and a damping ratio of .02 . Also note that the aileron deflections are not the same. The reason for this is a bias in the sensors of this flight test. The FAA allows the deflection of the control surfaces to be up to a few degrees different because of these biases. Our simulator aileron deflections are well within the bounds of the bias. 

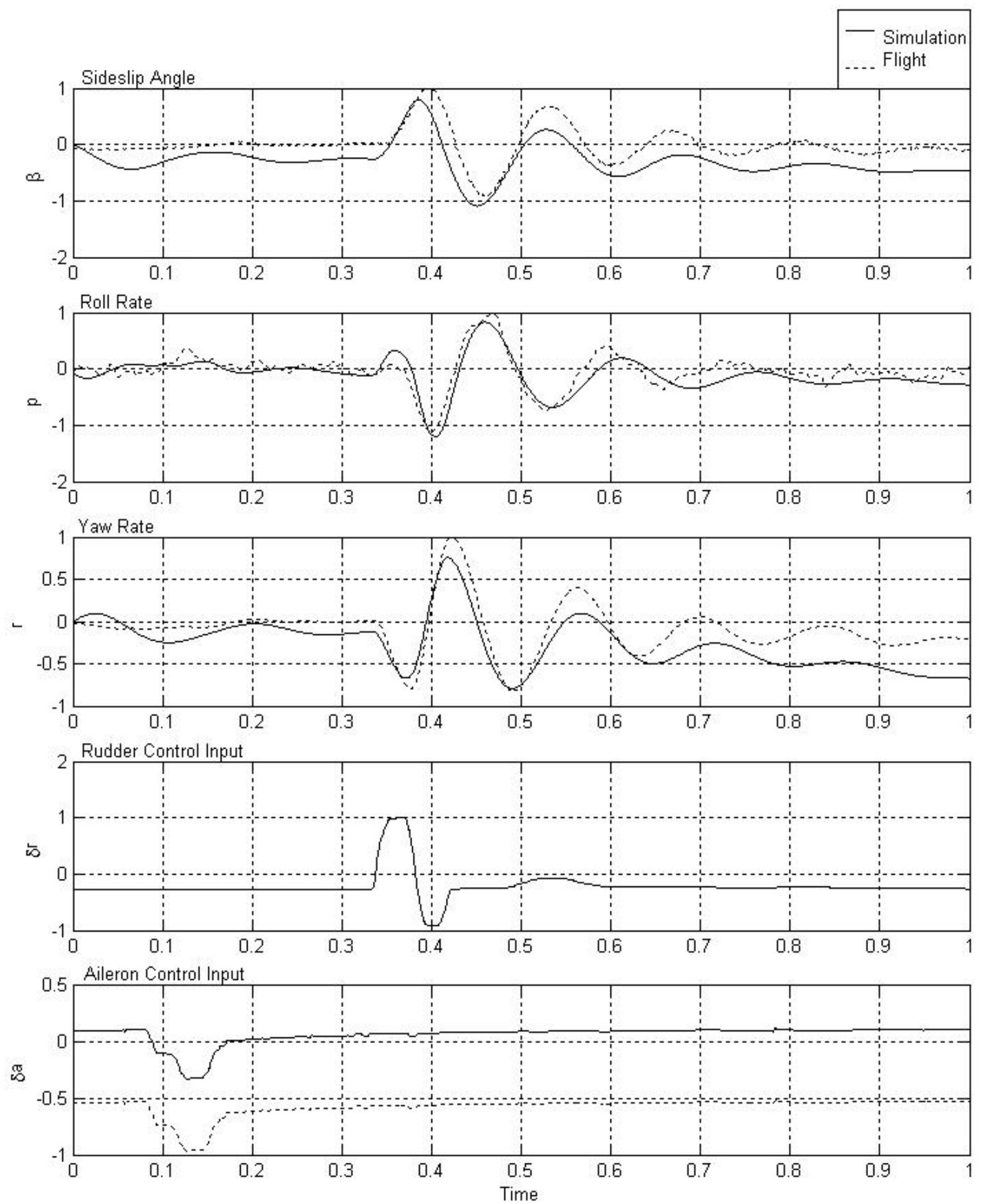

Figure 29. Normalized FAA Compliance Test 2.d.7. Dutch Roll at Approach Condition. 
Figure 30 shows the roll response test at the approach condition. The requirements for this test are the same as the requirements for the roll response test at the cruise condition plus the roll angle has to be within $+/-2$ degrees of the flight data within 10 seconds of neutral inputs. This test does comply with the FAA regulations but at the end of the test the roll angle slightly comes out of the bounds of the test. This still complies with the test because the requirements were for the bounds of the roll angle for $+/-2$ degrees in 10 seconds, which the simulator achieves. 

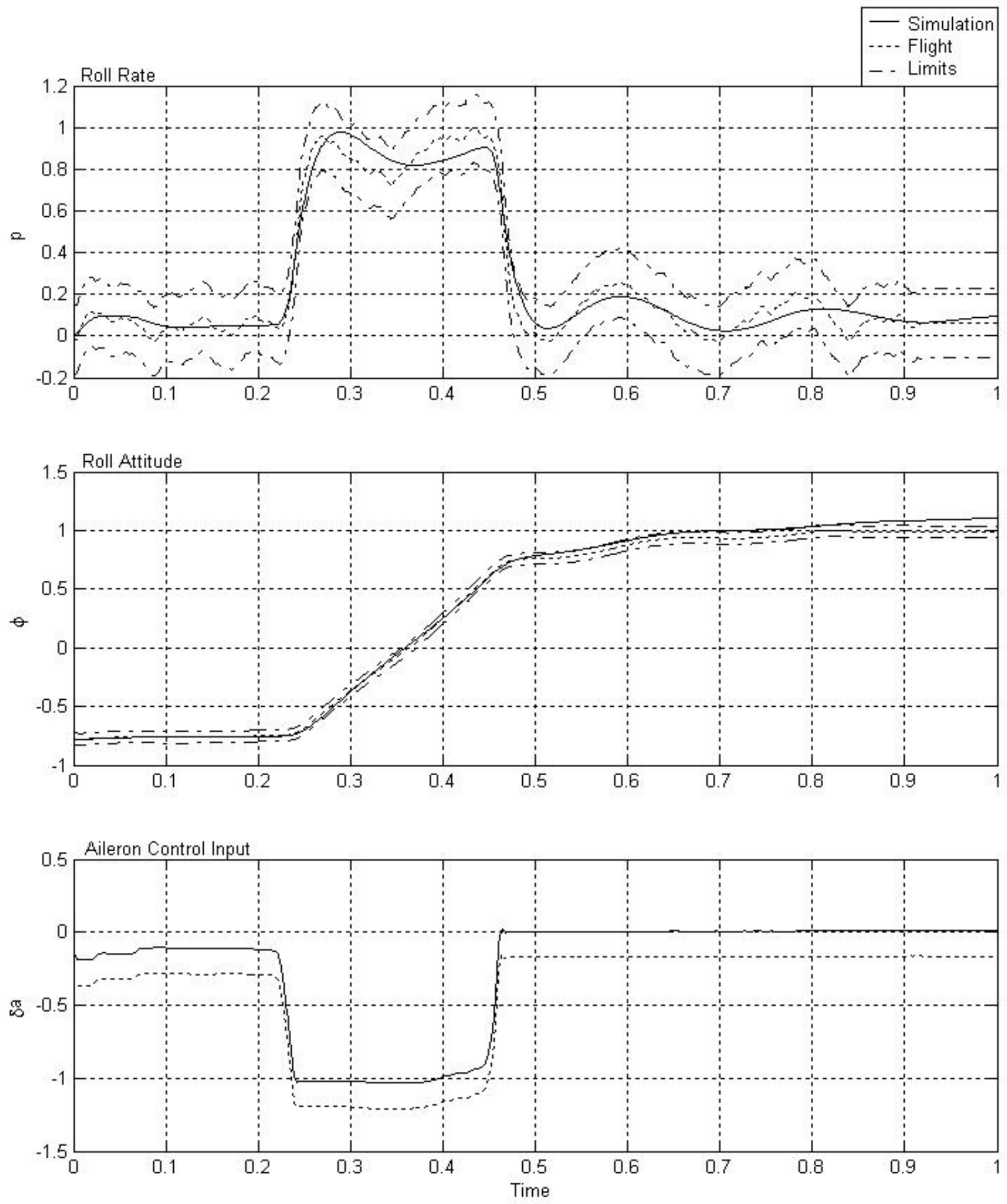

Figure 30. Normalized FAA Compliance Test 2.d.2 and 2.d.3. Roll Response at Approach

Condition. 
The next flight condition is the climb condition. In this condition there is only one test required. This test requires that the airspeed be within $+/-3$ knots airspeed of the flight data and the rate of climb be within $+/-100$ feet per minute for 1000 feet gained in altitude. Figure 32 is the climb test and at first glance does not pass the airspeed requirement of the FAA compliance test. It does pass the test, although there is a violation of the bounds at the end of the simulation, because the requirement is for 1000 feet of climb and that requirement was met before the simulator left the bounds of the flight data. 

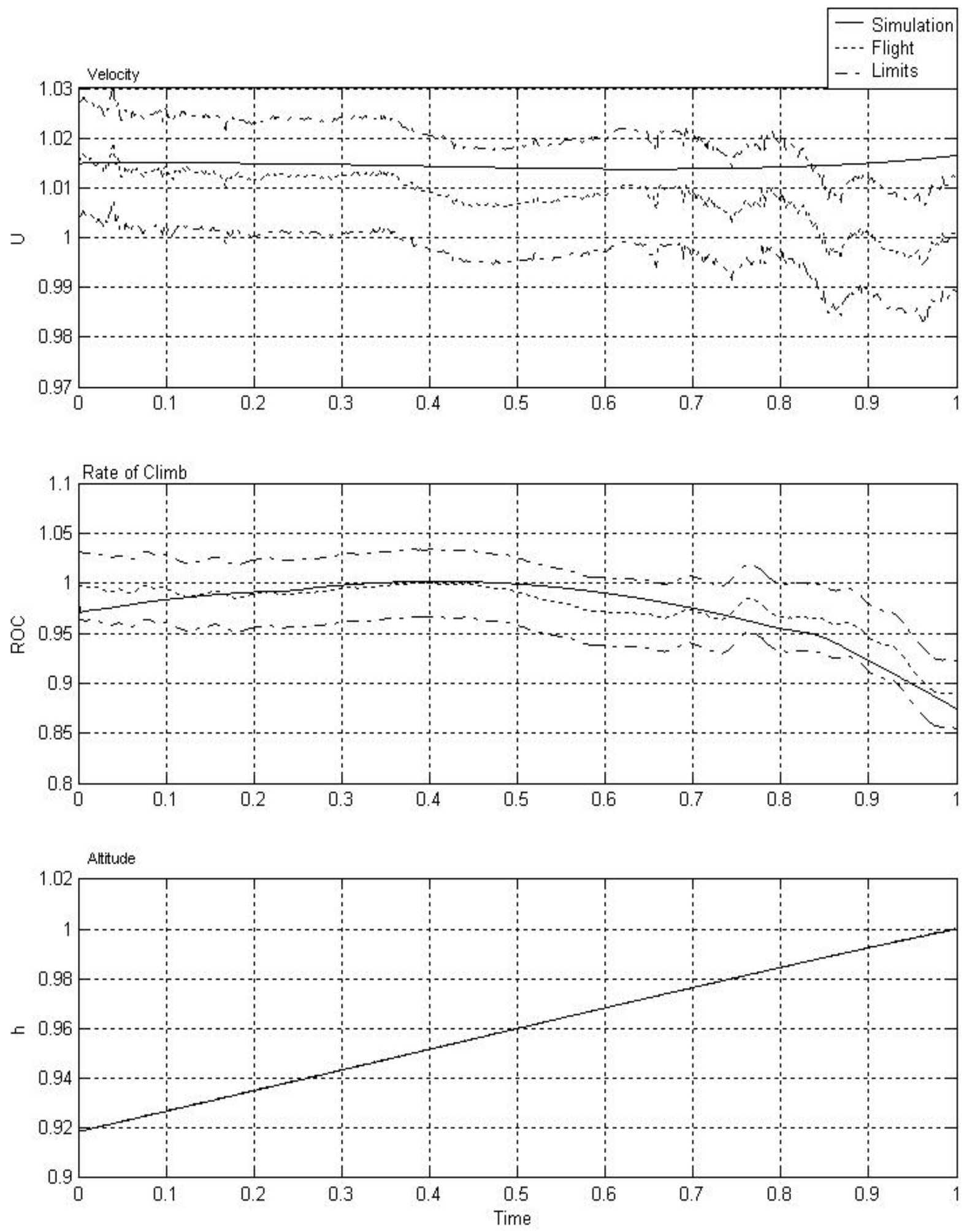

Figure 31. Normalized FAA Compliance Test 1.c.1. Normal Climb requirements. 
The next test requirement is for the steady state sideslip on approach condition. For this test requirements are: roll angle must be within $+/-2$ degrees of flight data; sideslip angle must be within $+/-1$ degree of flight data; aileron deflection must be within $+/-10 \%$ of the flight data. As seen in Figure 32, the simulator matches the aircraft very well in the steady state sideslip condition. 

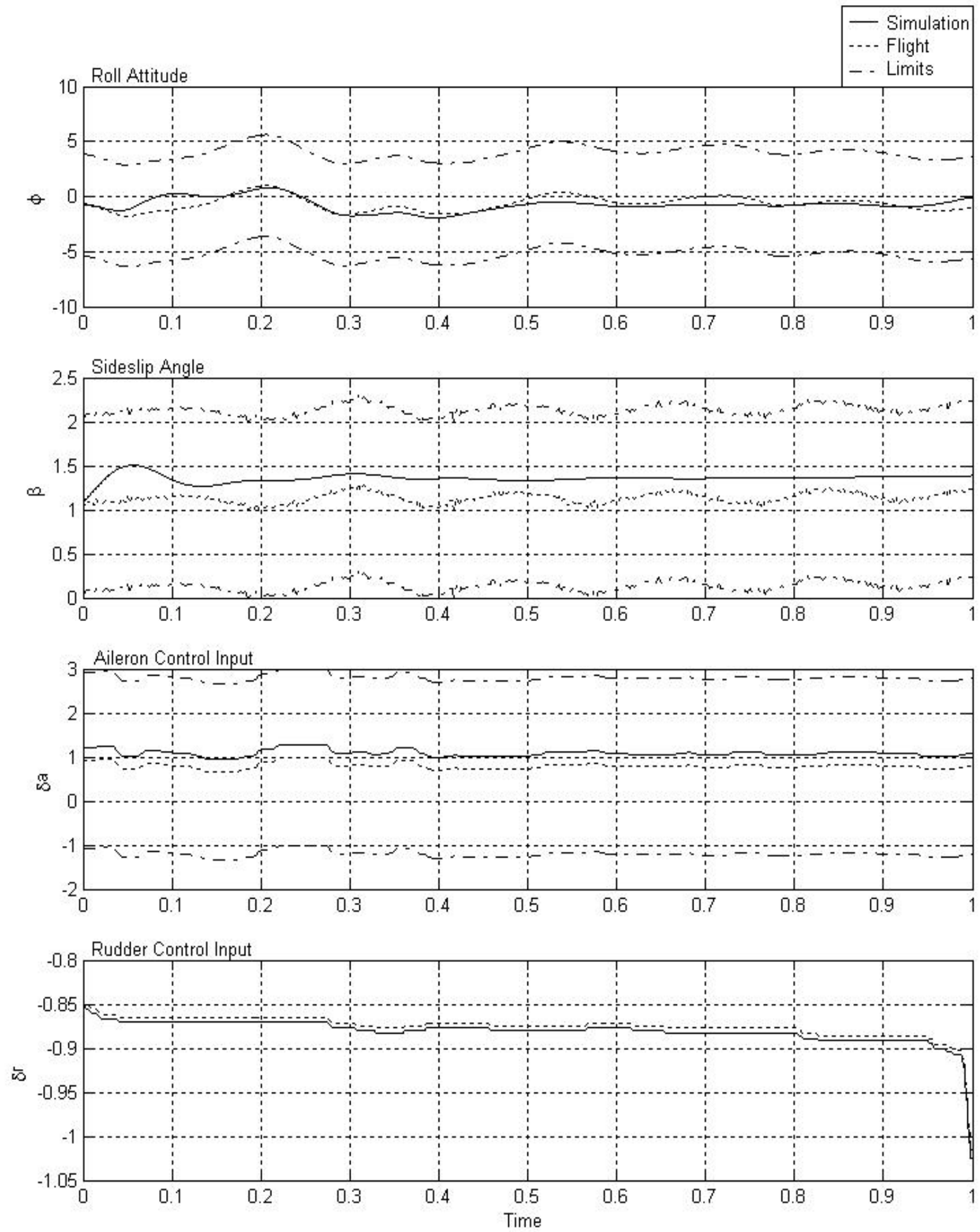

Figure 32. Normalized FAA Compliance Test 2.d.8. Steady State Sideslip at Approach

Condition. 
The last tests are the same test but at different flight conditions. The test is for the longitudinal trim. In this test, the elevator must be within $+/-1$ degree of the flight, the pitch angle must be within $+/-1$ degrees and the thrust must be within $+/-5 \%$ of the flight data. For the engine, the $\mathrm{N} 1$ variable of the engine directly correlates with the thrust of the engine and is therefore the variable compared in the flight data. The Figures 33, 34, and 35 are the longitudinal trim on cruise, approach, and landing respectively. In all three flight conditions, the simulation conforms to the requirements thus passing the test. 

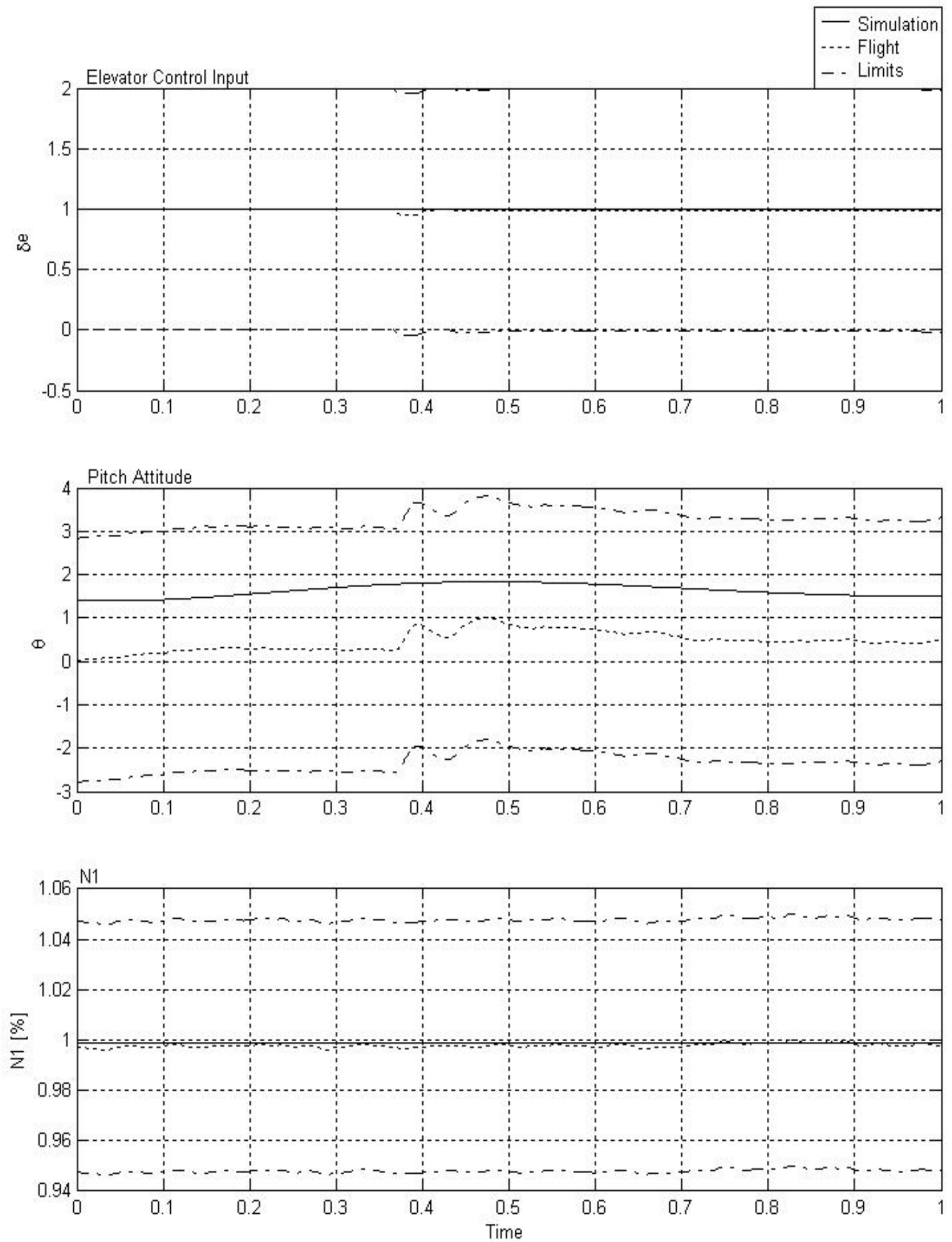

Figure 33. Normalized FAA Compliance Test 2.c.5. Longitudinal Trim at Cruise. 

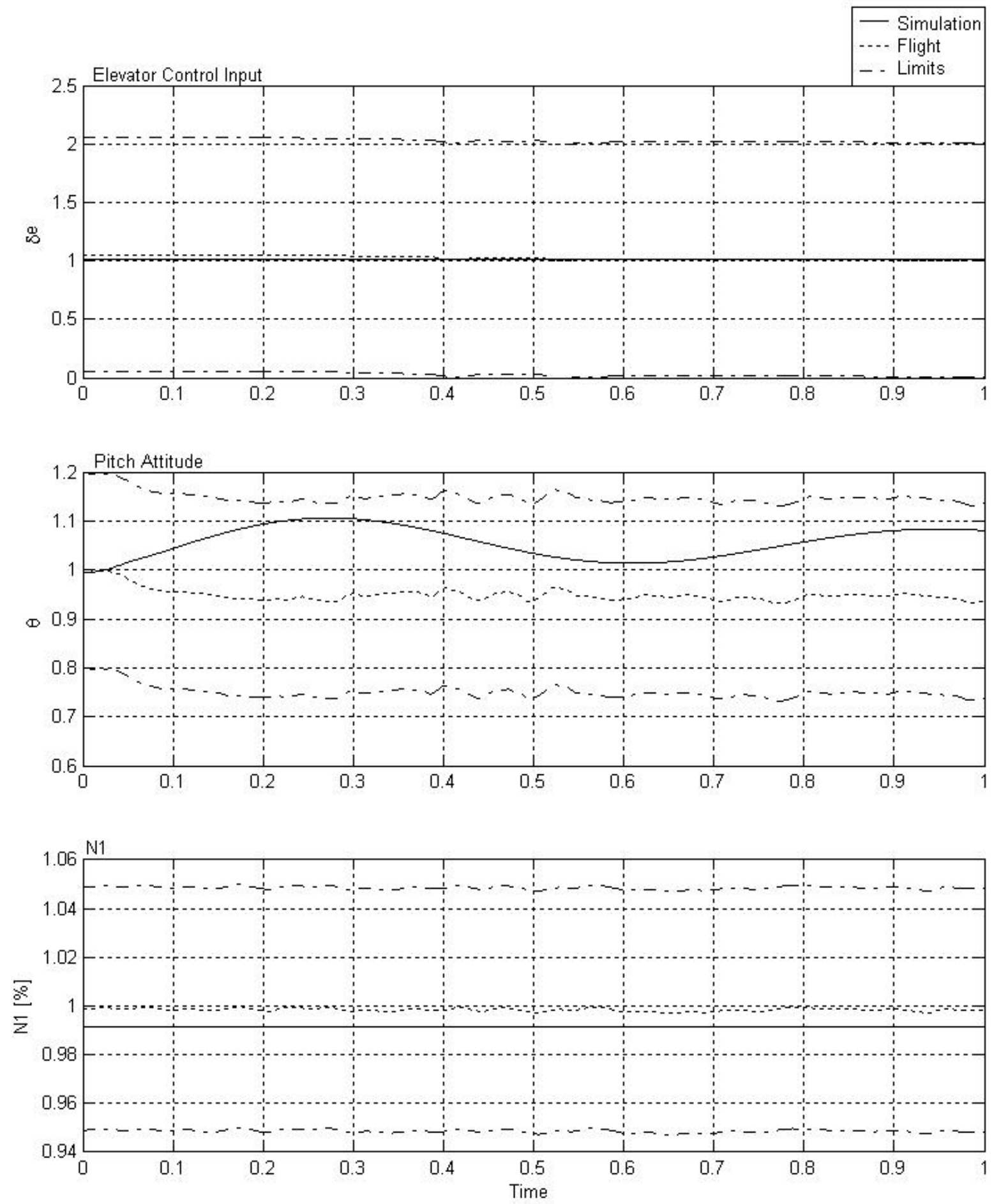

Figure 34. Normalized FAA Compliance Test 2.c.5. Longitudinal Trim at Approach. 

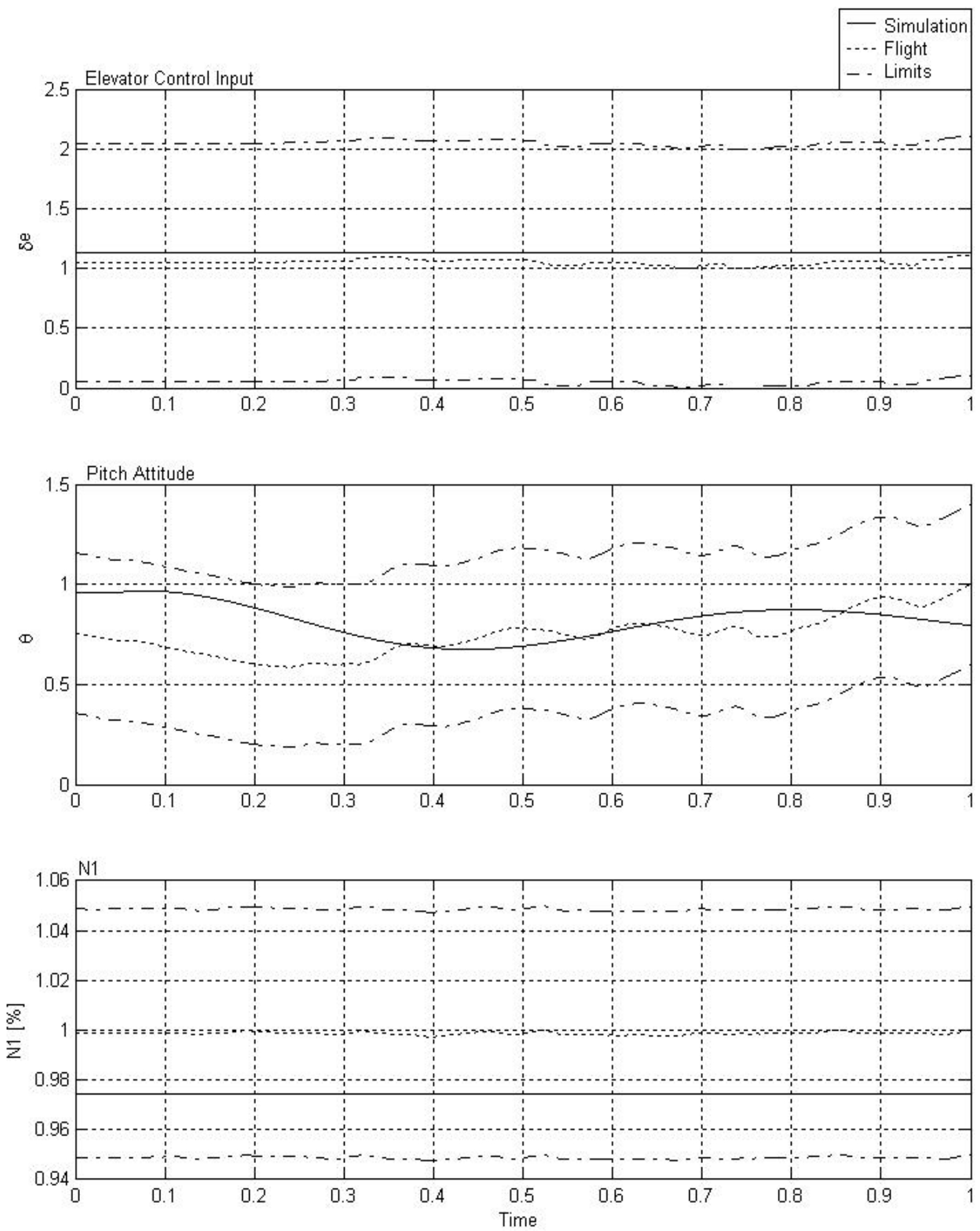

Figure 35. Normalized FAA Compliance Test 2.c.5. Longitudinal Trim at Landing. 
To show how sensitive the response is to the alteration of the stability or control derivatives, the stability derivative $\mathrm{C}_{\mathrm{lp}}$ was decreased by $3 \%$ and the FAA compliance test $2 . d .2$ and 2.d.3 were then attempted again with the new $\mathrm{C}_{\mathrm{lp}}$ value. In Figure 36, the roll rate does fail the test at about .45 and .65 of the normalized time. It is interesting to see how the stability derivatives affect the response of the aircraft model. The small variation in stability derivative here shows how stringent the FAA compliance tests are. The FAA objective tests are an excellent standard in developing very accurate models for flight training devices. 

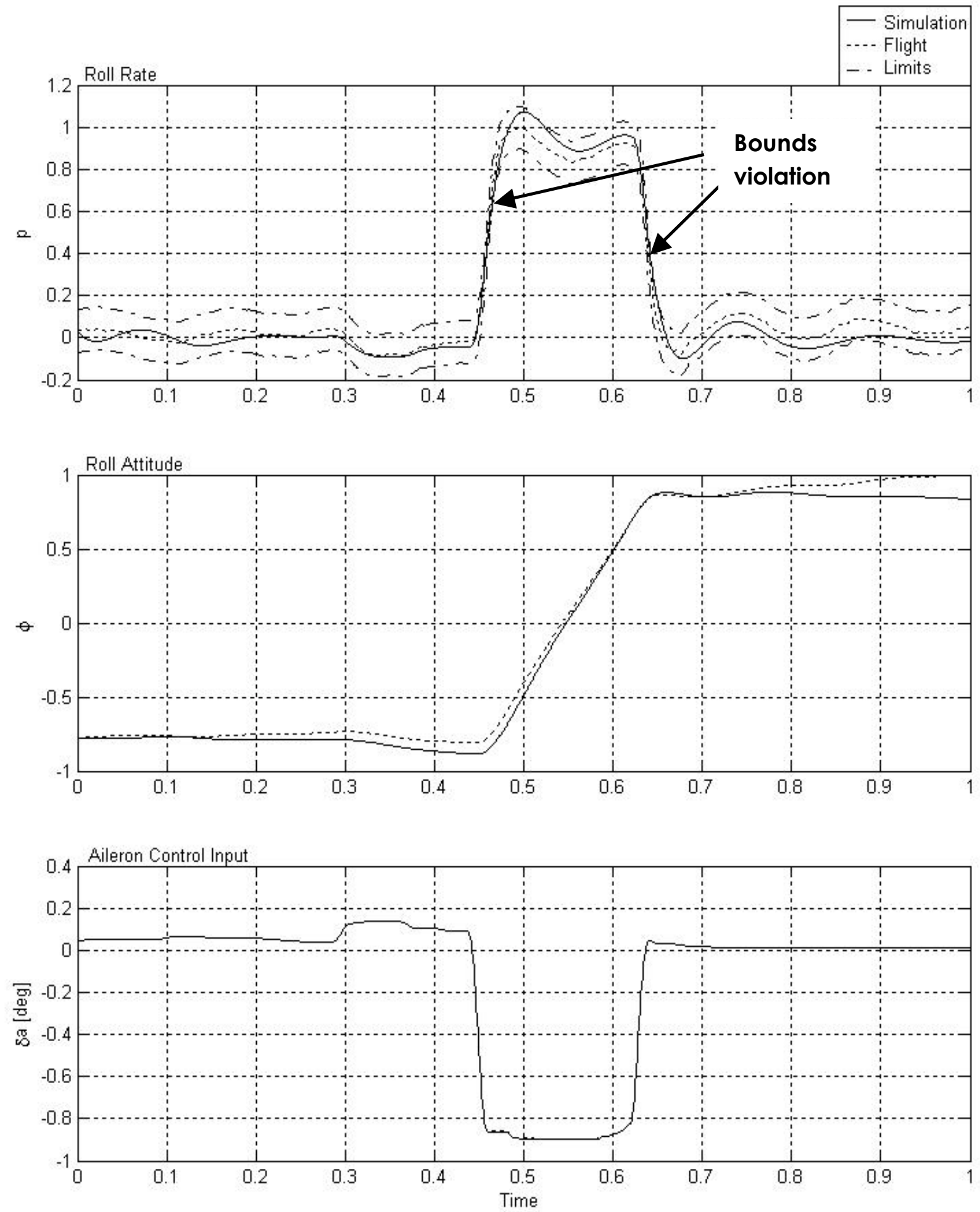

Figure 36. Normalized FAA Compliance Test 2.d.2 and 2.d.3. Roll Response at Cruise

Condition with Altered $\mathrm{C}_{1 \mathrm{p}}$. 


\subsection{Subjective Testing}

Another requirement is that the flight simulator be able to be flown by hardware control inputs and give the same reaction the pilots would expect from the aircraft. For an example of this, a simulation was done with inputs from a joystick. There was a bias in the joystick on the rudder input of -1 degrees and causes the steady state to occur later in the simulation. After the aircraft reached steady state, a maximum deflection rudder doublet was done to excite the dutch roll and the response was plotted in Figure 37. 

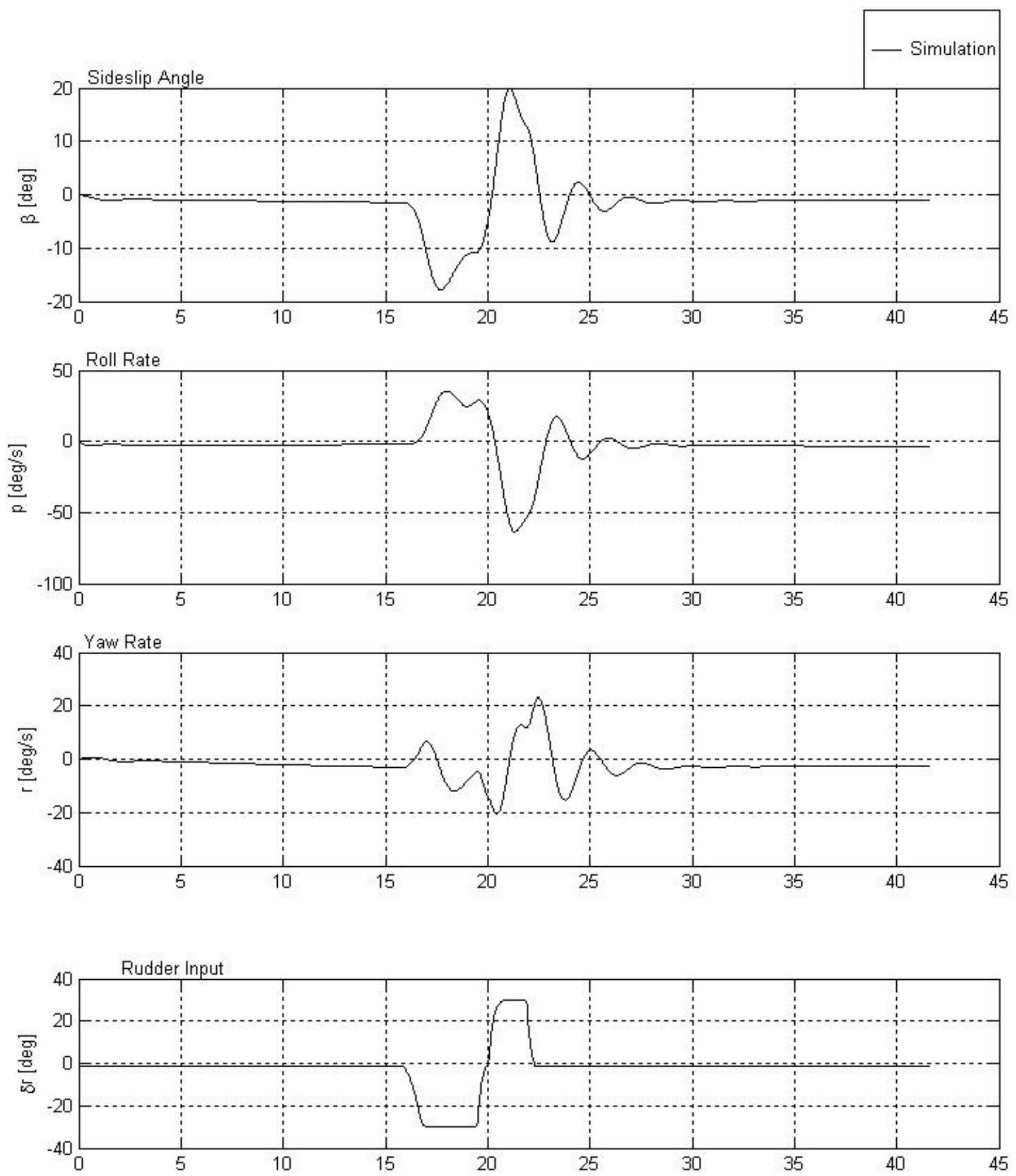

Figure 37. Piloted Input. 
An issue that arose in subjective testing would have never been found in the FAA objective tests. The issue was for steady state sideslip. When the pilot would input a large positive rudder deflection, the heading angle should decrease (the sign convention is that yaw angle and rate are negative when the nose of the aircraft moves to the left). In this case, the aircraft would start with a negative heading change and then have a positive heading change which was intuitively wrong. Looking at the stability derivatives the first derivative that came to mind that could possibly affect the heading due to rudder input was $\mathrm{C}_{\mathrm{n} \delta \mathrm{r}}$. Changing $\mathrm{C}_{\mathrm{n} \delta \mathrm{r}}$ by about $-5 \%$ had very little effect on the heading angle. $\mathrm{C}_{\mathrm{n} \delta \mathrm{r}}$ was then changed by $-20 \%$ and it still had a mediocre effect on the heading angle issue, but then the aircraft model failed the FAA requirements. $\mathrm{C}_{\mathrm{n} \delta \mathrm{r}}$ was changed back to its original value and then another approach was taken. A steady state sideslip was then attempted. With a steady state sideslip, a large rudder deflection is countered with an aileron deflection to keep a steady heading angle. If the yaw rate was negative, therefore a decreasing heading angle, it would have to be countered with a positive roll angle to keep a steady heading. A piloted test was done and there was a problem. To keep a steady state sideslip the aircraft had to have a negative roll angle with a negative yaw rate which was wrong. This led to looking at the lateral force coefficient. The problem was that the $\mathrm{C}_{\mathrm{y} \delta \mathrm{r}}$ was too large causing that term to be larger than $C_{y \beta}$, thus causing the steady state sideslip roll angle to be negative instead of positive. To solve this problem, pilot experience gave us the information for the steady state roll angle. Once the roll angle was known, the lateral force equation was set to zero and solved for this desired roll angle and sideslip angle to get the desired $\mathrm{C}_{\mathrm{y} \delta \mathrm{r}}$. The pilot then tested this maneuver again and was satisfied with the new $\mathrm{C}_{\mathrm{y} \delta \mathrm{r}}$. After finding the new $\mathrm{C}_{\mathrm{y} \delta \mathrm{r}}$, the FAA objective tests were affected only minimally and still passed. 
After the subjective and objective tests were completed, the model was implemented on the simulator hardware and will go through the FAA certification process. To help speed this process up, the objective tests were plotted as they were in the figures above and any requirements that required a $\%$ difference or difference, mainly the damping and natural frequency constants, will be put into a table. 


\section{Conclusions}

The strategy developed for building an FAA approved Level 6 Flight Training Device software was an overall success. With this strategy, similar Level 6 flight simulators can be created. Using the computational tool to analyze the flight test data to find the best data points for the tests and parameter identification greatly reduced the time it would have taken to look at the data individually for every file. The computational tool was also a very effective tool to take the desired data and processing it into a format to be used with the simulation program of Matlab and Simulink. The parameter identification techniques are a very efficient way to find the stability and control derivatives. However, it should be noted that the type of excitation present in the flight data and the specific parameters that need to be determined are correlated for successful PID. Tweaking the model though, requires an understanding of flight dynamics and how the stability derivatives affect the response of the aircraft. 


\section{References}

1. Page, Ray L. "Brief History of Flight Simulation."

2. Perkins C. D.; Hage R. E. "Airplane Performance, Stability, and Control," Wiley, New York, 1949

3. Etkin B. "Dynamics of Flight, Stability, and Control," Wiley, New York, 1959

4. Miele A. "Flight Mechanics: Theory of Flight Paths," Addison-Wesley Publishing Co., 1962

5. Seckel E. "Stability and Control of Airplanes and Helicopters," Academic Press, 1964

6. McCormick B. "Aerodynamics, Aeronautics, and Flight Mechanics," J. Wiley \& Sons, 1979

7. Babister A. “Aircraft Dynamic Stability and Response," Pergamon Press, 1980.

8. Etkin, B., and Reid, L., Dynamics of Flight: Stability and Control, J. Wiley \& Sons, 1996

9. Zipfel P. H. "Modeling and Simulation of Aerospace Vehicle Dynamics," AIAA Education Series, AIAA, Inc. Reston, Virginia, 2000

10. Stevens B. L. Lewis F. L., “Aircraft Control and Simulation,” John Wiley and Sons , Inc., Second Edition, Honoken, NJ, 2003

11. Tewari A. "Atmospheric and Space Flight Dynamics - Modeling and Simulation with MATLAB and Simulink,” Birkhaeuser, Boston, 2007

12. Dreier M. E. "Introduction to Helicopter and Tiltrotor Flight Simulation," AIAA Education Series, AIAA, Inc. Reston, Virginia, 2007

13. Roskam J. "Airplane Flight Dynamics and Automatic Flight Controls," Roskam Aviation and Engineering Corporation, Ottawa, KS, 1982

14. Klein, V. and Morelli, E.A., "Aircraft System Identification - Theory and Practice," AIAA Education Series, AIAA, Reston, VA, 2006. 
15. Debusk, W.; Chowdhary, G.; Johnson, E. N. "Real-Time System Identification of a Small Multi-Engine Aircraft,” Georgia Institute of Technology, Atlanta, GA, 2009

16. Morelli, E. A., "Real Time Parameter Estimation in the Frequency Domain," AIAA Journal of Guidance, Control and Dynamics, Vol.23, no.5.

17. United States Advisory Circular 120-40B, Airplane Simulator Qualification.

18. United States Advisory Circular 120-45A, Airplane Flight Training Device Qualification.

19. Yongkyu, S., Campa G., Napolitano M.R., Seanor B., Perhinschi, M.G. "Comparison of OnLine Parameter Estimation Techniques Within a Fault Tolerant Flight Control System,” AIAA Journal of Guidance, Control and Dynamics, May 2001

20. ***, “Aviator Visual Design Simulator (AVDS) - User Manual," Rassmussen Simulation Technologies, Ltd., Oct. 2000.

21. Meyer A. Van Kampen H., "X-Plane On-Line Instruction Manual," Laminar Research Inc., Columbia SC, $8^{\text {th }}$ edition, 2002 (www.X-Plane.com).

22. Sagoo G. K., Gururajan S., Napolitano M. R., Perhinschi M. G., Gu Y., Seanor B., Campa G., "Pilot-in-the-Loop Assessment of Neurally Augmented Dynamic Inversion Based Fault Tolerant Control Laws in a Motion-Based Flight Simulator," Proceedings of the AIAA Modeling and Simulation Technologies Conference, August 2008, Honolulu, HW

23. Perhinschi M. G., Napolitano M.R. "Integration of Computer Simulation for Flight Dynamics and Control Education," Computers in Education Journal, vol. XVIII, no. 1, pp 13-22, Jan.Mar. 2008 


\section{Appendix A - Altered Flight Test Data Example}
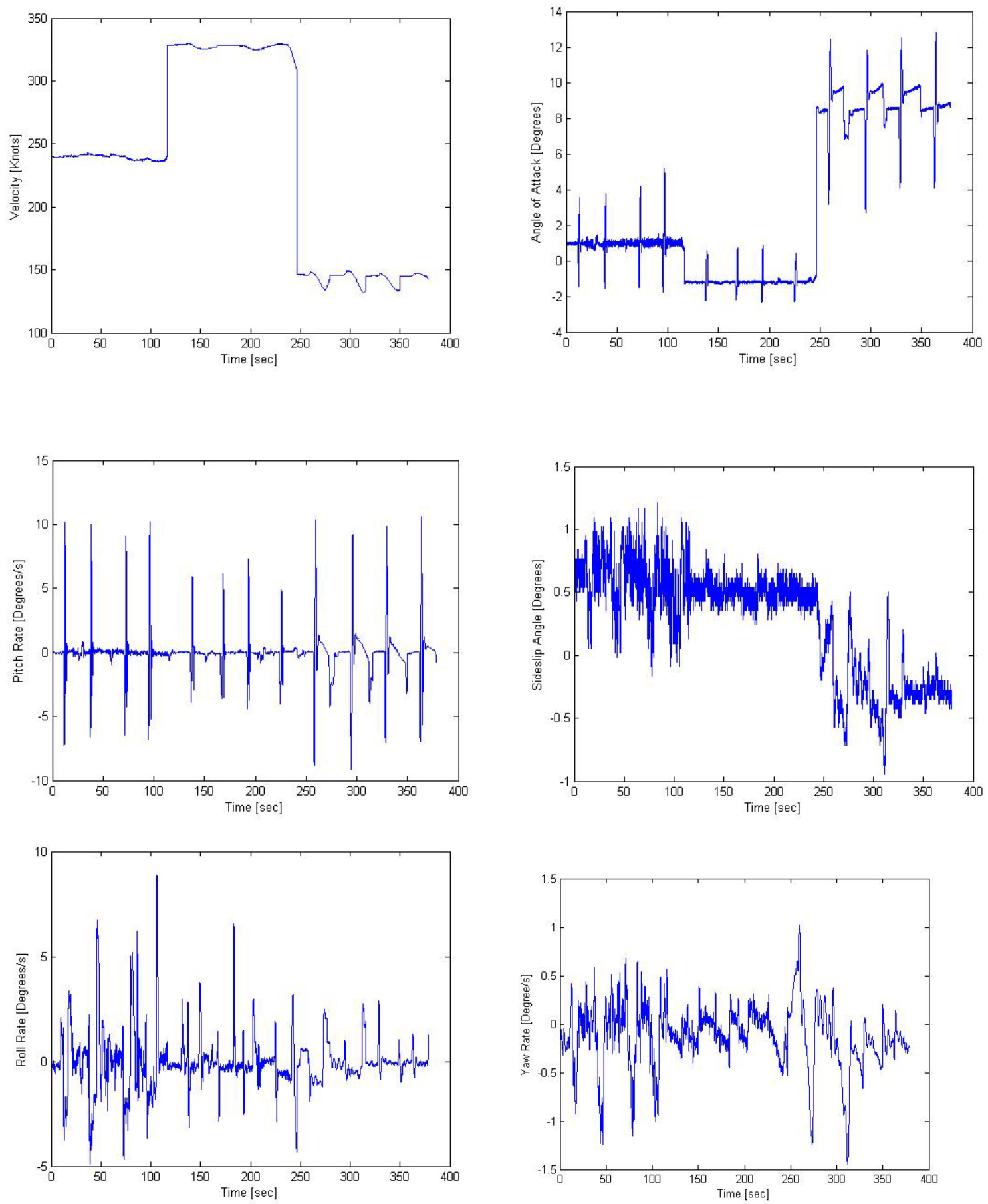

Figure A1. State Variables of Altered Flight Data for a Short Period Test 

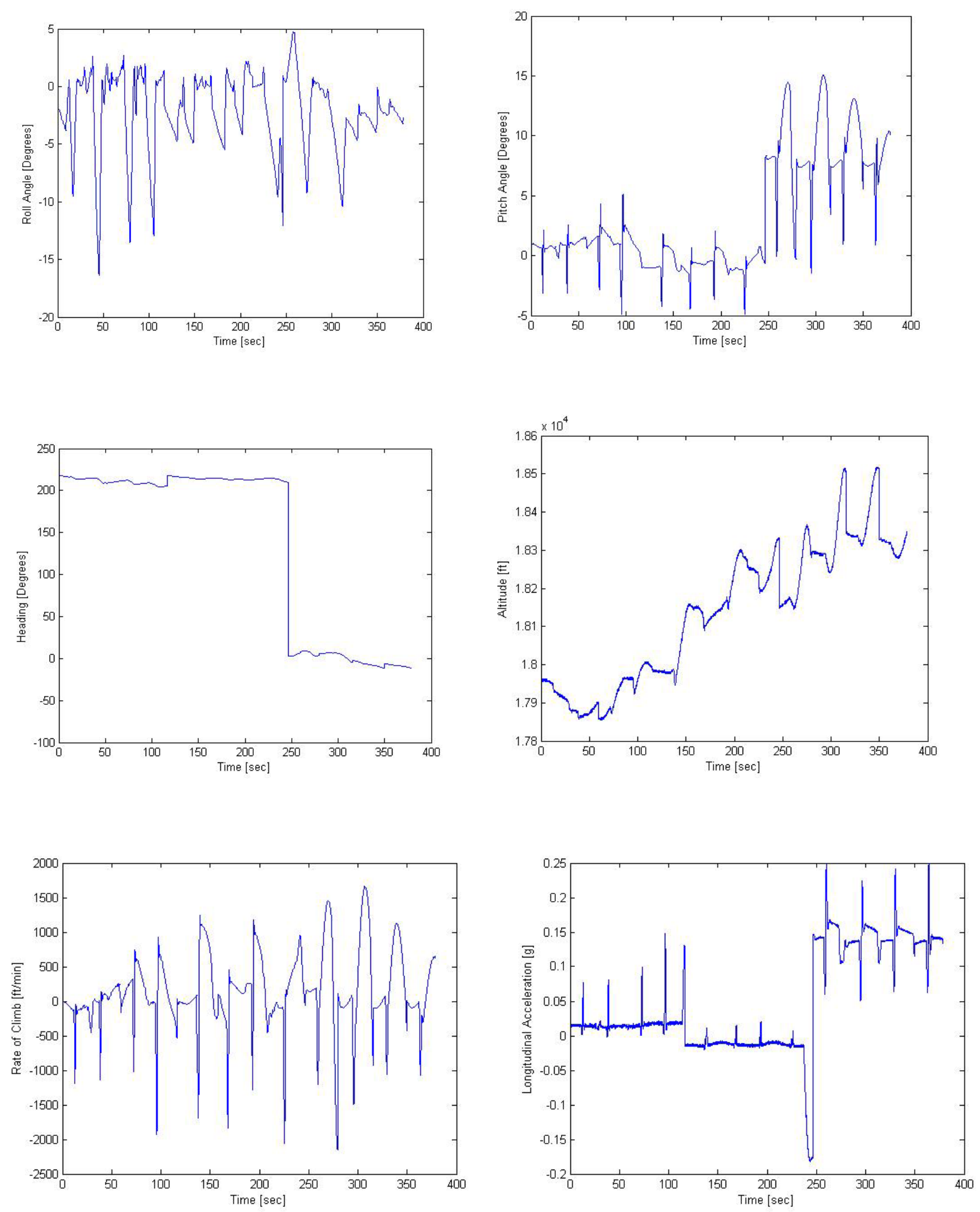

Figure A2. State Variables of Altered Flight Data for a Short Period Test. 

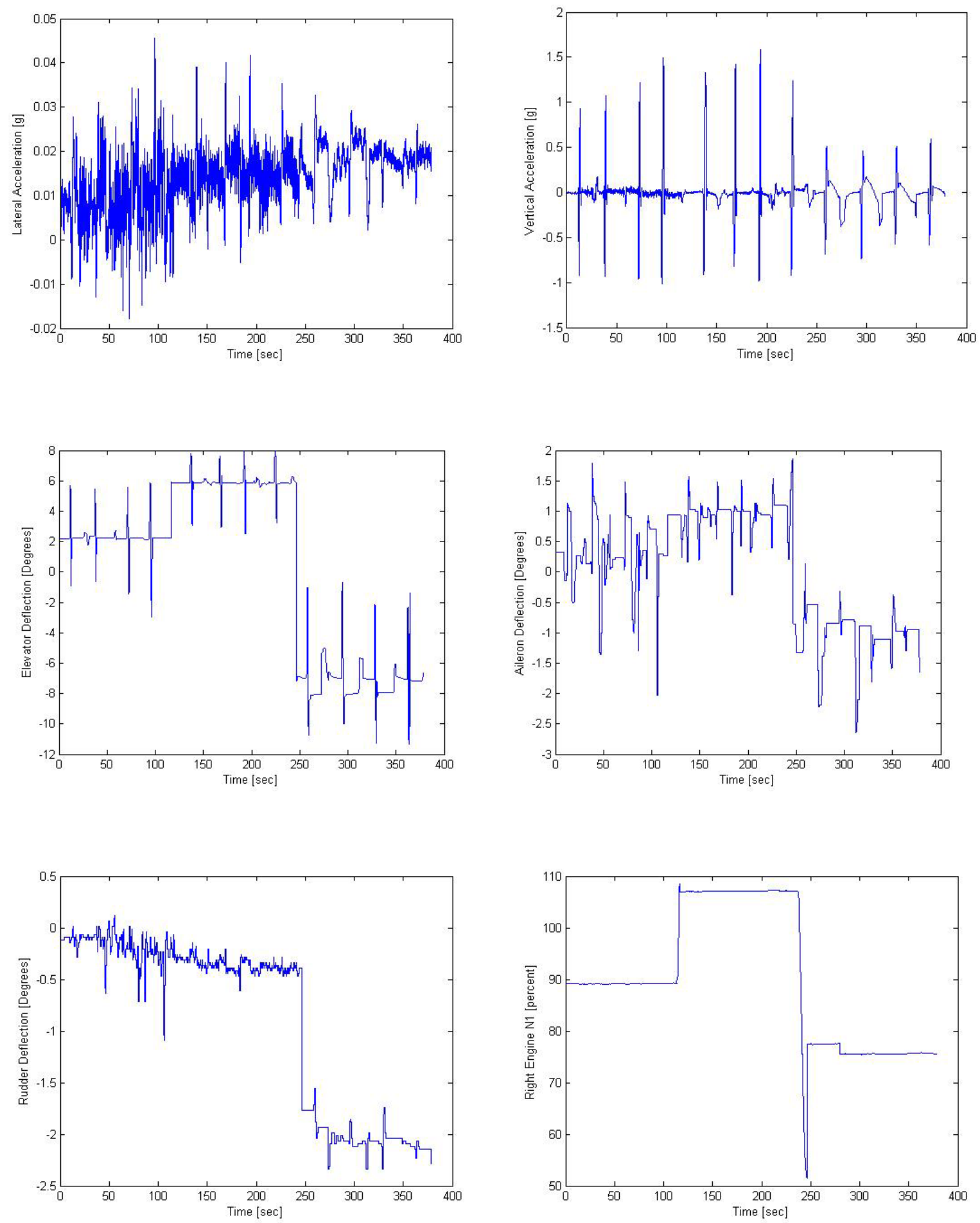

Figure A3. State and Control Variables of Altered Flight Data for a Short Period Test. 

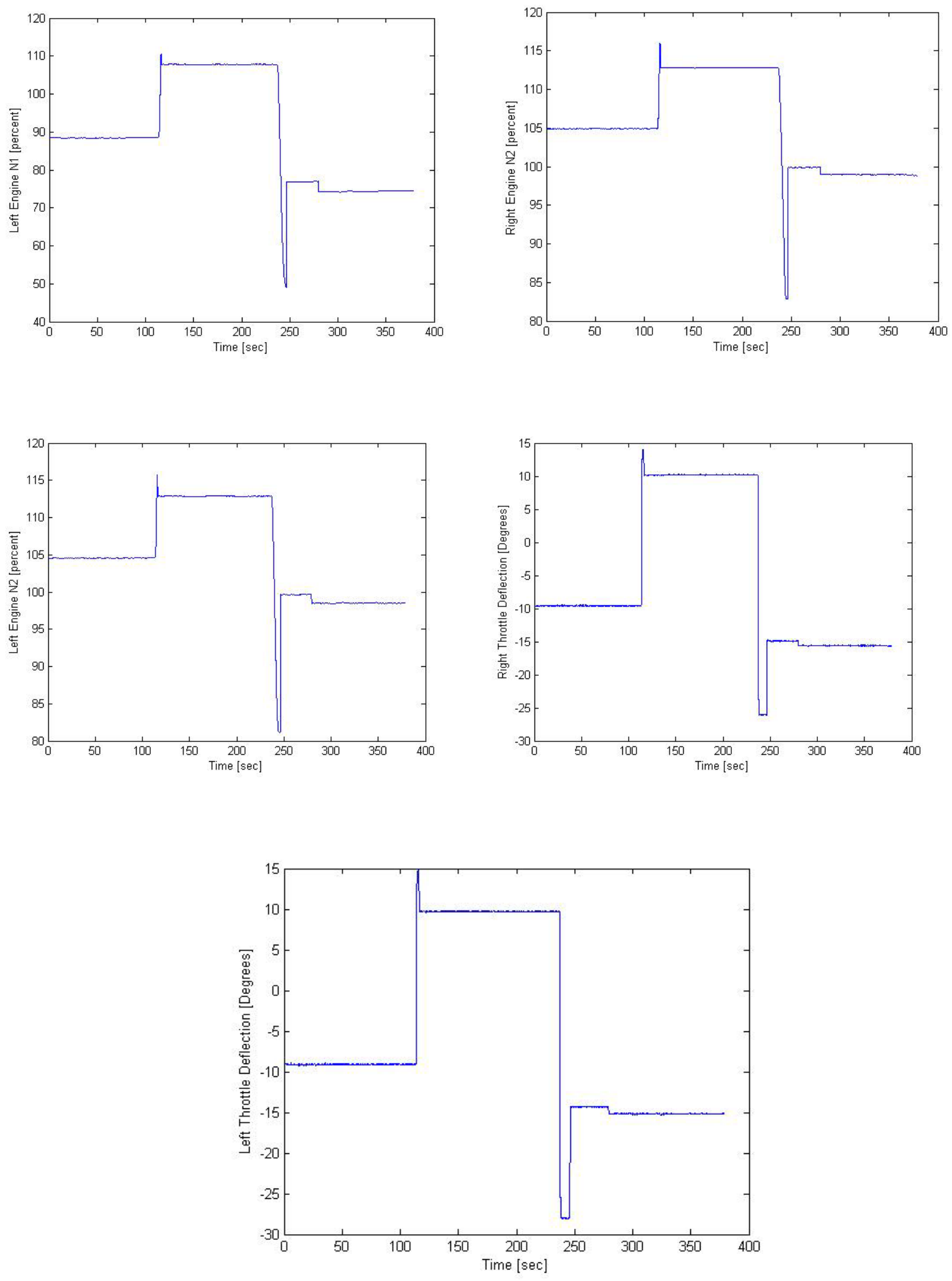

Figure A4. Control and Engine Variables of Altered Flight Data for a Short Period Test. 


\section{Appendix B - Altered Flight Test Data Segments Example}
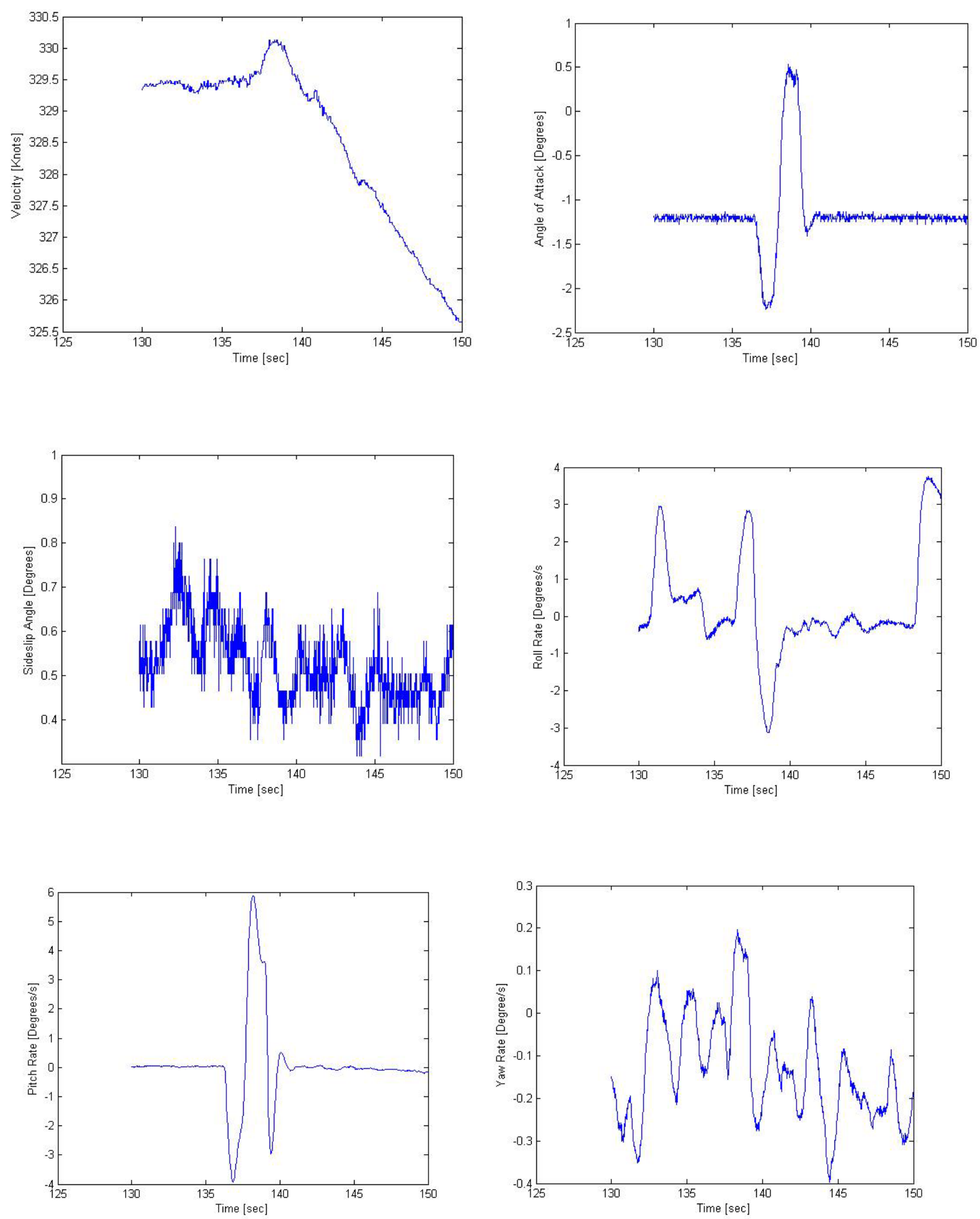

Figure B1. State Variables of Altered Flight Data Segment for a Short Period Test. 

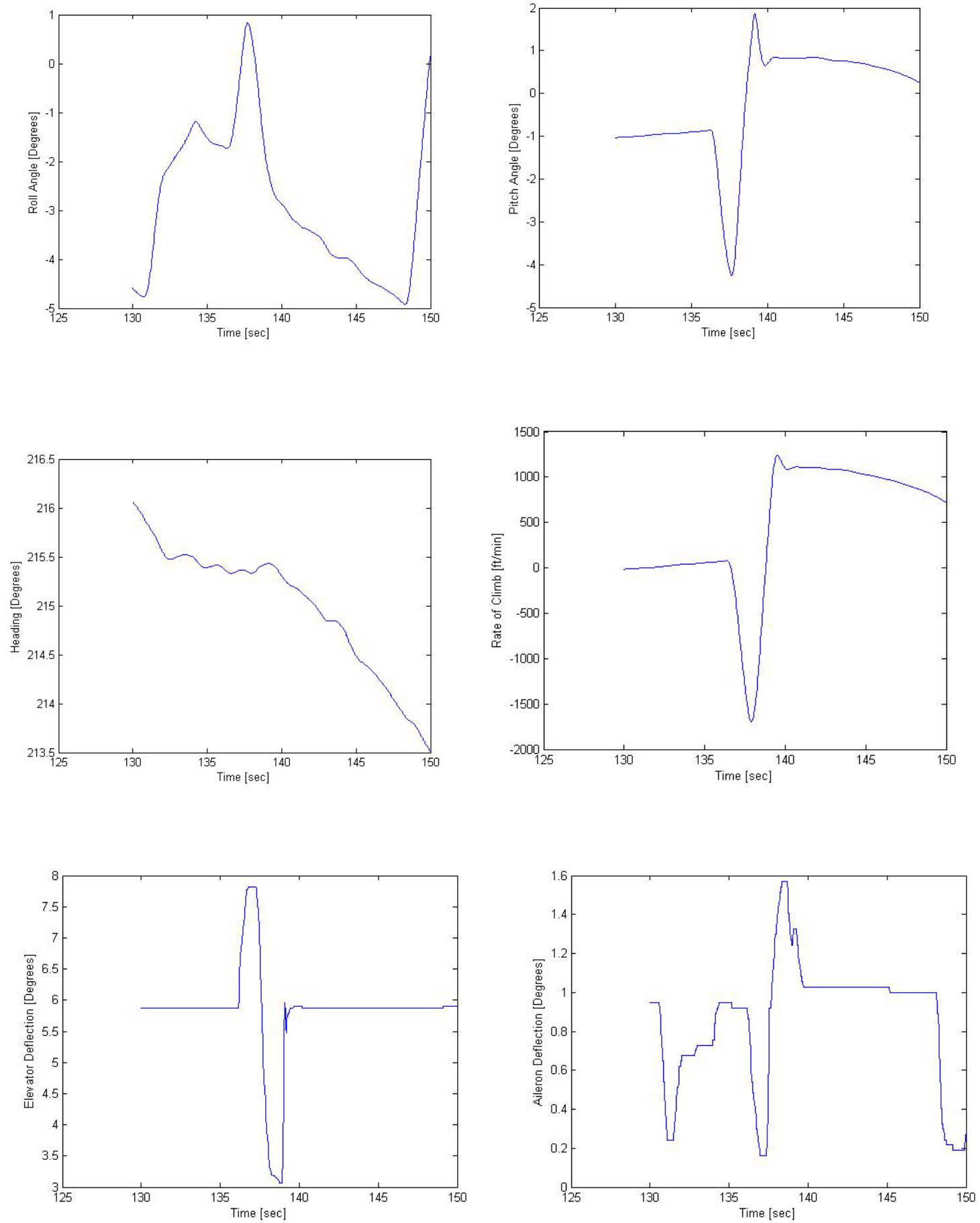

Figure B2. State and Control Variables of Altered Flight Data Segment for a Short Period Test. 

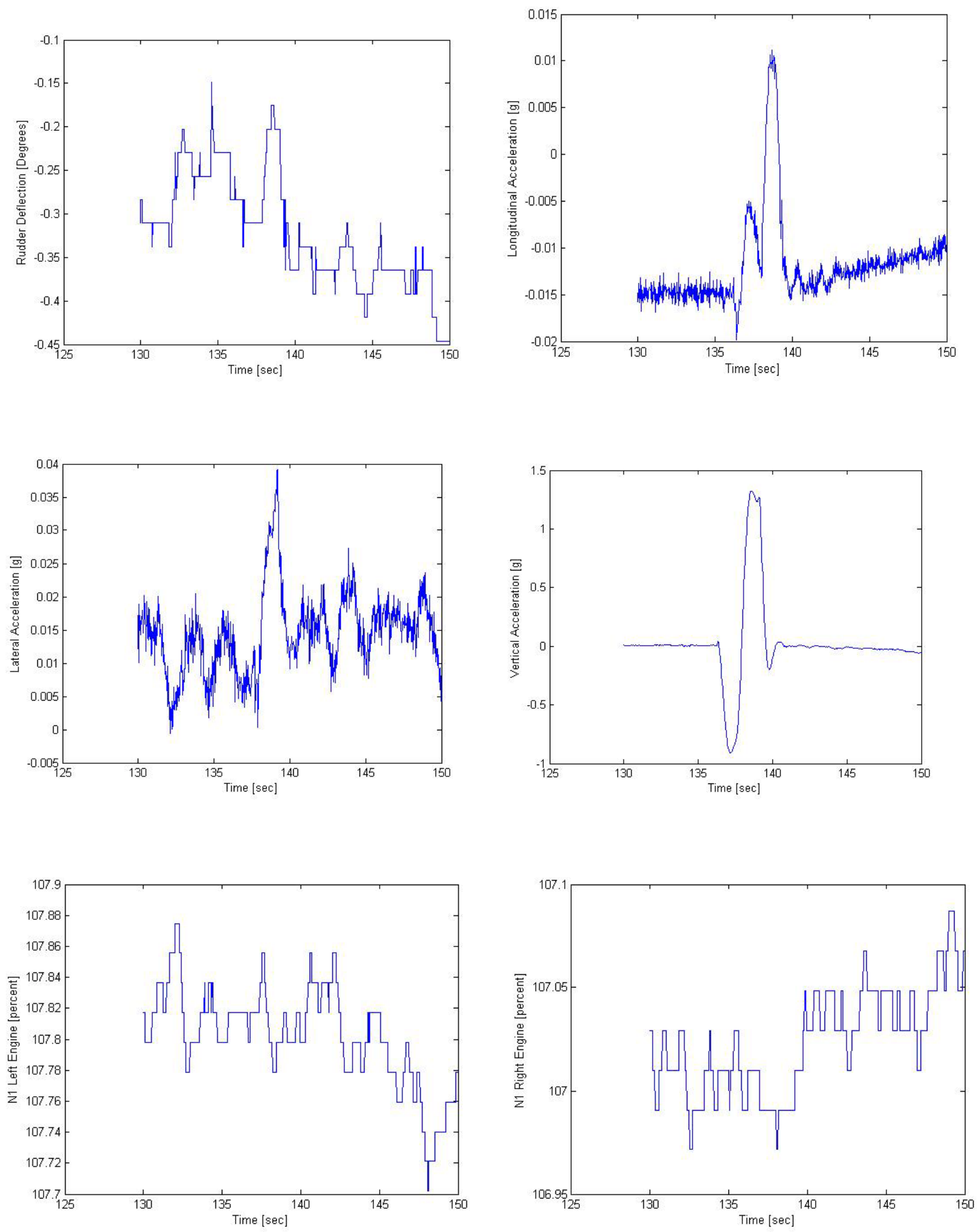

Figure B3. State, Control and Engine Variables of Altered Flight Data Segment for a Short Period Test. 

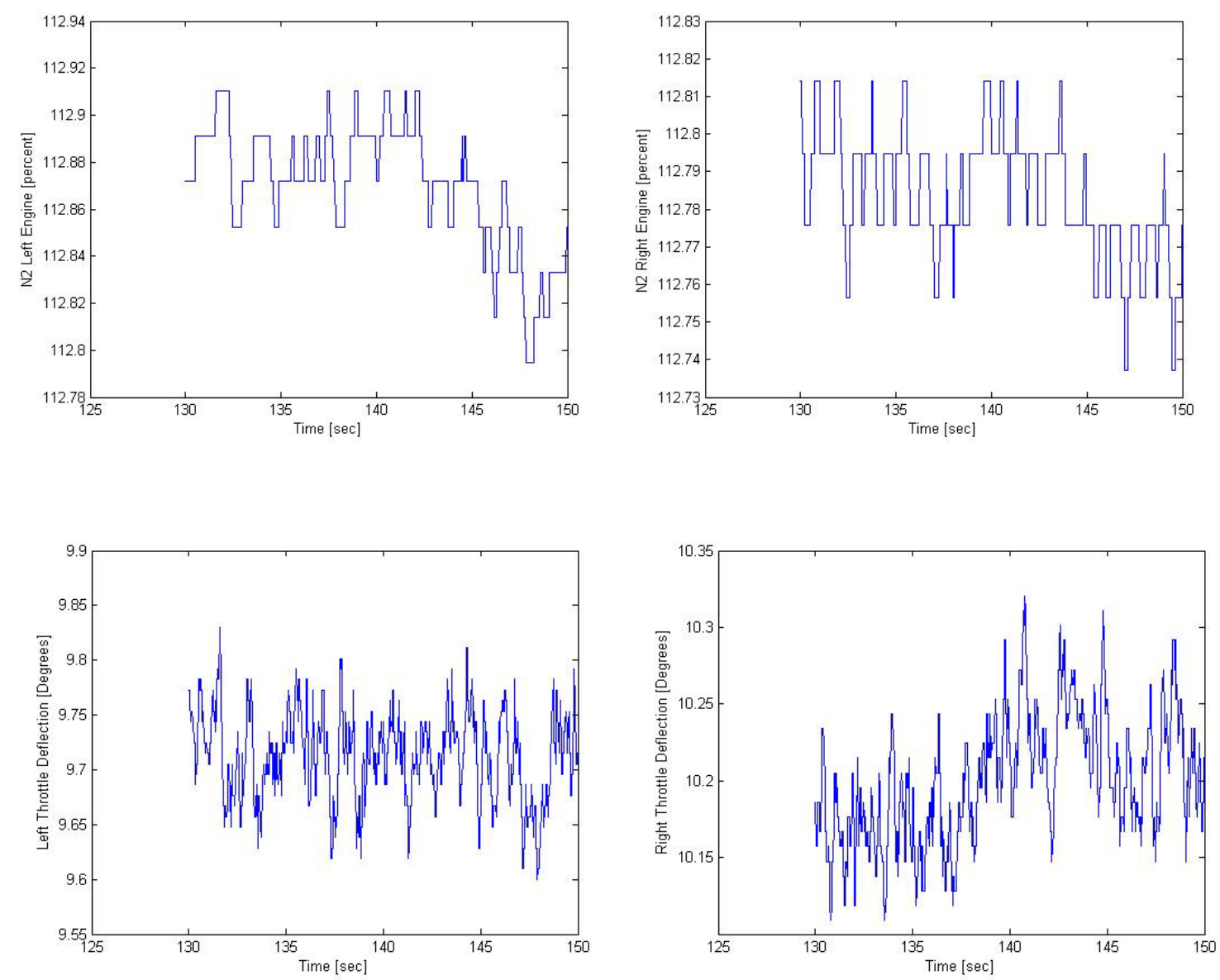

Figure B4. Engine Variables of Altered Flight Data Segment for a Short Period Test. 


\section{Appendix C - State Variable Model of Aircraft Dynamics}

The longitudinal state and output equations are:

$\left(\begin{array}{c}\dot{\alpha} \\ \dot{u} \\ \dot{q} \\ \dot{\theta}\end{array}\right)=\left[\begin{array}{cccc}Z_{\alpha}{ }^{\prime} & Z_{u^{\prime}} & Z_{q^{\prime}} & Z_{\theta^{\prime}} \\ X_{\alpha}{ }^{\prime} & X_{u}{ }^{\prime} & X_{q}{ }^{\prime} & X_{\theta}{ }^{\prime} \\ M_{\alpha}{ }^{\prime} & M_{u}{ }^{\prime} & M_{q}{ }^{\prime} & M_{\theta^{\prime}} \\ 0 & 0 & 1 & 0\end{array}\right]\left(\begin{array}{c}\alpha \\ u \\ q \\ \theta\end{array}\right)+\left[\begin{array}{c}Z_{\delta_{E}}{ }^{\prime} \\ X_{\delta_{E}}{ }^{\prime} \\ M_{\delta_{E}}{ }^{\prime} \\ 0\end{array}\right]\left(\delta_{E}\right)$

$\left(\begin{array}{c}a_{z} \\ \alpha \\ u \\ q \\ \theta\end{array}\right)=\left[\begin{array}{cccc}Z_{\alpha}{ }^{\prime \prime} & Z_{u}{ }^{\prime \prime} & Z_{q}{ }^{\prime \prime} & Z_{\theta}{ }^{\prime \prime} \\ 1 & 0 & 0 & 0 \\ 0 & 1 & 0 & 0 \\ 0 & 0 & 1 & 0 \\ 0 & 0 & 0 & 1\end{array}\right]\left(\begin{array}{c}\alpha \\ q \\ \theta\end{array}\right)+\left[\begin{array}{c}Z_{\delta_{E}}{ }^{\prime \prime} \\ 0 \\ 0 \\ 0 \\ 0\end{array}\right]\left(\delta_{E}\right)$

Where,

$X_{\alpha}^{\prime}=g \cos \left(\gamma_{1}\right)+X_{\alpha}$

$X_{\nu}^{\prime}=X_{\nu}$

$X_{q}^{\prime}=0$

$X_{\theta}^{\prime}=-g \cos \left(\gamma_{1}\right)$

$X_{\delta E}^{\prime}=X_{\delta e}$ 


$$
Z_{\alpha}^{\prime}=\frac{g \cos \left(\gamma_{1}\right)+Z_{\alpha}}{\left(U_{1}-Z_{\dot{\alpha}}\right)}
$$

$Z_{u}^{\prime}=\frac{Z_{u}}{\left(U_{1}-Z_{\dot{\alpha}}\right)}$

$Z_{q}^{\prime}=\frac{\left(U_{1}-Z_{q}\right)}{\left(U_{1}-Z_{\dot{\alpha}}\right)}$

$Z_{\theta}^{\prime}=\frac{g \sin \left(\gamma_{1}\right)}{\left(U_{1}-Z_{\dot{\alpha}}\right)}$

$Z_{\delta_{E}}^{\prime}=\frac{Z_{\dot{\delta}}}{\left(U_{1}-Z_{\dot{\alpha}}\right)}$

$M_{\alpha}^{\prime}=M_{\dot{\alpha}} Z_{\alpha}^{\prime}+M_{\alpha}$

$$
M_{u}^{\prime}=M_{\dot{\alpha}} Z_{u}^{\prime}+M_{u}
$$

$M_{q}^{\prime}=M_{\dot{\alpha}} Z_{q}^{\prime}+M_{q}$

$M_{\theta}^{\prime}=M_{\dot{\alpha}} Z_{\theta}^{\prime}$

$$
Z_{\alpha}^{\prime \prime}=U_{1} Z_{\alpha}^{\prime}-g \sin \gamma_{1}
$$




$$
\begin{aligned}
& Z_{u}^{\prime \prime}=U_{1} Z_{u}^{\prime} \\
& Z_{q}^{\prime \prime}=U_{1}\left(Z_{q}^{\prime}-1\right) \\
& Z_{\theta}^{\prime \prime}=U_{1} Z_{\theta}^{\prime}+g \sin \gamma_{1} \\
& Z_{\delta E}^{\prime \prime}=U_{1} Z_{\delta e}^{\prime}
\end{aligned}
$$

With the stability and control derivatives being,

$$
X_{u}=\frac{-\bar{q}_{1} S\left(C_{D_{U}}+2 C_{D_{1}}\right)}{m U_{1}}
$$

$X_{T_{u}}=\frac{-\bar{q}_{1} S\left(C_{T_{u u u}}+2 C_{T_{w 1}}\right)}{m U_{1}}$

$X_{\alpha}=\frac{-\bar{q}_{1} S\left(C_{D_{u}}-C_{L_{1}}\right)}{m}$

$X_{\delta_{E}}=\frac{-\bar{q}_{1} S C_{D_{\sigma E}}}{m}$

$$
\begin{aligned}
& Z_{u}=\frac{-\bar{q}_{1} S\left(C_{L_{U}}+2 C_{L_{1}}\right)}{m U_{1}} \\
& Z_{\alpha}=\frac{-\bar{q}_{1} S\left(C_{L_{\alpha u}}+C_{D_{1}}\right)}{m}
\end{aligned}
$$


$Z_{\dot{\alpha}}=\frac{-\bar{q}_{1} S \bar{c} C_{L_{\dot{\alpha}}}}{2 m U_{1}}$

$Z_{q}=\frac{-\bar{q}_{1} S C_{L_{q}}}{2 m U_{1}}$

$Z_{\delta_{E}}=\frac{-\bar{q}_{1} S C_{L_{G E}}}{m}$

$M_{u}=\frac{\bar{q}_{1} S \bar{c}\left(C_{m_{U}}+2 C_{m_{1}}\right)}{U_{1} I_{y y}}$

$M_{T_{u}}=\frac{\bar{q}_{1} S \bar{c}\left(C_{m_{T V}}+2 C_{m_{T 1}}\right)}{U_{1} I_{y y}}$

$M_{\alpha}=\frac{\bar{q}_{1} S \bar{c} C_{m_{\alpha}}}{I_{y y}}$

$M_{T_{\alpha}}=\frac{\bar{q}_{1} S \bar{c} C_{m T \alpha}}{I_{y y}}$

$M_{\dot{\alpha}}=\frac{\bar{q}_{1} S \bar{c} C_{m_{\dot{\alpha}}}}{l_{y y}} \cdot \frac{\bar{c}}{2 U_{1}}$ 
$M_{q}=\frac{\bar{q}_{1} S \bar{c} C_{m_{q}}}{I_{y y}} \cdot \frac{\bar{c}}{2 U_{1}}$

$M_{\delta_{E}}=\frac{\bar{q}_{1} S \bar{c} C_{m_{\delta_{E}}}}{l_{y y}} \cdot \frac{\bar{c}}{2 U_{1}}$

The lateral-directional state and output equations are,

$$
\begin{aligned}
& \left(\begin{array}{l}
\dot{\beta} \\
\dot{p} \\
\dot{r} \\
\dot{\varphi}
\end{array}\right)=\left[\begin{array}{cccc}
Y_{\beta}{ }^{\prime} & Y_{p}{ }^{\prime} & Y_{r}{ }^{\prime} & Y_{\theta}{ }^{\prime} \\
L_{\beta}{ }^{\prime} & L_{p}{ }^{\prime} & L_{r}{ }^{\prime} & 0 \\
N_{\beta}{ }^{\prime} & N_{p}{ }^{\prime} & N_{r}{ }^{\prime} & 0 \\
0 & 1 & \tan \left(\theta_{1}\right) & 0
\end{array}\right]\left(\begin{array}{l}
\beta \\
p \\
r \\
\varphi
\end{array}\right)+\left[\begin{array}{cc}
Y_{\delta_{A}}{ }^{\prime} & Y_{\delta_{R}}{ }^{\prime} \\
L_{\delta_{A}}{ }^{\prime} & L_{\delta_{R}}{ }^{\prime} \\
N_{\delta_{A}}{ }^{\prime} & N_{\delta_{R}}{ }^{\prime} \\
0 & 0
\end{array}\right]\left(\begin{array}{l}
\delta_{A} \\
\delta_{R}
\end{array}\right) \\
& \left(\begin{array}{c}
a_{y} \\
\beta \\
p \\
r \\
\varphi
\end{array}\right)=\left[\begin{array}{cccc}
Y_{\beta}{ }^{\prime \prime} & Y_{p}{ }^{\prime \prime} & Y_{r}{ }^{\prime \prime} & Y_{\varphi}{ }^{\prime \prime} \\
1 & 0 & 0 & 0 \\
0 & 1 & 0 & 0 \\
0 & 0 & 1 & 0 \\
0 & 0 & 0 & 1
\end{array}\right]\left(\begin{array}{l}
\beta \\
p \\
r \\
\varphi
\end{array}\right)+\left[\begin{array}{cc}
Y_{\delta_{A}}{ }^{\prime \prime} & Y_{\delta_{R}}{ }^{\prime \prime} \\
0 & 0 \\
0 & 0 \\
0 & 0 \\
0 & 0
\end{array}\right]\left(\begin{array}{l}
\delta_{A} \\
\delta_{R}
\end{array}\right)
\end{aligned}
$$

Where,

$Y_{\beta}^{\prime}=\frac{Y_{\beta}}{U_{1}}$

$Y_{p}^{\prime}=\frac{Y_{p}}{U_{1}}$

$Y_{r}^{\prime}=\frac{Y_{r}}{U_{1}}-1$ 


$$
Y_{\phi}^{\prime}=\frac{g \cos \left(\Theta_{1}\right)}{U_{1}}
$$

$Y_{\delta A}^{\prime}=\frac{Y_{\delta a}}{U_{1}}$

$L_{\beta}^{\prime}=\frac{\left(A_{1} N_{\beta}+L_{\beta}\right)}{\left(1-A_{1} B_{1}\right)}$

$L_{p}^{\prime}=\frac{\left(A_{1} N_{p}+L_{p}\right)}{\left(1-A_{1} B_{1}\right)}$

$L_{r}^{\prime}=\frac{\left(A_{1} N_{r}+L_{r}\right)}{\left(1-A_{1} B_{1}\right)}$

$L_{\delta A}^{\prime}=\frac{\left(A_{1} N_{\delta A}+L_{\delta A}\right)}{\left(1-A_{1} B_{1}\right)}$

$L_{\delta R}^{\prime}=\frac{\left(A_{1} N_{\delta R}+L_{\delta R}\right)}{\left(1-A_{1} B_{1}\right)}$

$N_{\beta}^{\prime}=\frac{\left(B_{1} L_{\beta}+N_{\beta}\right)}{\left(1-A_{1} B_{1}\right)}$ 


$$
\begin{aligned}
& N_{p}^{\prime}=\frac{\left(B_{1} L_{p}+N_{p}\right)}{\left(1-A_{1} B_{1}\right)} \\
& N_{r}^{\prime}=\frac{\left(B_{1} L_{r}+N_{r}\right)}{\left(1-A_{1} B_{1}\right)} \\
& N_{\delta A}^{\prime}=\frac{\left(B_{1} L_{\delta A}+N_{\delta A}\right)}{\left(1-A_{1} B_{1}\right)} \\
& N_{\delta R}^{\prime}=\frac{\left(B_{1} L_{\delta R}+N_{\delta R}\right)}{\left(1-A_{1} B_{1}\right)}
\end{aligned}
$$

Where $\mathrm{A}_{1}$ and $\mathrm{B}_{1}$ and the lateral-directional stability and control derivatives are:

$$
\begin{aligned}
& A_{1}=\frac{l_{x z}}{l_{x x}} \\
& B_{1}=\frac{I_{x z}}{l_{x x}} \\
& Y_{\beta}=\frac{\bar{q}_{1} S C_{Y_{\beta}}}{m} \\
& Y_{p}=\frac{\bar{q}_{1} S C_{Y_{p}}}{m} \cdot \frac{b}{2 U_{1}} \\
& Y_{r}=\frac{\bar{q}_{1} S C_{Y_{F}}}{m} \cdot \frac{b}{2 U_{1}}
\end{aligned}
$$




$$
Y_{\delta_{A}}=\frac{\bar{q}_{1} S C_{Y_{\delta_{A}}}}{m}
$$

$$
Y_{\delta_{R}}=\frac{\bar{q}_{1} S C_{Y_{\sigma_{R}}}}{m}
$$

$$
L_{\beta}=\frac{\bar{q}_{1} S C_{l_{\beta}} b}{I_{x x}}
$$

$$
L_{p}=\frac{\bar{q}_{1} S b C_{l_{p}}}{I_{x x}} \cdot \frac{b}{2 U_{1}}
$$

$$
L_{r}=\frac{\bar{q}_{1} S b C_{l_{r}}}{I_{x x}} \cdot \frac{b}{2 U_{1}}
$$

$L_{\delta_{A}}=\frac{\bar{q}_{1} S C_{l_{\delta_{A}}} b}{I_{x x}}$

$$
L_{\delta_{R}}=\frac{\bar{q}_{1} S C_{l_{\delta_{R}}} b}{I_{x x}}
$$

$$
N_{\beta}=\frac{\bar{q}_{1} S C_{n \rho} b}{I_{z z}}
$$




$$
\begin{aligned}
& N_{T_{\beta}}=\frac{\bar{q}_{1} S C_{n_{\beta}} b}{I_{s z}} \\
& N_{p}=\frac{\bar{q}_{1} S b C_{n_{p}}}{I_{s z}} \cdot \frac{b}{2 U_{1}}
\end{aligned}
$$

$N_{r}=\frac{\bar{q}_{1} S b C_{n_{r}}}{I_{z z}} \cdot \frac{b}{2 U_{1}}$

$N_{\delta_{A}}=\frac{\bar{q}_{1} S C_{n_{g_{A}}} b}{I_{g z}}$

$$
N_{\delta_{R}}=\frac{\bar{q}_{1} S C_{m_{R}} b}{I_{g Z}}
$$




\section{Appendix D - Flight Simulator Manual}

To start the program type in JetSim in the Matlab command window. Once the program has started, the JetSim.fig will be the first figure to pop up.

There are two buttons that can be pressed. The FAA Compliance button is for the FAA tests that are required to certify the simulator. The Full Envelope button is the button for the model with all of the components, i.e. landing gear, flaps, trim, that combined for the final simulation model.

\section{For FAA Compliance}

Press the FAA Compliance button to continue.

The FAA Compliance button will then run the sel_modelfile.m file.

The sel_modelfile.m file will then open the FlightCondition.fig figure. On this menu, it will ask which condition out of the six. Each condition in the drop down menu is used as a flag for the programming code. The flag name is sel_FC and they run from 1 to 9 which are:

\begin{tabular}{|l|l|}
\hline sel_FC & Flight Condition \\
\hline 1 & Cruise \\
\hline 2 & Approach \\
\hline 3 & Normal Climb, Clean \\
\hline
\end{tabular}




\begin{tabular}{|l|l|}
\hline 4 & Steady State Sideslip \\
\hline 5 & Acceleration on the Ground \\
\hline 6 & Acceleration on Approach \\
\hline 7 & Longitudinal Trim \\
\hline 8 & Flaps Operating Time \\
\hline 9 & Landing Gear Operating Time \\
\hline
\end{tabular}

Once the Continue button on the FlightCondition.fig menu has been pressed, the program then runs the sel_inp.m file. This file in turn then opens the PilotInput.fig figure. On this figure the types of inputs are displayed on the left side of the figure. When all stick inputs is selected and the Continue button is pressed the program loads the allstk.m file. For Pre-recorded inputs the file allrec.m is loaded and the channels that are recorded and the names of the files are required on this figure. The mixed input loads the mixed.m file and may use the pre-recorded channels part of the menu if applicable. Finally if the all from flight file is selected the allflight.m file is loaded. Regardless of which input is used, the file Ok_Pilotinput.m is loaded once the continue button is pressed.

The Ok_Pilotinput.m file then loads the corresponding figure for sel_FC flag. Where:

sel_FC=1 -- Reg_Cruise.fig

sel_FC=2 -- Reg_Approach.fig 


$$
\begin{aligned}
& \text { sel_FC=3 -- Reg_Climb.fig } \\
& \text { sel_FC=4 -- Reg_Sideslip.fig } \\
& \text { sel_FC=5 -- Reg_Ground.fig } \\
& \text { sel_FC=6 -- Reg_Acc.fig } \\
& \text { sel_FC=7 -- Reg_LgTrim.fig } \\
& \text { sel_FC=8 -- Reg_Flaps.fig } \\
& \text { sel_FC=9 -- Reg_LdGear.fig }
\end{aligned}
$$

Each figure is set up similarly in that the drop menu is used to select the wanted requirements. This drop down menu is also used to get flags that are named sel_test. Once the requirement is selected the program then runs the InitializeFE.m file.

The InitializeFE.m file is responsible for loading all of the aerodynamic look up tables, thrust, and constant parameters. Also, from the sel_FC and sel_test values, the corresponding flight data is loaded and the initial conditions of the flight are loaded. For the flight data it is important to make sure that the file path is correct so that it will be loaded. The flight data loads the following data and what the variable name is in the program.

\begin{tabular}{|l|l|}
\hline Name & Variable in Program \\
\hline Angle of Attack & alpha_saved \\
\hline
\end{tabular}




\begin{tabular}{|l|l|}
\hline Velocity & kias_saved \\
\hline Sideslip Angle & beta_saved \\
\hline Roll Angle & phi_saved \\
\hline Pitch Angle & theta_saved \\
\hline Yaw Angle & psi_saved \\
\hline Roll Rate & p_saved \\
\hline Pitch Rate & \\
\hline Yaw Rate & q_saved \\
\hline Longitudinal Acceleration & r_saved \\
\hline Lateral Acceleration & accx_saved \\
\hline Vertical Acceleration & dr_saved \\
\hline Start Time & accy_saved \\
\hline End Time & accz_saved \\
\hline Aileron Deflection & start_save \\
\hline
\end{tabular}




\begin{tabular}{|l|l|}
\hline Left Throttle Deflection & thrL_saved \\
\hline N1 of Left Engine & N1_L_saved \\
\hline N2 of Left Engine & N2_L_saved \\
\hline Right Throttle Deflection & thrR_saved \\
\hline N1 of Right Engine & N1_R_saved \\
\hline N2 of Right Engine & N2_R_saved \\
\hline Rate of Climb & ROC_saved \\
\hline
\end{tabular}

For each flight condition and test, an initial conditions file is loaded that has the initial conditions of the test, which include the mass moments of inertia. These files' names are in the format of IC_\#\#_\$. Where the \#\# inidicates the number of the flight the data was taken from and \$\$ indicates the numbering of the file. Finally, the time step used for the simulation and the end time of the simulation are created in this file. The time step is the variable known as $\mathrm{T}$ and the end time of the simulation is SimTime.

Once the data is loaded then the sel_FC flags are used to open two more files. These are:

\begin{tabular}{|l|l|l|}
\hline sel_FC & File 1 & File 2 \\
\hline 1 & OpenScopes2.m & Jet_FE.mdl \\
\hline 2 & OpenScopes2.m & Jet_FE.mdl \\
\hline
\end{tabular}




\begin{tabular}{|l|l|l|}
\hline 3 & OpenScopes3.m & Jet_FE.mdl \\
\hline 4 & OpenScopes2.m & Jet_FE.mdl \\
\hline 5 & OpenScopes4.m & Jet_FE.mdl \\
\hline 6 & OpenScopes4.m & Jet_FE.mdl \\
\hline 7 & OpenScopes4.m & Jet_FE.mdl \\
\hline
\end{tabular}

For sel_FC $=8$ and sel_test $=1$, the FlapsOT_R.m the switch in the Jet_FE.mdl for flaps must be switched to FAA compliance to read the inputs.

For sel_FC=8 and sel_test=2, the FlapsOT_E.m the switch in the Jet_FE.mdl for flaps must be switched to FAA compliance to read the inputs.

For sel_FC $=9$ and sel_test $=1$, the LdGearOT_R the switch in the Jet_FE.mdl for landing gear must be switched to FAA compliance to read the inputs.

For sel_FC $=9$ and sel_test $=2$, the LdGearOT_E the switch in the Jet_FE.mdl for landing gear must be switched to FAA compliance to read the inputs.

Once the OpenScopes files are loaded, the 2, 3, or 4 following the OpenScopes in the file name is used to open up the corresponding Scopes.fig.

In these new scopes figure, the scopes that are required can be selected and viewed as the program is running. Once the $\mathrm{OK}$ button is pressed the corresponding Ok_Scopes.m file is loaded which is what is used to open the scopes. 
In the Jet_FE.mdl files, in the Data Manager file, the block named FlightData15 takes all the variables saved from the flight data above and then sends it to the scopes to be compared with the simulator outputs.

The Jet_FE.mdl files are then used by selecting the amount of time to run the simulation or uses the SimTime variable for the test. In this block are a Scopes1, Scopes2, and To Workspace block. The Scopes blocks have the scopes that are opened up by the OpenScopes.m files. The To Workspace block contains blocks that save the simulation data, the limits of the tests, and the flight data to matrices in the workspace. These matrices have the data saved such that the first column is the simulation data, the second column is the flight data, the third column is the upper limit and the fourth is the lower limit for the FAA Compliance Tests.

Once the simulation is run, double-clicking the Plots for FAA Compliance block will run the Subplot_data.m file. In this file, for the corresponding sel_FC and sel_test, the To Workspace variables that are needed for the requirements of the test are then used to plot and find other parameters, i.e. time constants, damping, frequency, and to display the initial conditions of the flight.

\section{Full Envelope}

Once the full envelope button is pushed, sel_modelfile.m is run and the PilotInput.fig is opened. From this menu only the all stick input selection can be selected which uses the allstk.m file.

Once that is selected, and the OK button is pressed, the OK_PilotInput.m file is run and will then open the Initial Conditions of the simulation. There are currently three initial conditions. The first initial condition is the airplane is in the air with a velocity of $125 \mathrm{~m} / \mathrm{s}$ and $4450 \mathrm{~m}$ ASL with the sel_test value being 1. The second condition is starting on the ground with zero velocity and 
at $4450 \mathrm{~m}$ ASL and the sel_test value being 2 . The third condition has a starting velocity of 65 $\mathrm{m} / \mathrm{s}$ and an altitude of $530 \mathrm{~m}$. Once the OK button is selected on this the InitializeFE. $\mathrm{m}$ file is run. In this file, all of the aerodynamic look up tables, the thrust look up tables, constants, sensor bias, and mass moment of inertia are loaded. Then the Jet_FE.mdl file is opened. For this model, there is no subplot data block.

In the Jet_FE simulink file, there is a block with that is titled Pilot1, this block contains all of the inputs. The joystick block is the actual physical input device and its outputs. The axes outputs then go to the longitudinal, lateral, or directional channels, or the button outputs are the button outputs that go to the brake command, aileron trim, elevator trim, or rudder trim. These buttons commands are then separated using a selector block. For the default the selector for the brake command uses button 1 which when you double click selector will show that value in an element vector. For the aileron trim, the default buttons are 3 and 4 in that order, the position where the 3 is in makes the aileron trim left while the position of 4 trims the aileron right. For the elevator trim, 7 and 8 are the default buttons and the position of 7 trims the elevators for a nose down position while the 8 position trims the elevators nose up. The rudder trim selectors default values are 5 and 6 where the position of 5 trims the rudder for the nose left and the 6 trims the nose right. These values can be changed for a more convenient button selection. To calibrate the joystick axes the constants kstkdr (for the directional channel), kstklg (for the longitudinal channel), kstklt (for the lateral channel) are used for the calibration, and kthrhist (for the thrust channel). Increasing these values will increase the effectiveness of control input to the control surface deflections. These values will depend on the kind of joystick or input device you are using so it must be set up for individual devices. 
Lastly for the full envelope another figure is opened up that has four different buttons. The first button is the pause button and this button will pause the simulation until the pause button is hit again. The position freeze button is a toggle button that will freeze the aircraft at a certain but will be able to be rotated about all three axis while in the frozen position. The Altitude freeze button is a toggle that will freeze the aircraft at its current altitude while the heading and rotation about the 3 axis can be changed. Reposition button will bring up another menu to change the heading, latitude, longitude, and altitude of the aircraft and is confirmed by hitting the OK button at the bottom of the figure. 
$\underline{\text { Table of Variables }}$

InitializeFE.m

\begin{tabular}{|c|c|c|}
\hline InitializeFE.m & Descriptor & Type \\
\hline alphaLT & Angle of attack & conversion factor \\
\hline $\mathrm{t}$ & Altitude for thrust look up table & look up Table \\
\hline $\mathrm{b}$ & Wing span & variable \\
\hline brake_cmd & Braking Input & input \\
\hline c & Chord & variable \\
\hline $\mathrm{Cx} 0$ & Initial X-axis force coefficient & variable \\
\hline $\mathrm{CxV}$ & $\begin{array}{l}\mathrm{X} \text {-axis force variation with respect } \\
\text { to velocity }\end{array}$ & variable \\
\hline Cxa & $\begin{array}{l}\mathrm{X} \text {-axis force variation with respect } \\
\text { to alpha }\end{array}$ & variable \\
\hline $\mathrm{Cxq}$ & $\begin{array}{l}\mathrm{X} \text {-axis force variation with respect } \\
\text { to pitch rate }\end{array}$ & variable \\
\hline Cxadot & $\begin{array}{l}\mathrm{X} \text {-axis force variation with respect } \\
\text { to rate of change of alpha }\end{array}$ & variable \\
\hline Cxde & $\begin{array}{l}\mathrm{X} \text {-axis force variation with respect } \\
\text { to elevator deflection }\end{array}$ & switch \\
\hline CxLG & $\begin{array}{l}\mathrm{X} \text {-axis force variation with respect } \\
\text { to landing gear }\end{array}$ & variable \\
\hline $\mathrm{CxFL}$ & $\begin{array}{l}\mathrm{X} \text {-axis force variation with respect } \\
\text { to flaps }\end{array}$ & variable \\
\hline $\mathrm{CzO}$ & Initial Z-axis force coefficient & variable \\
\hline $\mathrm{CzV}$ & $\begin{array}{l}\text { Z-axis force coefficient variation } \\
\text { with respect to velocity }\end{array}$ & switch \\
\hline $\mathrm{Cza}$ & $\begin{array}{l}\text { Z-axis force coefficient variation } \\
\text { with respect to alpha }\end{array}$ & variable \\
\hline $\mathrm{Czq}$ & $\begin{array}{l}\text { Z-axis force coefficient variation } \\
\text { with respect to pitch rate }\end{array}$ & variable \\
\hline Czadot & $\begin{array}{l}\text { Z-axis force coefficient variation } \\
\text { with respect to change in alpha }\end{array}$ & variable \\
\hline Czde & $\begin{array}{l}\text { Z-axis force coefficient variation } \\
\text { with respect to deflection of } \\
\text { elevator }\end{array}$ & variable \\
\hline $\mathrm{CzFL}$ & $\begin{array}{l}\text { Z-axis force coefficient variation } \\
\text { with respect to flap deflection }\end{array}$ & variable \\
\hline $\mathrm{Cm} 0$ & Initial pitch coefficient & variable \\
\hline $\mathrm{CmV}$ & $\begin{array}{l}\text { Pitch coefficient variation with } \\
\text { respect to velocity }\end{array}$ & look up table \\
\hline
\end{tabular}




\begin{tabular}{|c|c|c|}
\hline Cma & $\begin{array}{l}\text { Pitch coefficient variation with } \\
\text { respect to alpha }\end{array}$ & look up table \\
\hline $\mathrm{Cmq}$ & $\begin{array}{l}\text { Pitch coefficient variation with } \\
\text { respect to rate of pitch }\end{array}$ & look up table \\
\hline Cmadot & $\begin{array}{l}\text { Pitch coefficient variation with } \\
\text { respect to rate of change in alpha }\end{array}$ & look up table \\
\hline Cmde & $\begin{array}{l}\text { Pitch coefficient variation with } \\
\text { respect to elevator deflection }\end{array}$ & look up table \\
\hline $\mathrm{CmFL}$ & $\begin{array}{l}\text { Pitch coefficient variation with } \\
\text { respect to flaps }\end{array}$ & variable \\
\hline Cy0 & Initial side force coefficient & variable \\
\hline $\mathrm{Cyb}$ & $\begin{array}{l}\text { Side force coefficient variation with } \\
\text { respect to sideslip angle }\end{array}$ & variable \\
\hline Сур & $\begin{array}{l}\text { Side force coefficient variation with } \\
\text { respect to roll rate }\end{array}$ & variable \\
\hline Сyr & $\begin{array}{l}\text { Side force coefficient variation with } \\
\text { respect to yaw rate }\end{array}$ & variable \\
\hline Cyda & $\begin{array}{l}\text { Side force coefficient variation with } \\
\text { respect to aileron deflection }\end{array}$ & variable \\
\hline Cydr & $\begin{array}{l}\text { Side force coefficient variation with } \\
\text { respect to rudder deflection }\end{array}$ & variable \\
\hline $\mathrm{Cl} 0$ & Initial lift coefficient & variable \\
\hline $\mathrm{Clb}$ & $\begin{array}{l}\text { Lift coefficient variation with } \\
\text { respect to sideslip angle }\end{array}$ & variable \\
\hline Clp & $\begin{array}{l}\text { Lift coefficient variation with } \\
\text { respect to rate of roll }\end{array}$ & variable \\
\hline $\mathrm{Clr}$ & $\begin{array}{l}\text { Lift coefficient variation with } \\
\text { respect to rate of yaw }\end{array}$ & variable \\
\hline Clda & $\begin{array}{l}\text { Lift coefficient variation with } \\
\text { respect to aileron deflection }\end{array}$ & variable \\
\hline Cldr & $\begin{array}{l}\text { Lift coefficient variation with } \\
\text { respect to rudder deflection }\end{array}$ & variable \\
\hline $\mathrm{Cn} 0$ & Initial yaw coefficient & variable \\
\hline $\mathrm{Cnb}$ & $\begin{array}{l}\text { Yaw coefficient variation with } \\
\text { respect to sideslip angle }\end{array}$ & variable \\
\hline Cnp & $\begin{array}{l}\text { Yaw coefficient variation with } \\
\text { respect to roll rate }\end{array}$ & variable \\
\hline $\mathrm{Cnr}$ & $\begin{array}{l}\text { Yaw coefficient variation with } \\
\text { respect to yaw rate }\end{array}$ & variable \\
\hline Cnda & $\begin{array}{l}\text { Yaw coefficient variation with } \\
\text { respect to aileron deflection }\end{array}$ & variable \\
\hline Cndr & $\begin{array}{l}\text { Yaw coefficient variation with } \\
\text { respect to rudder deflection }\end{array}$ & variable \\
\hline cg_at & Center of gravity & variable \\
\hline $\mathrm{c} 1 \mathrm{~N}$ & Damping constant nose gear & variable \\
\hline
\end{tabular}




\begin{tabular}{|l|l|l|} 
c1M & Damping constant main gear & variable \\
\hline d2r & Degrees to radians & variable \\
\hline dirHist_s.time & Recorded pilot input dir input time & input \\
\hline dirHist_s.signals.values & Recorded pilot input dir input & input \\
\hline dirHist_s.signals.dimensions & $\begin{array}{l}\text { Recorded pilot input dir input } \\
\text { dimensions }\end{array}$ & input \\
\hline dynPresLT & dynamic pressure & variable \\
\hline engang1 & Engine angles & vector \\
\hline fric_coef & Friction coefficient & variable \\
\hline Fric_ratio_N & Friction ratio for nose gear & variable \\
\hline Fric_ratio_M & Friction ratio for main gear & variable \\
\hline g & Gravity & variable \\
\hline GM1 & Mass moment of inertia vector & variable \\
\hline GM2 & Inertia coefficients vector & variable \\
\hline Igrnd & Velocity threshold for alpha and & \\
\hline Ixx & beta & variable \\
\hline Iyy & Mass moment of inertia & variable \\
\hline Izz & Mass moment of inertia & variable \\
\hline Ixy & Mass moment of inertia & variable \\
\hline Ixz & Mass moment of inertia & variable \\
\hline Iyz & Mass moment of inertia & variable \\
\hline I & Mass moment of inertia & variable \\
\hline I1 & Inertia coefficients & variable \\
\hline I2 & Inertia coefficients & variable \\
\hline I3 & Inertia coefficients & variable \\
\hline I4 & Inertia coefficients & variable \\
\hline I5 & Inertia coefficients & variable \\
\hline I6 & Inertia coefficients & variable \\
\hline kLG & Inertia coefficients & variable \\
\hline kFL & Landing gear switch & variable \\
\hline k1N & Flaps switch & switch \\
\hline K2N & Spring constant 1 nose gear & variable \\
\hline k1M & Spring constant 2 nose gear & variable \\
\hline k2M & Spring constant 1 main gear & variable \\
\hline kstklg & Spring constant 2 main gear & variable \\
\hline kstklt & Longitudinal stick constant & variable \\
\hline kstkdr & Lateral Stick constant & variable \\
\hline klghist & Directional stick constant & variable \\
\hline & Longitudinal time history constant & vector \\
\hline & & \\
\hline
\end{tabular}




\begin{tabular}{|l|l|l|} 
klthist & Lateral time history constant & vector \\
\hline kdirhist & Directional time history constant & variable \\
\hline kthrhist & Throttle time history constant & variable \\
\hline Lgdeploy & $\begin{array}{l}\text { Velocity threshold for alpha and } \\
\text { beta }\end{array}$ & variable \\
\hline Lecg & Left engine center of gravity & variable \\
\hline lgHist_s.time & $\begin{array}{l}\text { Recorded pilot input longitudinal } \\
\text { input time }\end{array}$ & input \\
\hline lgHist_s.signals.values & $\begin{array}{l}\text { Recorded pilot input longitudinal } \\
\text { input }\end{array}$ & input \\
\hline lgHist_s.signals.dimensions & $\begin{array}{l}\text { Recorded pilot input longitudinal } \\
\text { input dimensions }\end{array}$ & input \\
\hline ltHist_s.time & $\begin{array}{l}\text { Recorded pilot input lateral input } \\
\text { time }\end{array}$ & input \\
\hline ltHist_s.signals.values & Recorded pilot input lateral input & input \\
\hline ltHist_s.signals.dimensions & $\begin{array}{l}\text { Recorded pilot input lateral input } \\
\text { dimensions }\end{array}$ & input \\
\hline MachLT & Mach for thrust look up table & variable \\
\hline mwgN & Mass of nose wheel & variable \\
\hline mwgM & Mass of main wheels & variable \\
\hline max_brake & Maximum braking rorce & variable \\
\hline N1w1 & Engine model & variable \\
\hline N1zeta1 & Engine model & variable \\
\hline N1w2 & Engine model & variable \\
\hline N1zeta2 & Engine model & variable \\
\hline N1delay & Engine model & variable \\
\hline N1k & Engine model & variable \\
\hline N2w1 & Engine model & variable \\
\hline N2zeta1 & Engine model & variable \\
\hline N2delay & Engine model & variable \\
\hline N2k & Engine model & variable \\
\hline posN & Nose gear position in body axes & variable \\
\hline posML & $\begin{array}{l}\text { Left landing gear position in body } \\
\text { axes }\end{array}$ & vector \\
\hline posMR & $\begin{array}{l}\text { Right landing gear position in body } \\
\text { axes }\end{array}$ & variable \\
\hline PureDelayN1 & Engine model & variable \\
\hline PureDelayN2 & Engine model & variable \\
\hline P1 & Inertia coefficients & variable \\
\hline Pm & Inertia coefficients & variable \\
\hline Pn & variable \\
\hline
\end{tabular}




\begin{tabular}{|c|c|c|}
\hline Ppp & Inertia coefficients & variable \\
\hline Ppq & Inertia coefficients & variable \\
\hline Ppr & Inertia coefficients & variable \\
\hline Pqq & Inertia coefficients & variable \\
\hline Pqr & Inertia coefficients & variable \\
\hline Prr & Inertia coefficients & variable \\
\hline Q1 & Inertia coefficients & variable \\
\hline $\mathrm{Qm}$ & Inertia coefficients & variable \\
\hline Qn & Inertia coefficients & variable \\
\hline Qpp & Inertia coefficients & variable \\
\hline Qpq & Inertia coefficients & variable \\
\hline Qpr & Inertia coefficients & variable \\
\hline Qqq & Inertia coefficients & variable \\
\hline Qqr & Inertia coefficients & variable \\
\hline Qrr & Inertia coefficients & variable \\
\hline Recg & Right engine center of gravity & variable \\
\hline RtireN & Nose tire radius & variable \\
\hline RtireM & Main tire radius & variable \\
\hline R1 & Inertia coefficients & variable \\
\hline $\mathrm{Rm}$ & Inertia coefficients & variable \\
\hline $\mathrm{Rn}$ & Inertia coefficients & variable \\
\hline $\mathrm{Rpp}$ & Inertia coefficients & variable \\
\hline Rpq & Inertia coefficients & variable \\
\hline $\mathrm{Rpr}$ & Inertia coefficients & variable \\
\hline Rqq & Inertia coefficients & variable \\
\hline $\mathrm{Rqr}$ & Inertia coefficients & variable \\
\hline Rrr & Inertia coefficients & variable \\
\hline $\mathrm{S}$ & Wing surface area & variable \\
\hline SimTime & Time increment & vector \\
\hline steer_ang & Steering angle & variable \\
\hline SPEV_Force.time & Force special event time & special event \\
\hline SPEV_Force.signals.values & Force special event values & special event \\
\hline SPEV Force.signals.dimensions & Force special event Dimensions & special event \\
\hline SPEV_Moment.time & Moment special event time & special event \\
\hline SPEV_Moment.signals.values & Moment special event values & special event \\
\hline SPEV_Moment.signals.dimensions & Moment special event dimenstions & special event \\
\hline $\mathrm{T}$ & Time increment & variable \\
\hline Thrust & Thrust & variable \\
\hline Vhelp & Avoid division by zero & variable \\
\hline Vthres & Avoid division by zero & variable \\
\hline VrefND & Reference velocity & variable \\
\hline
\end{tabular}




\begin{tabular}{|l|l|l|} 
xawN & Length of nose landing gear & variable \\
\hline xawM & Length of main landing gear & variable \\
\hline xainN & Nose gear height above ground & variable \\
\hline xainM & Main gear height above ground & variable \\
\hline
\end{tabular}

\section{IC_\#\#_\$}

\begin{tabular}{|l|l|l|l|}
\hline IC_\#\#_\$\$.m & Descriptor & Unit & Type \\
\hline alpha0 & Initial angle of attack & radians & variable \\
\hline alt & Altitude & $\mathrm{m}$ & variable \\
\hline alt_ft & Altitude & feet & variable \\
\hline alt_ft_aport & Altitude of airport in feet & feet & variable \\
\hline alt_aport & Altitude of airport in meters & meters & variable \\
\hline beta0 & Initial sideslip angle & radians & variable \\
\hline Init_Long & Initial longitude position & $\mathrm{N} / \mathrm{a}$ & variable \\
\hline Init_lat & Initial lateral position & $\mathrm{N} / \mathrm{A}$ & variable \\
\hline in_flaps & Initial flaps position & $\mathrm{Degrees}$ & variable \\
\hline $\mathrm{N} 1 \_$init & Initial N1 & $\%$ & variable \\
\hline $\mathrm{N} 2$ init & Initial N2 & $\%$ & variable \\
\hline p0 & Initial roll rate & $\mathrm{rad} / \mathrm{s}$ & variable \\
\hline psi0 & Initial yaw angle & $\mathrm{radians}$ & variable \\
\hline phi0 & Initial roll angle & $\mathrm{radians}$ & variable \\
\hline q0 & Initial pitch rate & $\mathrm{rad} / \mathrm{s}$ & variable \\
\hline ro & density & $\mathrm{kg} / \mathrm{m}^{3}$ & variable \\
\hline r0 & Initial yaw rate & $\mathrm{rad} / \mathrm{s}$ & variable \\
\hline uaero0 & Initial surface deflections & $\mathrm{radians}$ & variable \\
\hline uprop0 & Initial throttle & $\mathrm{N} / \mathrm{A}$ & variable \\
\hline u0inco & Initial velocity & $\mathrm{m} / \mathrm{s}$ & variable \\
\hline V0 & Initial velocity & $\mathrm{m} / \mathrm{s}$ & variable \\
\hline v0inco & Initial velocity $/ \mathrm{s}$ & variable \\
\hline w0inco & Initial velocity & variable \\
\hline xinco & Initial conditions & $\mathrm{m}$ & vector \\
\hline X0 & Initial position in X & $\mathrm{N} / \mathrm{A}$ & variable \\
\hline y0 & Initial controls vector & $\mathrm{m}$ & variable \\
\hline Y0 & Initial position in Y & variable \\
\hline Z0 & Initial position in Z(altitude) & $\mathrm{m}$ & \\
\hline
\end{tabular}




\section{File Functions}

\begin{tabular}{|c|c|}
\hline File name & Function \\
\hline allflight.m & Function if all flight input selected \\
\hline allrec.m & Function if all recorded input selected \\
\hline allstk.m & Function if all stick input selected \\
\hline AltF31.m & Altitude table(needed for ALTflight.mat file) \\
\hline ALTflight.mat & Table of altitudes \\
\hline AltitudeFreeze.m & Function freezes altitude \\
\hline Ans_Block.mat & Gives the initial conditions and damping and frequency answers in cells \\
\hline Jet_FE.mdl & Actual model \\
\hline JetSim.fig & Figure that starts the whole simulation \\
\hline JetSim.m & Model \\
\hline CR.mat & Climb rate flight data files \\
\hline crate.m & Creates the CR.mat climb rate data files \\
\hline dirhist.mat & Directional history file (converts flight data into a table matlab can use) \\
\hline dirhist_crnt.mat & Directional history file (converts flight data into a table matlab can use) \\
\hline dirhist_zero.mat & Directional history file (converts flight data into a table matlab can use) \\
\hline flaps_OT_E.mat & Faps extension data \\
\hline flaps_OT_R.mat & Flaps retraction data \\
\hline FlightCondition.fig & Flight condition figure \\
\hline \multicolumn{2}{|l|}{ FlightConditon.m } \\
\hline IC_\$\$_\#\#.m & $\begin{array}{l}\text { Initial condition files used to load initial conditions for the correct test in } \\
\text { the InitializeFE.m file }\end{array}$ \\
\hline IntializeFE.m & $\begin{array}{l}\text { Initializes all flight model data, including landing gear and engine } \\
\text { modeling }\end{array}$ \\
\hline ldgear_OT_E.mat & Landing gear extenstion data \\
\hline ldgear_OT_R.mat & Landing gear retraction data \\
\hline lghist.mat & $\begin{array}{l}\text { Longitudinal history file (converts flight data into a table matlab can } \\
\text { use) }\end{array}$ \\
\hline lghist crnt.mat & $\begin{array}{l}\text { Longitudinal history file (converts flight data into a table matlab can } \\
\text { use) }\end{array}$ \\
\hline lghist save.mat & $\begin{array}{l}\text { Longitudinal history file (converts flight data into a table matlab can } \\
\text { use) }\end{array}$ \\
\hline lghist_zero.mat & Longitudinal history file \\
\hline lthist.mat & Lateral history file (converts flight data into a table matlab can use) \\
\hline lthist_crnt.mat & Lateral history file (converts flight data into a table matlab can use) \\
\hline lthist_save.mat & Lateral history file (converts flight data into a table matlab can use) \\
\hline lthist_zero.mat & Lateral history file (converts flight data into a table matlab can use) \\
\hline mixed.m & Function to load mixed signals i.e. recorded and pilot input \\
\hline Modes.m & General form of an S-function \\
\hline OK_PilotInput.m & OK button function if pilot input selected \\
\hline
\end{tabular}




\begin{tabular}{|c|c|}
\hline OK_Repos.m & OK button function for the repositon button \\
\hline OK_Scopes.m & OK button function for scopes \\
\hline OK_Scopes $2 . \mathrm{m}$ & OK button function for scopes \\
\hline OK_Scopes $3 . \mathrm{m}$ & OK button function for scopes \\
\hline OK_Scopes4.m & OK button function for scopes \\
\hline OK_ScopesFE.m & OK button function for scopes \\
\hline PauseFig.fig & Figure that pauses the simulation \\
\hline \multicolumn{2}{|l|}{ PauseFig.m } \\
\hline PauseFlags.m & Pause flags \\
\hline \multicolumn{2}{|l|}{ PauseReturn.m } \\
\hline PilotInput.fig & Pilot input figure (initial conditions for pilot input) \\
\hline \multicolumn{2}{|l|}{ PilotInput.m } \\
\hline PostionFreeze.m & Position freeze function for the position freeze button \\
\hline rec_input.m & Function to load recorded inputs \\
\hline Reg_Acc.fig & Acceleration flight condition FAA compliance menu \\
\hline Reg_Approach.fig & Approach flight condition FAA compliance menu \\
\hline Reg_Climb.fig & Climb flight condition FAA compliance menu \\
\hline Reg_Cruise.fig & Cruise flight condition FAA compliance menu \\
\hline Reg_FE.fig & Piloted flight, flight simulation menu \\
\hline Reg_Flaps.fig & Flaps flight condition FAA compliance menu \\
\hline Reg_Ground.fig & Ground flight condition FAA compliance menu \\
\hline Reg_LdGear.fig & Landging gear flight conditon FAA compliance menu \\
\hline Reg_LgTrim.fig & Longitudinal trim flight conditon FAA compliance menu \\
\hline Reg_Sideslip.fig & Sideslip flight condition FAA compliance menu \\
\hline Reposition.m & Repostion function \\
\hline RespostionFig.fig & Figure to select new position after the reposition button is selected \\
\hline Scopes\#.fig & Scopes figures \\
\hline thrhist.mat & Thrust history file (converts flight data into a table matlab can use) \\
\hline thr_crnt.mat & Thrust history file (converts flight data into a table matlab can use) \\
\hline thrhist_save.mat & Thrust history file (converts flight data into a table matlab can use) \\
\hline thrhist_zero.mat & Thrust history file (converts flight data into a table matlab can use) \\
\hline
\end{tabular}




\section{FAA Compliance Diagram}

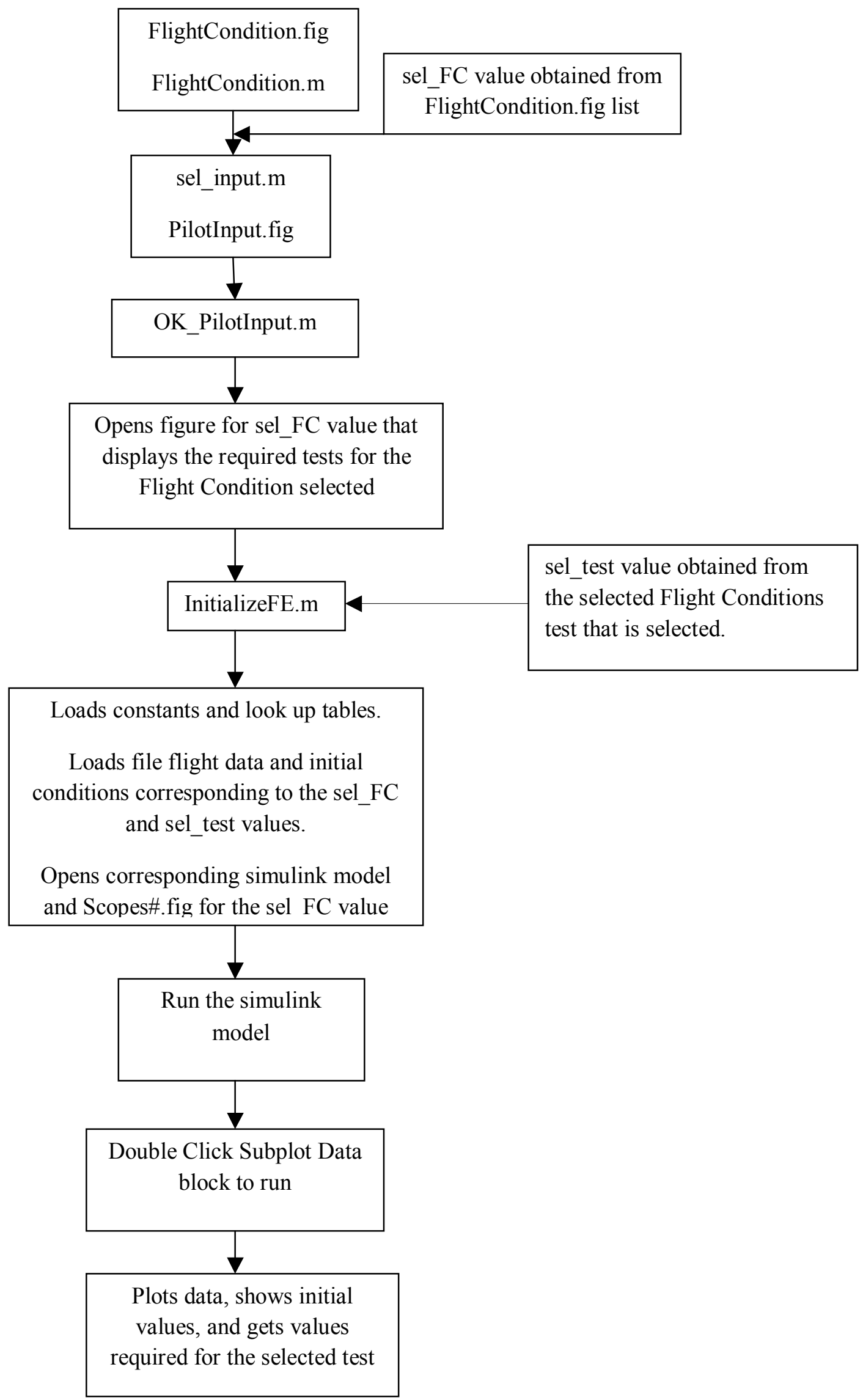




\section{$\underline{\text { Full Envelope Diagram }}$}

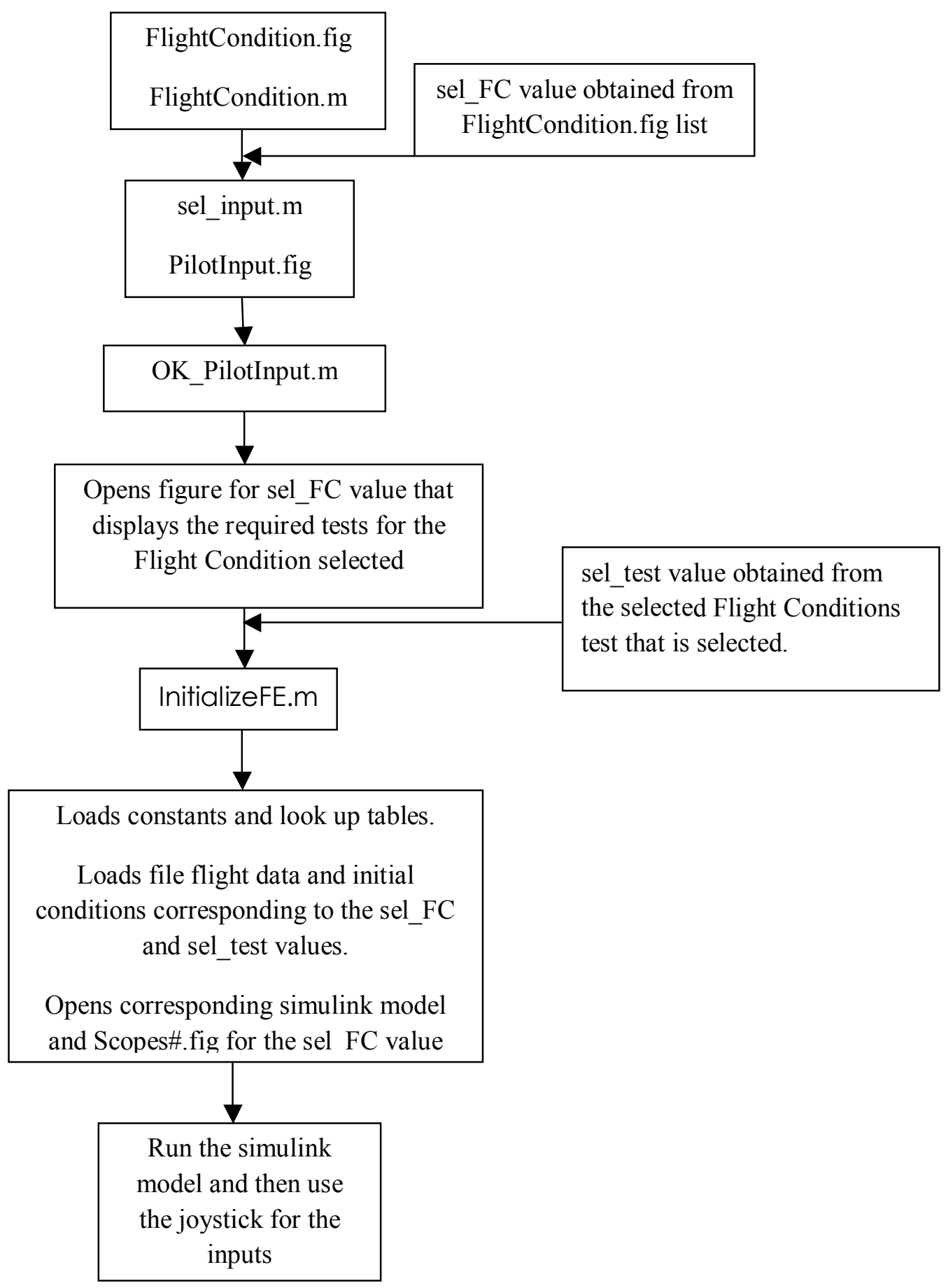

